\title{
Pseudomemories and Personality Characteristics
}

Citation for published version (APA):

Horselenberg, R. (2005). Pseudomemories and Personality Characteristics. [Doctoral Thesis, Maastricht University]. Datawyse / Universitaire Pers Maastricht. https://doi.org/10.26481/dis.20050520rh

Document status and date:

Published: 01/01/2005

DOI:

10.26481/dis.20050520rh

Document Version:

Publisher's PDF, also known as Version of record

\section{Please check the document version of this publication:}

- A submitted manuscript is the version of the article upon submission and before peer-review. There can be important differences between the submitted version and the official published version of record.

People interested in the research are advised to contact the author for the final version of the publication, or visit the DOI to the publisher's website.

- The final author version and the galley proof are versions of the publication after peer review.

- The final published version features the final layout of the paper including the volume, issue and page numbers.

Link to publication

\footnotetext{
General rights rights.

- You may freely distribute the URL identifying the publication in the public portal. please follow below link for the End User Agreement:

www.umlib.nl/taverne-license

Take down policy

If you believe that this document breaches copyright please contact us at:

repository@maastrichtuniversity.nl

providing details and we will investigate your claim.
}

Copyright and moral rights for the publications made accessible in the public portal are retained by the authors and/or other copyright owners and it is a condition of accessing publications that users recognise and abide by the legal requirements associated with these

- Users may download and print one copy of any publication from the public portal for the purpose of private study or research.

- You may not further distribute the material or use it for any profit-making activity or commercial gain

If the publication is distributed under the terms of Article $25 \mathrm{fa}$ of the Dutch Copyright Act, indicated by the "Taverne" license above, 
PSEUDOMEMORIES and

PERSONALITY CHARACTERISTICS 
(6) R Horselenberg, MAASTRICHT 2005

OMSLACONTWERP \& LAYOUT: designacima " wWw, designocima.com

DRUK: Datawsse - Universitaire Pers Maastricht

$158 N 9052784582$ 


\title{
PSEUDOMEMORIES
}

\section{and}

\section{PERSONALITY CHARACTERISTICS}

\author{
PROEFSCHRIFT
}

ter verkrijging van de graad van doctor aan de Universiteit Maastricht, op gezag van de Rector Magnificus, Prof. mr. G.P.M.F. Mols, volgens het besluit van het College van Decanen, in het openbaar te verdedigen op vrijdag 20 mei 2005 om 14:00 uur

door

Robert Horselenberg

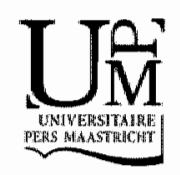




\section{PROMOTOR}

Prof. dr. H.L.G.J. Merckelbach

\section{BEOORDELINGSCOMMISSIE}

\section{Prof. dr. P.J. wan Koppen (voorzitter)}

Prof. dr. J. Baneke (Universiteit Twente)

Dr. M. Jelicic

Prof. dr. P. Muris (Erasmus Universiteit Rotterdam)

Dr. M. Peters 



\section{CONTENTS}

INTRODUCTION

CHAPTER I

HELPING WITNESSES REMEMBER

7

CHAPTER 2 PSEUDOMEMORIES AND PERSONALITY

CHARACTERISTICS

CHAPTER 3 ABSORPTION, FANTASY PRONENESS, AND

THE FALSE FAME EFFECT

CHAPTER 4 IMAGINING FICTITIOUS CHILDHOOD EVENTS:

THE ROLE OF PERSONALITY CHARACTERISTICS

IN IMAGINATIION INFLATION

65

CHAPTER 5 PERSONALITY CHARACTERISTICS AND THE ACCURACY OF AUTOBIOGRAPHICAL MEMORY

CHAPTER 6.1 PERSONALITY CHARACTERISTICS AND

FALSE CONFESSIONS: A CONCEPTUAL

REPLICATION OF KASSIN AND KIECHEL (1996) 
CHAMTER 6.2 FALSE CONFESSIONS IN THE LAB: DO

PLAUSIBILITY AND CONSEQUENCES MATTER?

CHAPTEP 7 FANTASY PRONENESS AND DISSOCIATIVE

EXPERIENCES IN ADULTS WITH PREVIOUS-LIFE MEMORIES

SUMMARY

SAMENVATTING

REFERENCES

DANKWOORD

CURRICULUM VITAE

LIST OF PUBLICATIONS

213 


\section{INTRODUCTION}

During the Republican convention for the presidential election of the United States of America in September 2004, the Governor of California, Arnold Schwarzenegger, declared to "have seen communism with my own eves [in Austria]." He claimed to remember how the streets of Stiermarken (his homeland) were filled with Soviet Army tanks. These remarkable memories, however, must be wrong. In the year Schwarzenegger was born, 1947, the occupying army was British. The Soviets had already left Austria in July 1945. Not only did he misremember the "communist periad" in Austria, his recollections of the political situation in Austria in 1968, the year he left for America, were also completely messed up.

Memory illusions ${ }^{2}$ come in all shapes and sizes. They may vary from rather innocent white lies in which one believes - Schwarzenegger's recollections - to more serious misinterpretations arising spontaneously or during therapy. These pseudomemories have one thing in common with accurate memories. Both contain vivid details (e.g., have a strong sensory loading) and are reconstructed without much cognitive effort, so that the person is convinced of recalling the truth. False (autobiographical) memories are, therefore, best defined as recollections of events that never happened or that are recalled very differently from what actually happened. 
People; however, differ in the extent to which they are susceptible to developing pseudomemories. Most people undergoing psychotherapy or police interrogation stick to their memories or recognize false ones. Also, most accounts of eyewitnesses, victims, and suspects are roughly in accordance with what actually has happened. Meanwhile, in the past decades, the legal system has encountered various cases in which pseudomemories played a pivotal role. Germane to this issue are not only law suits based on memories of childhood sexual abuse recovered during therapy, but also to cases in which defendants were convicted on the basis of their false confessions. As the evidentiary problems surrounding these cases became more and more apparent, interest has grown into what characteristics make people vullnerable to develop such memories.

The present dissertation concentrates on pseudomemories and how they relate to certain personality characteristics. In the chapters that follow, we describe several studies relying on different paradigms to elicit false memories. The paradigms are structured in a hierarchical way. That is, they range from mild manipulations to highly manipulative interrogation tactics and hypnosis. Two research questions lie at the basis of these studies. The first concerns the issue of whether pseudomemories can be ellicited. The second question is whether such memories are modulated by certain personality characteristics.

The first chapter critically reviews techniques used by police investigators to aid memory recall of evewitmesses. There are compelling parallels between various techniques of eyewitness interviewing and therapeutic techniques for memory recovery. With these parallels in mind, chapter 2 gives a more theoretical outline of the current thesis. Here, two accounts of false memories are described. Both emphasize that a source monitoring error, l.e., confusing fantasy with reality, is the crux of pseudomemory development. Alsia, personallity characteristics that might be relevant to false memories are introduced. A closer look at source monitoring errors in relation to personality characteristics is taken in chapter 3 . Two studies addressed source monitoring errors in samples selected on the basis of fantasy related measures. The studies presented in chapter 3 relied on a mild 
manipulation of participants' feelings of familiarity. in chapter 4 we turn to a paradigm that is more invasive. More specifically, the chapter describes studies in which participants had to undergo imagery acts and then the memory effects of these acts in relation to personality characteristics were examined. Chapter 5 addresses spontaneous autobiographical memory distortions by means of diaries kept by participants. Here, participants underwent a recognition task of their diary records. The majority of their autobiographical material though, was altered. The studies presented in chapter 6 involved far-reaching manipulations. In three studies, false confessions were elicited, using a computer crash paradigm. Manipulations varied from offering false evidence to increasing the sanctions for participants who refused to confess. The fourth study in this chapter describes a navel paradigm in which participants are falsely accused of exam fraud in order to elicit a false confession. An exploratory study on previous-life memories is described in chapter 7 . These memories were obtained by therapists who employed hypnotic techniques. As previous-life memories are highly exceptional, and most likely to be false, they may shed a light on the relation between personality characteristics and pseudomemories. Finally, in chapter 8 , results of our work is summarised, discussed, and some final conclusions are drawn. To further illustrate these findings some new data on previous-life memories and a case report on a supposedly false confession are provided. Also, directions for future research on the connection between pseudomemories and persomality characteristics are discussed. 
CHAPTER 1

\section{Helping Witnesses Remember}

This chapler is an adjusted and trablated wartion of the following

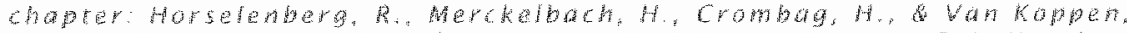

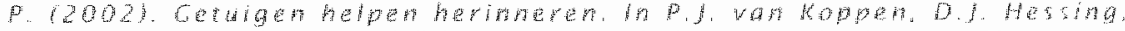

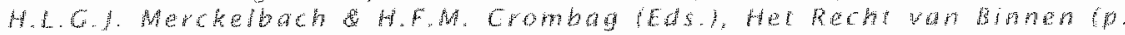
445 , $454:$ 


\section{INTRODUCTION}

On November 21 sr 1995 Dirk $V$. and his ex-wife get into a two-door Ford Escort and drive to a furniture store in Maasluis, Belgium. Dirk is driving the car and his ex-wife is sitting in the rear seat. After searching for a parking spot, Dirk finally parks the car on the Govert van Wijnkade. He gets out of the car and his ex-wife remains seated in the rear seat. Suddenly the vehicle begins to roll and ends up in the water of the Buitenhaven, where it sinks almost instantly. The woman fails to escape the sinking vehicle and drowns.

Dirk who thad relationship problems with his ex-wife for some time and who had taken out a rather large life-insurance policy on the victim, denies the murder allegations. Despite conflicting explanations concerning the nature of the trip, Dirk insists he did not notice the car roll into the water. The police on the other hand, have a different opinion. As it turns out, the car doors were locked and the front seats were in an upright position. This made it difficult, if not impossible, for the woman to escape the drowning car. The car, which had an automatic transmission, was in the reverse position and not the park position. This could be considered an indication that the woman attempted to stop the car from rolling. Perhaps of greater concern was that the pollice found two types of bereavement cards with his ex-wife's name on them in Dirk's house; a funeral speech for his wife; a design for a thank you card for the employees of a crematorium; as well as a list of potential purchases from the life-insurance money. Dirk"s explanation: "As an undertaker and a narrow-minded speciallist you tend to do stuff like that." There was also a witness, named Teunis. Teunis was standing on the embankment on the other side of the water when he noticed the car. However, he could not remember what had happened thereafter. Because the police was particularly interested in what Teunis had seen, especially where Dirk was when the car hit the water, a clinical psychologist was recruited. The clinical psychologist interrogated Teunis once more, this time under hypnosis. This resulted in a new testimony, according to which Dirk stood motionless by the 
driver's side of the car and watched the vehicle hit the water and submerge the fatal moment). Dirk was sentenced to 12 years in prison. Teunis" testimony under hypnosis played an important role in the conviction. In an appeal "the discussion on Teunis" testimony under hypnosis escalated to the Supreme Court where the testimony under hypnosis was ruled to be inadmissible as evidence 3 following this judgment, the case was delegated back to the Amsterdam Court of Appeal, where Dirk was acquitted. ${ }^{4}$

In this chapter; we will discuss psychological techniques that law enforcement can employ to refresh or improve witnesses' memories. It is not surprising that these technilques stem primarily from psychiatry and psychotherapy, where such techniques are used in the treatment of patients. Are these techniques useful when dealing with witnesses?

\section{THE WITNESS AND HIS 5 MEMORY}

During a criminal investigation, law enforcement is frequently interested in various details, which are too trivial for a witness to remember in daily life. After only a couple hours we forget what the baker told us, what the cashier at the supermarket looked like, and what model of car was at the next gas pump. Perhaps, we never knew any of these details to begin with simply because we never noticed, or did not consider them important enough to store them in our memory. Nevertheless, such details are potentially relevant in eyewitness testimonies. Eyewitness testimonies are the most important evidence lin civil and criminal cases. In fact, many legal decisions are based on eyewitness evidence; a

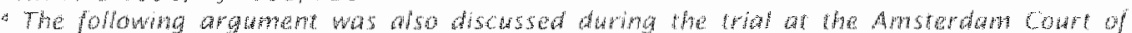

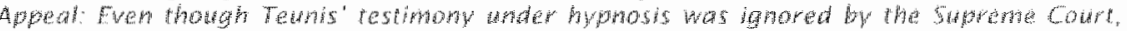

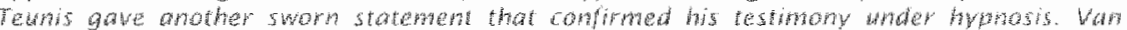

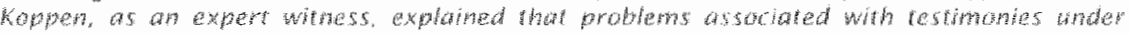

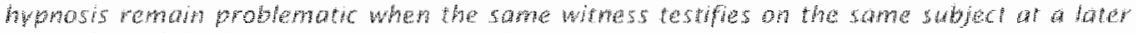

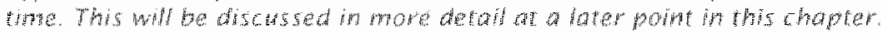

"We refer to the male gendef onfly simplify the text. 
state of affairs sometimes called the "tyranny of the eyewitness" (Haber \& Haber, 2000). For this reason it is important that eyewitness statements are as complete and accurate as can possibly be.

Witnesses are individuals who were present at the time of the crime and then later report what they saw and heard to law enforcement and judges. However, problems occur when interrogators want to know more than the witness can remember. This is not uncommon. In this situation, the interrogator can employ techniques to improve the witness. memory. Not every technique is equally suitable when trying to unveil the truth. Before taking a critical look at such techniques, we will first briefly discuss memory.

Memory processes are commonly described in three stages: encoding, storage, and retrieval of information. Information is subject to interpretation and alteration in each stage. Memory researchers refute the idea that memory is reproductive as the computer or video recorder metaphor suggests; they believe it is reconstructive. Observed events are stored selectively, after interpretation. During the storage stage, a witness can (a) forget what he observed, (b) add information from another source (post-hoc information) to the memory, or (c) substitute elements of the memory with other information, from other experiences. If a witness is subsequently encouraged to retrieve memories, then the result will depend largely on the method of interrogation. At the time of interrogation, there are many means, by which a memory can be transformed, especially options (b) and (c).

Memories are not randomly retrieved: they are conjured by retrieval cues. $A$ voice, scent, or location can function as typical cues that can suddenly bring back a memory, whether we like it or not. Not all types of cues are equally effective. When considering cues to belong to one of four categories, namely what, who, where and when, then the "when" cue is least effective and the "who" cue is most effective. The person with whom you share an experience is evidently a stronger retrieval cue than is the time of the event. Combinations of cues are more effective than any isolited cue. 
Memories must be sought for and gathered by means of cues. If this is not possible then the event is said to have been forgotten. On the other hand if enough cues, especially specific ones, are provided then we can even recollect very old memories (Wagenaar, 1986). Questionable is whether such a large amount of cues leads to the retrieval of a genuine memory or something that "feels" like a memory, but in fact is an inaccurate reconstruction (a pseudomemory). A study conducted by Hyman, Husband and Billings (1995; see also Hyman \& Pentiand, 1996; Hyman \& Billings, 1998; Porter, Yuille \& Lehman, 1999) serves as an instructive example. In this study, students were presented a number of events. These events concerned youth experiences that the researchers had become knowledgeable about through the students' parents. The researchers presented retrileval cues for actual memories, but additionally mixed in a bogus cue that referring to a fabricated event. The fabricated event was that when the student was still a child, he knocked over a bowl of punch at a wedding while playing. The punch ended up spilling on the parents of the bride. The researchers interrogated the students on a number of occasions about the event and asked them to describe the event as detailed possible. The participants seemed to remember approximately 84 percent of genuine events. After two interrogation sessions, approximately 20 percent of participants seemed to have vivid memories of the fabricated event. In this study it is obvious that pseudomemories were created.

\section{POST-HOC INFORMATION}

The questions that are asked during the interrogation of a witness function as retrieval cues for sought information. Information provided with each question is supposed to stimulate recall of additional associated information. The more information provided in the question, the easier it is for the witness to reconstruct a memory. However, the more information provided, the more questionable is the source of the resulting story. This is a dilemma for 
interrogators. When asking "What did you witness on the 24 th of last month? the interrogator is providing the witness with a neutral but ineffective retrieval cue. When asking "Do you know how the fatal confrontation in the Zeezicht cafe started" the interrogator gives the witness a powerful cue, yet it is simultaneously conveying critical information. For example, that a physical confrontation preceded the death of an attendee (according to the interrogator). If a physical confrontation truly took place, then conveying this information to the witness is not necessarily detrimental to his testimony. However, if the physical confrontation is simply the interrogator's assumption then the effect of this information on the witness will be similar to that demonstrated in the Hyman et al. (1995) study. The mechanism responsible for this was first described by Elizabeth Loftus (Loftus, Miller \& Burns, 1978) as the post-hoc information effect. In one of Lofrus" classic studies, subjects were shown a series of slides depicting a car standing still in front of a stop sign and later involved in an accident. Following the slide show, half of the subjects were asked what happened after the car stood still before the stop sign. The other subjects were misleadingly asked what happened after the vehicle stood still before the yield sign. Later, all subjects were asked whether the car stood still before a stop sign or a vield sign. The majority of subjects in the second group incorporated the non-existent vield sign in their memory.

It is not difficult to imagine how post hoc information can affect eyewitness testimonies. Not only can a witness become knowledgeable of information through other witnesses or the newspaper, some of the information can also be the product of collaborative storytelling (Crombag, 1999; Gabbert, Memon, Allan Wright ${ }_{\text {i }}$ 2004; Roediger, Meade \& Bergman, 2001; Victor, 1993). If people are confronted with information that they are unsure of and that is no longer verifiable, then confidence in their memory will depend on other people"s judgment. Consensus of what must have happened will be reached by discussing the event with co-witnesses. 
The preceding discussion implies that not only other people are the source of post-hoc information. The witness himself can also be the source: what the witness has observed and what he has heard from others will become mingled with whatever he has thought of or imagined on his own (Loftus, 1979). Of course, there is a theoretical possibility that a witness can perfectly distinguish different sources on which his testimony is based. This is called source monitoring (Johnson, Hastroudi \& Lindsay, 1993). On the other hand, we are unable to remember the source of much of what we (think we) know. This is referred to as source amnesia. The probability of source amnesia is greatest when witnesses are knowledgeable of a substantial amount of information as a result of observing the event first-hand. It is especially difficult for these witnesses to differentiate additional information acquired from other sources (other people, the imagination, and the media) from what they actually observed. It is easy to get confused when trying to remember the source of a memory. Thus, source amnesia may lead to a source monitoring error: describing a memory that you think is based on your own perception, but that in fact originates from what others have told you or from your own fantasies.

Remembering the source of our knowledge is commonly of little value in the routine of daily life. Of greater importance is that this knowledge is correct. However, in the legal setting the source of a witness' knowledge is very important. This is because the law only allows witnesses to testify about "facts and circumstances which were directly observed or experienced." This is the de auditu-prohibition, a doctrine which is no llonger strictly followed in The Netherlands. Witnesses are now also allowed to testify about things they have heard from others, provided they inform the court about their source. This enables the judge to form an opinion about the credibility of the original source. of course, a witmess can only state the original source if he made a mental note about iit, something that is rarely true. 


\section{THE "OBSERVATION"}

\section{OF CAUSAL RELATIONSHIPS}

Witnesses are people who tell pollice what happened, as far as they can remember. This is a rough description. Police officers are often not only interested in what witnesses have seen or heard, but also how it happened. In other words, they are interested in cause and consequence. Howewer, causallity is not an observable phenomenon. A causal relationship is derived from the set of circumstances. Therefore, witnesses can be misguided in that they adjust their memory to any causality that may be suggested by interrogators. People have a natural tendency to infer causality from events: they want to know how the world operates and why. This tendency is stronger when confronted with radical, unexpected events, such as most offences. Witnesses are especially inclined to attribute large causes to offences with large consequences (Nisbett \& Ross, 1980). Imagine the following incidient: witnesses see a police officer push a homeless person out of a police station. The drifter falls and passes away some time later. Additionally, assume that some witnesses are aware of the drifter's demise at the time of interrogation, while other witnesses are unaware of this. Pollice are investiglating the force of the police officer"s push. Based on psychological research on "causal observations", we expect witnesses who were aware of the drifter's demise to report a larger causality (a more violent push) than witnesses who were unaware of the drifter"s demise. That is exactly what happened in a 1997, case which the media called the Warmoesstraat case.

The particulars of that case were used by Remijn and Merckelbach (submitted) as a frameworlk for an experiment. In that experiment, participants were shown a video of the eviction of a homeless man from a police station by a police officer, during which the evictee fell. Next, participants were assigned to one of two groups. One group was told that the homeless man had died after he fell. The other group was informed that the man had not been injured. Participants who 
had been informed that the victim had died more often blamed the officer for the fall than those who had not been given this information (59\% versus $29 \%$ ).

\section{OMISSIONS AND COMMISSIONS IN WITNESS TESTIMONIES}

What do we expect from a technique aiming to improve witnesses memory? $\mathrm{A} 2 \mathrm{x}$ 2 matrix is helpful (see Table 1) in answering this question. There are techmiques which attempt to help witnesses forget less and testify more. However, we want to ensure the testimonies reflect the truth. Let us assume that this is the case. In signal detection jargon: the number of omissions (forgetting) decreases and the number of true-positives increases (remembering), as intended. Nevertheless, measuring the success of a technique on such a pattern alone is misleading. We must also consider the number of pseudomemories the technique elicits, as well as the extent to which witnesses realize they cannot have memories for events which never occurred. In signal detection terminology, these are called commissions and true-negatives, respectively. A technique that causes many true-positives as well as many commissions is of little value. We may consider a technique to be good when an increase in the number of correct memories is associated with a constant, or even a decreasing number of commissions.

Table 1.1: The fou possble effect of memory enhamaing techmians

\section{Reality}

Interrogation

Happened

In testimony

Not in testimony

\section{Correct (positive)}

False Negative

(omission)
Did not happen

False-Positive

(commission)

Correct (negative) 
All this is somewhat abstract. Here is an example that is taken from a recent experiment in our lab (Merckelbach, Zeles, Van Bergen \& Giesbrecht; submitted). Students witinessed a staged incident ${ }_{\text {in }}$ which a confederate of the experimenter stood up and angrilly confronted the experimenter with a story about a friend who had committed suicide. Subsequently, students were asked to write down exactly what they had seen. On completion, they were told that new memories might come up later. On a second occasion, students were asked to write down what they had seen once more. This procedure was repeated two more times. Repeatediy telling them that more memories might occur with time seemed to be successful. Subjects reported more correct memories with each new session. In other words, there was an increase in the number of true-positives. There was, however, also an increase in the number of incorrect memories or commissions. The proportion of commissions increased from 5 to 15 percent meaning that approximately 1 in 8 memories were incorrect (i.e., output-order effect: see flgure 1.1).

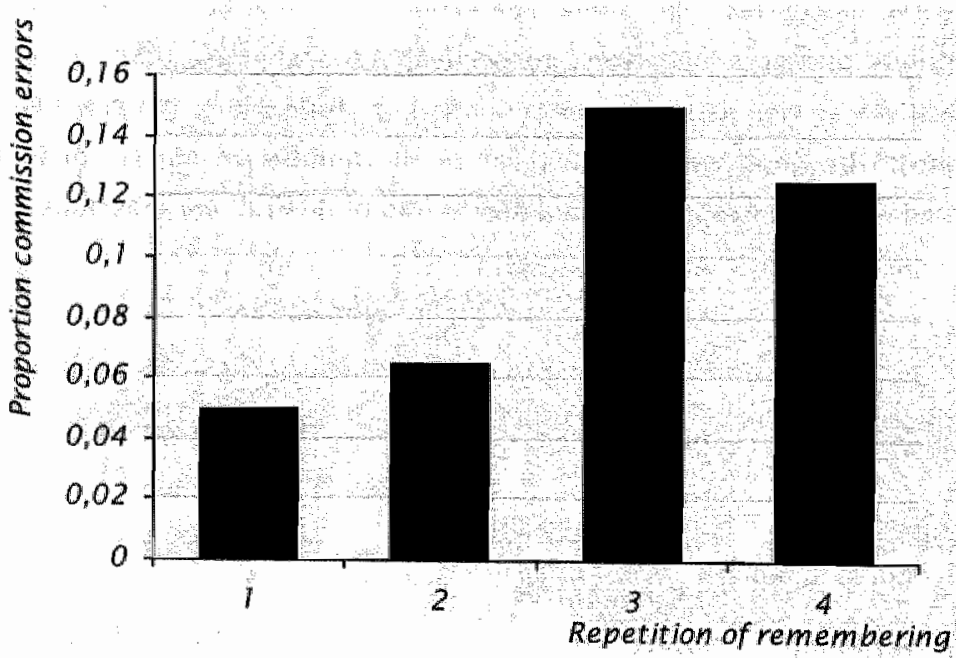

Fighe 1. 1: The ontputorder effect: 


\section{INTERROGATING}

A good interrogation contains cues which stimulate the witness to remember more without compromising the quality of such memories. Commonlly, police interrogations fail to do so despite much training on this.?

Fisher, Geiselman and Raymond (1987) found that a typical interrogation is conducted in the following way. First a couple of open questions are asked. On average, $7 / 2$ seconds after the witness has started answering the question, the interrogator asks a more detail-oriented question. Often, the interruption takes place at a point when the witness is getting to the most relevant part of the testimony. Such questions disturb the witness" train of thought and distract the witness from attempts to retrieve and verbalize memories. If the witness is unable to answer the detail-oriented question then this will have a detrimental effect on the witness' ability to continue the story. The middle and end of a typical interrogation consist primarily of closed questions, which witnesses are supposed to answer with "yes" or "no." Perhaps of greater importance is the absence of silences, which give the witness the opportunity to remember and picture scenes of the crime.

Can the quality of interrogations be improved? Yes, it certainly can. An example is the standard-witness interrogation. ${ }^{8}$ Since 1990 , detectives in the Netherlands have been taught this method. Additionally, this method is recommended by the British Home Office Memorandum of Good Practice (e.g., Van den Adel, 1997). Essentially it avoids any type of influence and, as the name suggests, presents questions in a standardized fashion. A standard-witness interrogation begins with an explanation of the goal and method of the interrogation. Next, the witness is asked to give a brief outline of what was witnessed. Only after the witness has completed the brief outline does the interrogator start the second

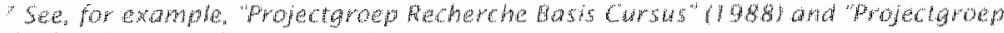

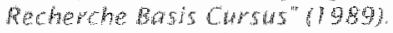

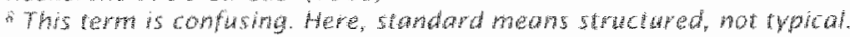


stage: The interrogator asks open questions pertaining onlly to what was said earlier by the witness. Additionally, questions about the event's circumstances are asked. Only then does the interrogator inquire about topics that have not been brought up by the withess, but that are nevertheless relevant. The interrogator never interrupts the witness; instead he assumes the role of a listener. In this way, maximal understanding is encouraged, giving the witness every opportunity to tell his version of the story (Köhnken, 1995).

There are methods other than the standard-witness interrogation, which try to help witnesses remember. The guided memory technique, the cognitive interview or hypnosis are employed to a certain extent by detectives. Not long ago, the so called "Zwolse interrogation method" was added. Finally, there is narco-analysils. which is outdated in The Netherlands. The next section deals with these methods.

\section{GUIDED MEMORY}

In the guided memory technique, the witness is initially asked to visually imagine the incident. Subsequently, the interragator tries to guide the witness through this image by means of open questions. Two steps precede this. The witness is first put at ease so that he feels comfortable. Secondly, the witiness is asked to give general outline of the incident. This provides the interrogator with a first impression of the incident's context and creates a starting point for the guided memory. Onlly then is the witness asked to close his eyes and direct his attention to this starting point. The questions that the interrogator subsequently asks are specific to the context. They are supposed to structure the course of the interrogation: "Walk a little bit further" "Stop", "What do vou see now?" All questions are in the present tense ("What does he look like?") and relate to what the witness reports seeing at that instant. An important characteristic of guided memory, If utilized in the correct way, is the absence of any form of influence of suggestion (Thiecke, Sijbling \& Jackson, 1996). 
The guided memory approach differs from the standard-witness interrogation in that it relies heavily on the context. In memory literature this is known as context reinstatement. Context reinstatement refers to memories that are conjured by the context of the incident. Indeed, the best way to achieve this is by taking the witness back to the location of the incident. The guided memory technique can be of significant value when witnesses are interrogated directly after the event (Malpass, 1996). If the witness has already been interrogated, or if he has already tried his utmost best to remember everything, then the method has no added value (Thiecke et al., 1996).

Thus, under certain conditions, the guided memory approach seems to be a useful method. For examplle, Malpass and Devine (1981) applied it to subjects trying to identify a culprit. Subjects were able to do so significantly better using the guided memory technique, a finding that was also confirmed by Shapiro and Penrod (1986), yet contradicted by Memon (1985). Thiecke et al. (1996) compared the guided memory technique with the standard-witness interrogation and found that both methods yielded equal amounts of correct details and commissions. Perhaps this was because they did not compare the guided memory technique with a typical interrogation "but with a standard-witness interrogation where interrogators were trained considerably better. Also, this research demonstrated that many witnesses that were interrogated using standardwitness interrogation spontaneously apply context reinstatement.

If the guided memory technique is considered in more detail, several issues are noticeable. Firstly, this interrogation technique is dependant on the interrogator's ability (Memon \& Higham, 1999). Effectively guiding a witness through his memories requires certain skills. This method uses the imagining instruction a lot (e.g. "Imagine that you are ... again"). However, there is a risk of confidence inflation. For example, suppose that somebody was asked on an earlier occasion if he experienced a certain (fabricated) event before the age of 10, for example getting lost in a forest, or finding a hundred euros. The person has no recollection for this event. Several days later, the individual is invited to consider 
the fabricated event again. While the person is trying to magine this, he is guided through the induced image: "Where could you have been standing? What could the weather have been like?" Subsequently, if this person is asked on yet another occasion whether he ever experienced the pertinent event, there is the distinct possibility that the individual judges the likelihood of the imagined event to be considerably greater. This increased likelihood is called "imagination inflation". There has been much research on this phenomenon (Garry, Manning, Loftus \& Sherman; 1996; Garry \& Polaschek, 2000; see also chapter 4). Indeed, it appears that an imaginative acts lead to subjective confidence inflation and even to the occurrence of commissions. This effect is exacerbated when the imagination exercise is conducted more often and under more pressure from a researcher or a false witness: Goff \& Roediger, 1998; Loftus, 1993). Hyman and Pentland (1996) demonstrated that instructing subjects "to think real hard about it again" resulted in more commissions in 9 percent of their subjects. Nevertheless, this effect is less drastic when the fictive event does not fit in the person's autobiography (Sherman, Cialdini, Schwartzman \& Reynolds, 1985).

Of course, the imagination inflation effect is related to source confusion. If people have vivid fantasies about an event while imagining, then it is possible that they perceive such fantasies as "real" memories. Although the study by Thiecke et al. (1996) suggests that the guided memory technique does not produce more commissions than a standard-witness interrogation, there has not been enough systematic research to reach consensus. The imagination inflation phenomenon itself has been documented enough and that is why, in anticipation of further research, the method of guided memory can be taken to be risky.

\section{THE COGNITIVE INTERVIEW}

In October 1999, the U.S. Department of Justice published the first national handbook for the gathering and safeguarding of witness testimonies, entitled "Eyewitness Evidence: A Guide for Law Enforcement" (Technical Working Group for 
Eyewitness Evidence, 1999). This guide makes recommendations based on all information that was available to the authors at the time, regarding witness interrogation. One of the recommendations concerns the utilization of the cognitive interview.

According to the Guide, the success of this interrogation method relies on the trust relationship the interrogator develops with the witness. The emphasis on trust relationship between interrogator and witness resembles therapy. For example, it is reminiscent of Carl Rogers" unconditional acceptance. Once a trust relationship has been established, there are four strategies that can be employed to improve memory performance. Firstly, evoke the witnes ${ }^{*}$ mental and personal context at the time the event took place. At the same time ${ }_{n}$ the witness is encouraged to tell the interrogator everything that happened, no matter how insignificant a detail may seem. Furthermore, the event must be told in the correct order as well as in reverse order. Finally, in describing the event the witness must adopt different perspectives (see for a extensive reviews: Fisher \& Geiselman, 1992; Memon \& Köhnken, 1992; Köhnken, 1995; Bull, 1995).

The cognitive interview and the guided memory approach have severall characteristics in common. Both techniques try to bring the witness to a state of elevated concentration for example, by asking him to cllose his eyes. Also, both use context-reinstatement as a starting point, for example, by evoking into memary inrelevant external details such as the weather and the time of day. The goal is to offer the witness' potential retrieval cues. This approach is in accordance with what we know about state dependent memory. This is the phenomenon that people remember an event better when they are questioned under circumstances that strongly resemble the circumstances at the time of the event (Eich, 1989). One could call both the cognitive interview and guided memory wirtual forms of state dependent learning. The guided memory and cognitive interview techniques also differ on a number of aspects. The cognitive interview focuses less on obtaining specific information, the interrogator is mot 
responsible for the course of the interrogation, and more memory strategles are utilized.

Is the Guide correct in claiming the cognitive interview to be a good interrogative instrument? Using meta-analysis, it was found that a cognitive interview resulted in 41 percent more correct information while causing only a small increase in the number of commissions, compared to all sorts of other interrogation methods (Köhnken, Milne, Memon \& Bull, 1999). Furthermore, this study showed that the cognitive interview is more effective with adults than it is with children. According to kohnken et al. (1999) the success of the cognitive interview is not only based on laboratory-staged offences ( 50 -called mock crimes). Applying this technique to the interrogation of real witnessies and real offences could also result in more memories and relatively few commissions.

There has, however, also been criticism on the cognitive interview. It costs the interrogator a lot of time and energy (e.g., Kebbell, Milne \& Wagstaff, 1999; Mello \& Fisher, 1996). Besides this, it is not clear how it affects the witness" ability to identify the culprit. Some studies show that the accuracy of such an identification decreases after a cognitive interview (Finger \& Pezdek, 1999), while other studies report no effect (Fisher, Quigley, Brock, Chin \& Cutler, 1990; Cwyer \& Clifford, 1997 ) or improvement (Brandimonte, Schooler \& Gabbino, 1997; Fallshore \& Schooler, 1995; Köhnken, Schimossek, Aschermann \& Höfer, 1995). This is an important issue, because it is not unlikely that a witness is first subjected to a cognitive interview and subsequently asked to pick out a suspect in an Osloconfrontation. More research is meeded. Such research should weigh out the advantages and disadvantages and compare these to the standard-witness interrogation.

There is also a risk of imagination inflation with the cognitive interview. Although the witness is not emphatically asked to imagine and is not guided by the interrogator, there is still the danger that the context reinstatement leads the witness to fantasize and imagine in an uncontrollable fashion. Evoking the context is in fact no different than a disguised imagination assignment. 
Additionally, the "report everything" instruction during the cognitive interview makes this aspect potentially risky.

\section{ZWOLSE INTERROGATION METHOD}

In November 2000, an article appeared in the Algemeen Politieblad introducing a time-saving interrogation method, the so called Zwolse interrogation method: youthful witmesses and suispects are asked to write down their story in chronological order, in essay format. Although this happens in a group, it is forbididen to talk to others while writing. As soon as the stories have been documented, they are read by police, In a written format, the police return conflicting statements to withesses and suspects, in writing. A definitive testimony is created by filling in the gaps in the essay.

In the Algemeen Politieblad article, the Zwolse interrogation method is praised for the minimal pressure on the witness. The article also stresses that the testimony is derived entirely from the witness, that inconsistencles are resolved immediately, and that many testimonies can be acquired in a short amount of time. The author describes it as "a pleasure to see and a great experience." (Vermaas, 2000; p.15). Moreover, the article emphasizes that the Zwolse interrogation method, unlike the Zaanse interrogation method, is within the legally accepted domain.

This enthusiasm about the Zwolse interragation method is hard to share. Before explaining this hesitation, its similarities with journaling should be considered (Brandon \& Boakes, 1999). In journaling the patient writes down what he thinks went wrong im his life. While composing a good story, it is not unusual that the writer creates a clear, causal association and employs rhetorical twists. For therapeutic purposes, this is all of little concern. The product does not have to be consistent with the facts. This is not true when searching for the truth.

In our owin research we asked subjects to write down a good story about a fictive event (Horselenberg et al., 2000; experiment 2; see chapter 4). Even more so 
than in the usual imagination inflation experiments described earlier, the writing seemed to produce a confidence inflation effect as the writers came to view the fictitious events as not unlikely. This indicates that journaling and therefore also the Zwolse interrogation method are potentially able to provoke commissions. Older social psychological hiterature on cognitive dissonance teaches us why this is the case (Cohen, 1962). If we can somehow get a person to write down something that is not true, then dissonance develops. This is an unpleasant feeling which can be stopped in two ways. One way is to destroy the paper with the incorrect statements. However, if the paper is already in a therapist's, detectives, or researcher's possession, then there remains only the second way, which is adapting one's memories to fit the misstatements. In this way, writing about what could have happened can cause robust commissions. The Canadian psychollogist Spanos (1996; p. 100) stated: "One factor that probably helps patients to define their memories as real involves encouraging them to take concrete behavioural steps that heighten their commitment to the reality of their "memories". A simple and relatively subtle means for achieving such commitment involves encouraging patients to write their 'memories' down. (....) Writing the beliefs and showing the writing to others (e.g., the therapist) make those belliefs public. Once such a permanent public record is created, people experience pressure to behave (and believe) in a manner consistent with the record they created." What is true for patients is also true for witnesses. For this reason the Zwolse interrogation method should be regarded ats being risky.

\section{FORENSIC HYPNOSIS}

As far as we are aware, forensic hypnosis made its introduction in the Netherlands in the $1970^{\prime} \mathrm{s}$. Knibbeler (1985) stated that as of 1977 "in response to law enforcement and police authority requests, the neuropsychiatrist and psychotherapist H.H. Kloos te Huizen (...) interrogated a large number of witnesses in wanted cases for serious affences using hypnosis.". Shortly 
thereafter, Goltstein, Heijboer, and O'Breen $\left(1986_{*}\right.$ p.7) wrote that they had founded the Forensic Hypnosis Working Group that was committed to the further understanding and perfecting of methods in this field." The authors quickly noted hypmosis "is not a means of finding the truth." However, on the same page they also write: "In general, one can assume that memories recalled under hypnosis are more detailed than when recalled without hypnosis."

The thought that Ihypnosis can improve memory is not new (Laurence \& Perry, 1988). The claim has been a topic of research many times and has been refuted by research an equal number of times. After a series of experimental studies, Clark Hull in 1933 (p. 127) concluded: "The experimental evidence shows rather definitely that recently acquired memory material is recovered no better in hypnosis than in the waking state (...).". On the contrary, he describes hypnosis as "heightened susceptibility to prestige suggestion" and somewhat later as "generatized hyper-suggestibility." (p. 391). However, hyper-suggestibility can not be a desirable characteristic for a witness to have.

Some 50 years later, Marilyn Smith reviewed the literature avallable to her at the time and concluded "controlled laboratory studies have consistently failed to demonstrate any hypnotic memory improvement." (Smith, 1983; p. 387). The Canadian expert on hypnosis Nicholas Spanos confirmed Hull's 63 year old conclusion in 1996: "The bulk of evidence fails to support the hypothesis that hypnotic procedures do anything to improve memory, and, under at least some circumstances, such procedures may make people owerconfident about incorrectly remembered events." (Spanos, 1996: p. 94).

Therefore, hypnosis does not yield more correct memories but does cause commissions. An experiment conducted by Sanders and Simmons (1983) clearly supports this. They showed their subjects a movie about a pick-pocket thief in action. One week later, subjects were asked to identify the culprit in a line-up (Oslo-confrontation). While doing so, some subjects were under hypnosis, while others were not. In the control condition, 40 percent of the subjects succeeded, but under hypnosis the percentage of successful identifications fell to 14 percent. 
Thirty percent of the hypnotized subjects identified an innocent suspect as the culprit if he wore the thief's jacket during the Oslo-confrontation, while only 13 percent of subjects in the controll condition were misled by this.

Although it is true that warning witnesses of their susceptibility to commissions. under hypnosis beforehand lowers the number of people with such commissions " this does not make the phenomenon disappear completely. In a study by Green, Lynn and Malinoski (1998), it was found that even when witnesses were warned explicitly, a substantial number of subjects still confabulated memories, when hypnotized and asked to think about "last week, when you woke up in the night: tell me whether you can hear a loud noise." In the warned group, 1 in 3 subjects were able to describe a loud noise. In the group that was not warned, 75 percent of thypnotized subjects had vivid memories of the noise.

In the United States, results from this type of research were ignored for a long time. A small group of police officers who called themselves specialists in forensic hypnosis trained thousands of colleagues in the 1970's and 80's. The hypnosis experts liked to think of human memory in terms of a giant videotape recording many memories, even on a subconscious level. They regarded hypnosis as a fantastic method of making experiences consciously accessible. A prime example specialists used to support their views was the Chowchilla kidnapping case (Churchill, 1997). The incident took place in the summer of 1976. Three masked and armed men kidnapped a group of schoolchildren, using several getaway cars. An important witness was the driver of the school bus, whom the kids were with at the time of the kidnapping. According to a propagandistic version of the story, the driver Ed Ray was hypnotized and then remembered a license plate number of one of the getaway vehicles. The real story is less prosaic. Under hypnosis, Ray remembered two license plates: one was completely wrong and the other was only partially consistent with the license plate in question (Laurence \& Perry, 1988). However, Ed Ray remembered the part that corresponded with the real license plate even before being hypnotized. 
Hypnosis should not be used for interrogation purposes to obtain a reliable testimony. Memories are not improved by doing so. There is a llarge chance that pseudomemories (commissions) occur because of the interrogators suggestions or other factors and whatever lay people may think, lying under hypnosis is still possible. The last two scenarios are not only contended by Spanos (1996; $p$;8), but also by the founders of the Forensic Hypnosis Working Group themselves, despite one member saying elsewhere that "the idea of behaving correctly is present more strongly under hypnosis", a statement for which he does not provide a reference (Heijboer "1985; p. 335).

In The Netherlands as well as in other countries, the hypnotic memoryenhancement myth has caused a lot of confusion among the judicial authority. In the United States, itt was the hypnotically refreshed testimony that imitially caused confusion (Grisham, 1987). In California, for example, a judge ruled "a previously hypnotized witness [to be] wholly incompetent to testify on any matters dealt with while under hypnosis," while in other states, for example New Jersev, a judge considered such witness testimonies admissible as long as strict criteria were met. ${ }^{10}$ Subsequently courts were bombarded with cases involving recovered memories stemming mostly from hypnosis.

In the Netherlands the issue of hypnosis took a course similar to that in the American state New Jersey. Evidently inspired by the establishment of the Forensic Hypnosis Working Group, the Minister of Justice set guidelines in 1983 for the use of forensic hypnosis." It was ruled that interrogation under hypnosis (1) is only allowed in serious criminal cases, where customary detective methods have come to a deadlock; (2) is to be carried out by an 'expert hypnotist', in the absence of a third party; (3) where the public prosecutor is later informed of the contents; (4) is only allowed as a clue for somebody's whereabouts; and (5) only with the witness" consent in the criminal proceedings. (6) Additionally, the 
witness must be informed of these guidelimes prior to being interrogated under hypnosis. By issuing these guidelines, the Minister of Justice implied hypnosis to be a usefull forensic tool:

In the same year, a suspect in a murcler investigation requested permission to be interrogated under hypnosis so that he could prove his innocence. The logic behind the request must have been that denial of the charges during hypnosis would be more credible than the earlier denial, because memory for the event would be better and because deceitful behaviour was believed to be impossible under hypnosis. The court agreed to the propasal, as later did the Supreme Court. The Supreme Court was of the opinion that "it could not be determined whether the testimony given under hypnosis was by free will: ${ }^{n}$ However, now that the testimony was put forward in the defendant"s defence, "he was allowed to request that the court incorporate the testimony in making their judgment, taking into account the cautiousness that is necessary in the evaluation of the convineing power."1z This judgment implied the Supreme Court did not consider it impossible that an interrogation under hypnosis could lead to more or better Information than a regular interrogation.

The Supreme Courts point of view seemed to imply that interrogation of a witness under hypnosis can be very useful and is permitted in any case. Since then, witnesses lin the Netherlands are interrogated under hypnosis every once in a while. For example, in a 1993 case known as the Maastricht Carnival Murder, ${ }^{13}$ interrogation of a witness took place under hypnosis. This interrogation never vielded any additional information.

On April 24th 7996 , al girl named Robin B., who was almost four years old at the time, disappeared from Breda, The Netherlands. She went to play at a neighbour's house that day. The neighbour's name was. Trudy J.. Robin B. never returned home that day. Mrs. J. was soon suspected to be responsible for Robin's disappearance. Shortly after the little girl's disappearance, one of her body parts 
was found in a dumpster. Mrs. J. was suspected of murder. Despite extensive interrogations, Mrs. J: denied the allegations. However, the police persisted in their endeavours and this resulted in a taped confession on August $10^{\text {th }}$, which she revoked in September. ${ }^{14}$

Subsequently Mrs. J. announced via her counsel that she wanted to be interrogated under hypnosis. This is possible as long as the acquired information is used exclusively in the defendant's interest. That probably explains why the public prosecutor, Mr. C. Van Spierenburg protested such an interrogation: According to De 5 rem, he also stated that $J$."s recent revocation of her confession mattered little: "We have the woman's confession to the police and investigative judge". That probably also explains why the suspect's counsel, Mr. D. Moszkowicz, insisted on such an interrogation. After all, his client had nothing to lose. In light of the jurisprudence, they hoped the court would wiew a denial of the charges under hypnosis as being more credible than the earlier denial and confession. The court granted the counsel's request and instructed the investigative judge to appoint a hypnotist expert. This interrogation under hypnosis did not yield anything new. The court sentenced Mrs. j. to a long time in prison, which she later appealed to without success. There are also cases where victims claim they were brought into a helpless state by means of hypnosis and were then raped by the hypnotist (see Hoenkamp, 1990). These cases are based on the idea that the hypnotic trance is a special type of consciousness where patients or clients are not able to execute their will. There is little scientific evidence to support this idea (Kirsch and Lynn, 1995; for a recent Dutch example see Nanninga, 2001\%.

We reviewed the Dutch cases on forensic hypnosis for two reasons. Firstly, it demonstrates that the Dutch courts are regularly confronted with cases where witnesses or suspects have been subjected to hypnosis. The rationale behind this is that hypnosis has a memory-improving effect. This idea is propagated by a

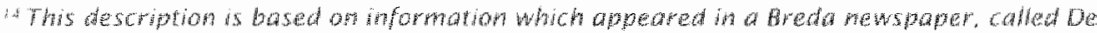
stem.
} 
small group of specialists that have lost sight of scientific consensus on this topic. To this date, these specialists argue that "there is no evidence for a systematic association between hyprosis and memory dilstortions, pseudomemories or hypermnesia", and "there is evidence $(.$.$) that hypnosis (\ldots)$ thas a positive effect on the retrieval of meaningful material" (Ligthart; 2004 ; $\mathrm{p}$. 515). However, in scientific quarters, the consensus is that hypnosis does not increase the number of correct memory details, but may - and often does increase the number of commissions. Therefore, for forensic purposes, this technique is one of the worst possible methods. Meanwhile; advocates of hypnosis are not exclusively found in the Netherlands. For example, there is a small group of hypnosis specialists active in Belgium (De Pauw, 1999):15

Secondly, the jurisprudence is not very clear, even after the case whit which we started this chapter. Legal scholars like Corstens (1999) believe that a testimony given under hypnosis can be regarded as admissible in the Supreme Court, if it is in the defendant's interest. These scholars assume that the suspect does not lie, or lies less, when hypnotized. This assumption is not in accordance with scientific opinion. It is time for some clarity: hypnosis complicates witnesses" and suspect's testimonies and renders them unfit for use. The same is true for the technique discussed in the following section.

\section{NARCO-ANALYSIS}

Like guided memory and hypmosis, narco-analysis originated from psychotherapy. During the First World War, the American Dr. Lovenhart accidentally discovered that silent patients became more talkative when given a

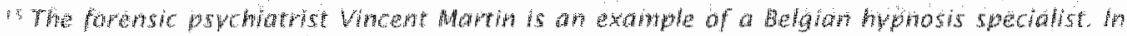

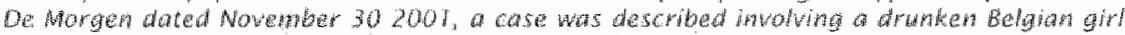

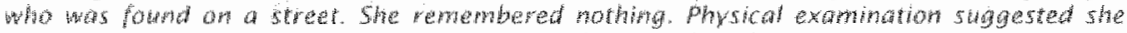

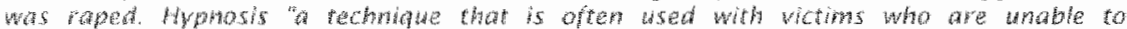

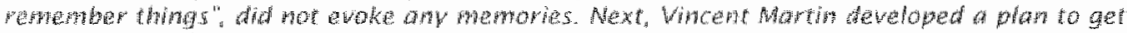

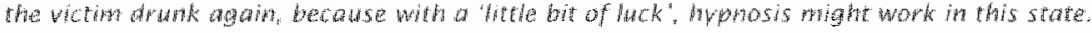


light dosage of the opiate sodium amytal. That observation gave his colleagues two new ideas regarding the application of sodium amytal and related substances, such as pentothal and seconbarbital (see Killistrom, 1998, for a historic review). One inwolved the treatment of traumatized soldiers. The idea was that sodium amytal could be used to release suppressed experiences from the front, which would speed up recovery. The second application was a forensic one. Ever since the 1930's, there were a number of fanatic police officers and forensic psychiatrists that thought sodium amytal could be used to acquire more detailed testimonies from suspects who refused to talk. The term narco-analysis is used to describe both applications: interviewing silent patients, witnesses or suspects who are under the influence of sodium amytal or a related substance. 16 Narco-anallysis could be disregarded as an American anomaly. However, the method also branched out to The Netherlands (for a more detalled history see Snelders, 2000). It has only been a couple of years since the psychiatrist Koerselman (1996) claimed narco-analysis could be useful with certain clinical disorders, because it makes suppressed trauma's accessible. Koerselman's claums were supported by professor Bastiaans, who untill the 1990's, used pentothal and/or LSD in the treatment of many patients with war traumas. Bastiaans had a psycho-analytical background, and in line with Freudian tradition, he was convinced that such substances temporarily alleviate the suppression of unpleasant memories.

In the winter of 1985 , a young man who was in a confused state of mind was found in Amsterdam's red-light district. He was unable to remember who he was or anything from his past. An immigration officer took pity on the man and started investigating leads on the man's background and identity. When the investigation failed the officer took the patient to Bastiaans, who conducted several narco-analytic sessions with him. This yielded a large amount of fantastic stories, in which the $C \| A, F B \mid$, Soviet Union and Canada all played a prominent 
role. Ut was later determined that the patient came from a suburb of Paris and that it was impossible that he had ever worked as a spy. Nevertheless, the patient felt comfortable with his new identity as a CIA-officer and he reported feeling no sense of recognition when confronted with reminders of his real background (Merckelbach, Jelicic, Candel \& Horselenberg, 2002).

Narco-analysis produces even more commissions than guided memory and hypnosis. That is the conclusion when reading a review article written by the psychiatrist Piper (1993; p. 455). In one of the studies the cites; "a patient claimed to have a child who in reality did not exist; another stated that a child who in fact was alive had not yet born; a third threatened to kill someone who had already been dead for a year. The investigators found patients' claims about dates, specific places, names, and events to be untrustworthy, of questionable veracity, and often contradictory because of the loss of time sense." Can it get any worse? This question is not entirely irrelevant, because Koerselman (1996; p. 749) reported that his expertise on marco-analysis originates from the Dijkzigt hospital in Rotterdam, where the technique "is applied primarily for diagnostic purposes in forensic psychiatry:" Although the meaning of this is not clear, there is one well-documented case that gives us an impression of this forensic application (Van Leeuwen, 1990). The case took place in 1988 and concerns a man who was suspected of killing another man after a night of partying downtown. The suspect claimed he did not remember anything. The court appointed psychiatric expert thought the suspect was suppressing memories of the incident. He belleved the victim made sexual advances which resulted in a violent reaction. With the suspect's consent, he was given pentothal. In the resulting "pentothal-delirious" state, the suspect remembered strangling the victim. With this confession, the psychiatric expert considered the case to be solved. The court agreed. Based on the confession from the narco-anallysis session they sentenced the defendant to 2 years in prison for manslaughter. In an appeal, the court ruled differently: manslaughter, yet dismissal from any 
prosecution. This case is recent and disturbing enough to stress the following: narco-analysis is hopeless at improving memory.

\section{CONCLUS\|ON}

In many respects our autobiographical memory has a sociall function. We use it when telling others a story in which we play a role and must give a "suitable" explanation for how it all happened (Haber \& Haber, 2000; Crombag, 1999). Patients might "lose" such a story. In such a case, a psychotherapist might employ techniques such as relaxation, imagination, hypnosis " and maybe even narco-anallysis. Whether or not stories told under the influence of such techniques actually reflect the truth is not important. Of importance is whether it is beneficial to the patient.

This is not true for stories in the legal setting. Suitable explanations are not sought; of importance is what really happened. That is why detectives' and forensic psychiatrists' inspiration from psychotherapeutic techniques is not a good thing. We have discussed several techniques in this chapter. For many of them, it was concluded that they produce commissions, which should be avoided in the legal arena.

All in all, only the standard-witness interrogation can yield an increase in accurate memory details that is not accompanied by an increase in the number of commissions. The added value of the cognitive interview is very little, costs more time, and potentially interferes with line-up identification of the perpetrator (McMahon, 2000; Memon, Wark, Holley. Bull \& Köhnken, 1997; Kebbell et al.. 1999). Contrary to what is implied by the name, the standard-witness interrogation is cumbersome as it is. 

CHAPTER 2

Pseudomemories and Personality

Characteristics

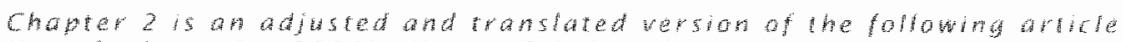

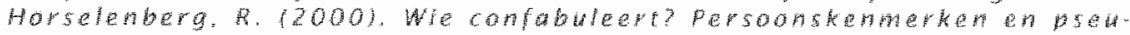
dowemineringer. Depsycholoog. 3, 216-223. 


\section{INTRODUCTION}

The previous chapter introduced some of the problems that the police may have with eyewitness memories and the way they try to solve such problems. As said earlier, eyewitness interrogation often relies on techniques borrowed from psychotherapy. However, whereas in psychotherapy accurate recollection is of minor importance, in police interviews the truth is of major concern. Meanwhile, we know that clients" recollections can be altered by therapists' interventions such that false memories may emerge (Loftus, 2003a;b).

During the past century, a bulk of research has focused on how pseudomemories may develop. The early works of Burnham (1889); Münsterberg (1908), and Bartlett (1932) already showed that incorrect details of an event can be implanted and that memory reconstruction is based upon general knowledge. Since this pioneering work, many studies have documented the same findings, eventually converging on the notion that proactive interference (i.e., memories can be distorted by things we experienced earlier) or retroactive interference (i.e., memories can be distorted by things we experienced later on) causes these memory failures (Loftus \& Pickrell, 1995). At this moment, there are two theoretical accounts of pseudiomemories: the fuzzy-trace theory (FTT; for a review, see Brainerd, Reyna \& Poole, 2000) and a model introduced by Hyman and Kleinknecht (1999). Both modiels will be briefly discussed in the following paragraphs.

\section{FUZZY TRACES}

According to $F \pi$, target events are simultaneously stored in verbatim (episodic; e.g., in his left hand he had a bag and in his right hand a gun) and gist (semantic; e.g., armed rabbery story) traces. Both traces elicit different types of subjective impressions. Whereas verbatim traces are accompanied by feelings of specific recollection and give access to representations of detailed surface structures cone 
clearly remembers how the robber looked like), gist traces go hand in hand with a global impression of familiarity that are accompanied by recollections that are consistent with many possible events (e.g., robbers usually wear masks and carry guns). Both categories of feelings, in turn, support all-or-none or graded similarity judgments, respectively. However, verbatim traces rapidly decay over time (i.e., within days; e.g., Koriat, Goldsmith \& Pansky, 2000), whereas güst traces are resistant to decay. When time passes, people will increasingly use global gist traces to reconstruct their memories.

According to this framework, spontaneous false memories can occur for two reasons. Either retrieval is based on gist memories of targets. Thus, when gist memories are retrieved, pseudomemories may develop as the deciston to accept a recollection as true is based on a fictitious event evoking feelings of familiarity. Or this decision irelies on various non-mnemonic processes (e.g.; response bias). In the case of implanted pseudomemories, verbatim traces come into play. Here, verbatim traces of inconsistent distractors ("the clerk saw the robber"s face") may be retrieved because these distractors were presented during the post-hoc misinformation phase, that is, after the event. During this post hor misinformation phase, additional verbatim traces may become available that conflict with previously stored verbatim traces (e.g., "the robber wore a mask"). These newly stored verbatim traces support a false judgment (i.e., accepting it as a genuine memory; Brainerd et al., 2000).

\section{PLAUSIBILITY, NARRATIVE, AND SOURCE MONITORING ERRORS}

Another recent account of pseudomemories was introduced by Hyman and Kleinknecht (1999; see also Hyman \& Loftus, 1998). According to these authors, three ingredients are required to create a pseudomemory: incorrect plausibility assessment, memory construction, and, most importantly, a source monitoring error. To begin with, a fictitious event suggested to a person needs to be rated as 
plausible by him. Obviously, the person should believe that such an event could have happened. Plausibility assessments may be influenced by the source of the parricular suggestion (e.g., authority figure), the nature of the event itself, and the odids one could have undergone an event similar to the suggested event. So, only plausible events may enter the next stage in the development of pseudomemories (Hyman \& Billings, 1998; Hyman, Husband \& Billings, 1995; Hyman \& Pentland, 1996). Germane to this issue is the study of Pezdek, Finger, and Hodge (1997). They showed that false memories were easier to elicit when the fietitious target event was having been lost in a shopping mall (plausible) than when the event was having had a rectal enema (relatively implausible).

After having evaluated the suggested event as plausible, a memory about this event must be constructed. Memory construction should consist of an image and an accompanying narrative. It might seem hard to construct such a memory. Yet, research has shown that by simply linking suggested information to information that already exists in autobiographical memory (Hyman et al., 1995) or by prompting a person to describe the suggested information (Hyman \& Pentland, 1996) images and narratives about the fictitious events may emerge. In fact, probably every activity in which people are being prompted to think or talk about events leads to memory constructions containing images and narratives (Hyman \& Kleinknecht, 1999).

However, if a person has rated the suggested event as plausible and has constructed images and narratives, even then the person does not necessarily need to think the event actually occurred (Hyman \& Pentland, 1996). To truly create a pseudomemary, a person should make a source monitoring error since one has to claim that it is a personal memory. Here, source refers to the conditions under which a memory is acquired (e.g., spatial, temporal, and social context of the event and the modalities through which the information was obtained; Johnson, Hashtroudi \& Lindsay, 1993). Source monitoring involves making attributions about the origins of memories. There are three important types of source monitoring. Source monitoring can either be external-external 
(e.g., distinguishing information of person $A$ and $B$ ), internal-internal ( $e_{\text {.g. }}$ discriminating memories of what one thought and what one dreamty, or internalexternal (e.g., distinguishing memories for actual events from memories of thoughts or imaginations). For all three types, several cues as to the source exist. They are, for example, based on perceptual and contextual information "semantic details, affect, and/or cognitive acts (Johnson et al., 1993): Source monitoring is basically accurate when the event memory is detailed, is accompanied by unique characteristics, and if correct decision processes and criteria are used during remembering. However, as the term source monitoring error indicates, under some conditions deficient monitoring does occur. For example, there is a strong tendency for people to forget the source of their memories (Zaragoza \& Lane, 1994), an issue discussed in the previous chapter. Thus, people often do recognize the content of what happened or what was said, but not the source. Recognition, then, is merely based on feelings of familliarity. Source monitoring errors are also affected by factors such as time elapsed since the suggested information or when others (e.g., authority figure, group members) maintain that the suggested event actually took place (Hyman \& Klleinknecht, 1999). Furthermore, when the suggestion is given on repeated occasions, more errors are made (Zaragoza \& Mitchell "1996).

\section{PERSONALITY CHARACTERISTICS I}

What both models have in common is that they picture memory as a constructive process (Hyman \& Loftus, 1998; Schacter, 1999) and that familiarity judgments lead to crucial interferences. This does not mean, though, that everything a person remembers is incorrect. In fact, most memories will be accurate in a global sense. In the words of Barclay (1986; p. 97): "There is a fundamental integrity to human memory". Moreover, although research has shown that false memories can be implanted through various techniques, these techniques are not always and in all participants successful. An estimated average of one out of five 
participants is willing to accept stiggestions made during an experiment (Loftus; 1997). This notion has shifted interest from whether it is possible to create pseudomemories to the characteristics that make people vulnerable to accept incorrect detalls or even whole events as part of their autobiography. The need for understanding these characteristics is twofold. Firstly, knowledge about them may alert a therapist not to use certain memory recovery techniques with clients displaying characteristics related to pseudomemory creation. Secondly, such information can be helpful in interpreting eyewitnesses', victims', or suspects" memory in the legall system (Wilkinson \& Hyman; 1998).

\section{MISINFORMATION ABOUT EVENTS}

Research on pseudomemories has basically used three different paradigms (Platt, Lacey, lobst \& Finkelman, 1998). The first paradigm is the misinformation paradigm introduced by Loftus and colleagues (e.g., Loftus, Miller \& Burnsi 1978). Here, participants are shown videotapes or slides depicting crimes or accidents. Afterwards, the participants are exposed to post-event mislleading information about the event (i.e., misinformation). After this misinformation phase, memory is tested to explore whether the misinformation is, often unintentionally, incorporated into the memory of the original event. A good example of this paradigm is the early work of Loftus and Palmer (1974). They showed their participants short traffic safety films depicting car accidents. After having seen the films, participants were asked to describe what they saw and to estimate the speed of the cars involved in the accidents. All five groups of participants were given the question about how fast the cars were driving when they hit each other, except that the word hit was altered over the groups (i.e., smashed, collided, bumped or contacted). The groups that were exposed to the stronger verbs (i.e., smashed, collided) gave higher speed estimations. There are many experimental variations on the misinformation theme le.g., stop sign versus yield sign; moustache instead of clean shaven), yet, all studies demonstrate that post-event 
misinformation can modify dietails of a witnessed event (e.g., Hyman \& Loftus, 1998; Loftus, 1997). However "since these misinformation studies are not related to the self or to emotional events; the question can be raised whether they provide convincing evidence that suggestion may lead to a pseudomemory of a complete event. Therefore, a second type of paradigm was introduced.

In this approach, participants are generally asked to recall events from their childhood. These events are gathered by the researcher from parents or other family members and pertain to things that really happened to the participant. What participants don't know, though, is that among these real events, one false event is introduced, and presented as if it were also an actual event reported by the participants" family. Usually, participants are interviewed several times about both categories of events. The outcome of these studies indicate that if suggested information pertains to self-involved and even emotional bogus events, some participants recall or even remember details about them. A good example of this type of research is an experiment by Wade, Garry, Read, and Lindsay (2002). They exposed 20 participants to a false childhood event via a fake photograph and imagery instructions. During three interviews, participants thought about the fake photograph picturing them on a hot air balloon ride and tried to recall the event using guided-imagery. In this study, 6 participants partially recalled the particular event, whereas 4 participants developed complete memories about the fictitious hot air balloon ride (see also Lindsay, Hagen, Read, Wade \& Garry, 2004).

The third type of paradigm employed is concerned with the creation of false memories about laboratory events. Recent replications and extensions of Deese's (1959) work on false memory intrusions in recall of wordlists by Roediger and McDermott (1995), the so-called DRM paradigm, demonstrate that this is a fruitful approach to study pseudomemories. In general, participants are presented with lists of semantically rellated words (e.g., sleep, night, dark, etc.), all pertaining to a non-presented theme word (i.e., the critical lure; e.g., bed). During recall and recognition tasks, intrusion of the critical lure is measured. 
Whenever such intrusions occur it is marked as a pseudomemory. So, for example, if one hears words like sour, candy, sugar, bitter, good, taste, nice, honey, chocolate, cake, and tooth, some participants will later also remember to have heard the word sweet since this word is strongly related to the other words (Roediger McDermatt, 1995).

\section{PERSONALITY CHARACTERISTICS II}

In returming now to personality characteristics, based on previous research (see for a review: Eisen \& Lynn, 2001), several characteristics can be nominated that may be related to false memories. These characteristics are dissociation, absorption, fantasy proneness, imagery vividness, cognitive failures, suggestibility, compliance, and self-reported depressive symptoms. Before discussing their possible contribution to the creation of pseudomemories, each characteristic and its measurement, will be briefly described.

An often cited definition of dissociation is "the lack of the normal integration of thoughts, feelings, and experiences into the stream of consciousness and memory" (Bernstein \& Putnam, 1986, p. 727). Dissociation can either be nonpathological (e.g., one arrives at one's destination and one does not know how one got there), a discrete response to a traumatic event (i.e., peritraumatic dissoiciation; Marmer; Weiss, Metzler \& Delucchi, 1996; but see Candel \& Merckelbach, 2003), or a stable trait (Eisen \& Lynn, 2001). Regardless of the precise type of dissociation, central to dissociation are memory problems and increased suggestibility (e.g., Lynn, Knox, Fassler, Lilienfeld \& Loftus, 2004). As demonstrated by several self-report scales (e.g." the Dissociative Experiences Scale; DES; Bernstein \& Putnam, 1986), there are individual differences in dissociative symptoms and experiences. The DES consists of items that pertain to dissociative phenomena (e.g. feelings of derealization, depersonalization, and disturbances in memory). Sample items are: "Some people have the experience of feeling that their body does not seem to belong to them" or "Some people have 
the experience of finding themselves in a place and having no idea how they got there."

A trait closely associated with nompathological dissociation is absorption, which refers to the disposition to experience "episodes of total attention that fully engage one"s representational (i.e., perceptual; enactive, lmaginative, and ideational) resources ${ }^{n t}$ (Tellegen \& Atkinson, 1974; p. 268). The Tellegen Absorption Scale (TAS: Köhlstrom et al., 1994), deweloped by Tellegen and Atkinson (1974), is a widely used index of absorption. It consists of items like: "The sound of a voice can be so fascinating, that I can listen to it endlessly" and "I like to watch the changing of cloud shapes."

Another trait strongly related to nonpathological dissociation is fantasy proneness (Lynn \& Rhue, 1988; Spanos, 1996). According to Wilson and Barber (1982), a person is fantasy prone if $s /$ he has a longstanding history of profound imaginative involvement. These authors also reported that high fantasy prone individuals have difficulties distinguishing between actual events and imagined events. Based on extensive case reports of fantasy proneness by Willson and Barber (1982), the Creative Experiences Questionnaire was developed (CEQ: Merckelbach, Horselenberg \& Muris, 2001). Typical CEQ-items are: "In general, I spend at least half of the day fantasizing or daydreaming" and "My fantasies are so vivid that they are like a good movie."

Yet another close cousin of dissociation, absorption, and fantasy proneness is imagery vividness or mental imagery (Aleman \& de Haan, 2004: Lynn \& Rhue, 1988). Dobson and Markham (1993) reported that individuals with vivid imagery are more likely to produce source monitoring errors. There are several questionnaires measuring this characteristic, one of them being the Questionnaire upon Mental Imagery (QMI; Sheehan, 1967). The QMI is a selfreport instrument that aims at measuring individual differences in imagery ability. Illustrative items are "How vividly and lively cam vou imagine the taste of salt" and "How vividly and lively can you imagine the sensation of a soar throat." 
According to Merckelbach, Muris, and Rassin (1999), a lack of cognitive control (e.g., absent mindedness) is closely related to dissociation (see also Hacking. 1995 ) but not to fantasy proneness. Furthermore, absent minded individuals have reduced memory confidence (Merckelbach et al, 2000). The Merckelbach et al. (2000) study also suggests that absent mindedness, at least in part, mediates the connection between dissoclation and receptivity to misleading information. A good measure of absent mindedness is the Cognitive Failures Questionnaire (CFQ; Broadbent, Cooper, Fitzgerald \& Parkes, 1982). The CFQ is a self-report instrument that measures the frequency of everyday lapses and minor blunders in perception and attention (e.g., "do you fall to notice signposts on the road?"), memory (e.g., "do you forget appointments?"), and action (e.g., "do you bump iinto people?").

Another characteristic related to pseudiomemories is suggestibility. There are two distinct types of suggestibility, one being hypnotic suggestibility which involves dissociation, absorption, and fantasy proneness, and the other being interrogative suggestibility. The first type is relevant to a wide array of phenomena ranging from susceptibility to hypnosis to naiveté (Schooler \& Loftus, 1993) and is extensively studied in relation to memory distortions (e.g., Barnier \& McConkey, 1992; McConkey, Labelle, Bibb \& Briant, 1990). According to Gudjonsson (1997), interrogative suggestibility incorporates a social interaction, a questioning procedure, a question containing a suggestion, the acceptance of this suggestion, and a behavioural response. Memory distrust plays a key role in Interrogative suggestibility and is strongly rellated to self-confidence (Gudjonsson, 1992). Individuals differ in the extent to which they trust their own and other people's memory (Crombag, Merckelbach \& Elffers, 2000). People who mistrust their own memory are sensitive to misleading information offered by others and this may make these individuals susceptible to pseudomemories, which may take the form of false confessions (see also chapter 6).

The Gudjonsson Suggestibility Scale (GSS; Gudjonsson, 1984) was developed to measure interrogative suggestibility and comprises a short story that is read out 
to participants. This is followed by several specific questions about the story. Most of the questions convey misleading information about the story. The extent to which an individual gives in to leading questions constitutes the Yield score. Other items measure memory performance. Following the questions, particlpamts are told in an authoritative manner that they made many mistakes and that all questions have to be answered for a second time. The number of times a participant changes his/her initial answers constitutes the Shift score. A Total suggestibility score can be obtained by summing Yield and Shift-scores. There are some indications that high GSS scores predict the tendency to give in to misleading suggestion about an event that has been witnessed (Merckelbach, Muris, Wessel \& Van Koppen, 1998)

Like individuals who are susceptible to interrogative suggestibility, individuals reporting depressive symptoms suffer from a lack of self-confidence, a phenomenon which is closely connected to their attributional style (Buchanan \& Seligman, 1995). Furthermore, their cognitive resources are limited such that they perform poorly on recognition and recall tasks, although their implicit memory is intact (Roediger \& McDermott, 1992). Moreover, clinical studies indicate that depressive mood is intimately linked to overgeneral autobiographical memory (Peeters, Wessel, Merckelbach \& Boon-Vermeeren, 2002). A possible explanation for this memory deficit concerns reduced working memory capacity due to ruminative self focus (Williams, 1996). Hence, ruminating exploits working memory capacity, which makes it difficult for people to retrieve specific memories, because this also requires extensive cognitive resources (Van Vreeswijk \& De Wilde, 2004). Depressive symptoms are commonly measured with the Beck Depression Inventory (BDI; Beck, Rush, Shaw Emery, 1979). The $\mathrm{BDI}$ is a self-rating questionnaire consisting of items that address the behavioural manifestations of depression. Sample items are: "I am so sad and unhappy that I can't bear it anymore" and "I totally lost interest in other people." Two further characteristics may sensitize individuals to accept misleading information or accept entire false memories, namely compliance and social 
desirability. According to Gudjonsson (1989), complance overlaps with suggestibility in that both characteristics include avoidance of conflict and eagerness to please. Compliance differs, however, from suggestibility because the first does not involve the acceptance of the proposition or request. That is, even if a person does not agree with the requested or proposed behaviour, the person makes a decision, whilst $s /$ he is under pressure, to carry it out. Gudjonsson developed the Gudjonsson Compliance Scalle (CCS) to measure compliance. It is a self-report questionnaire consisting of several statements that have to do with how individuals deal with conflicts and confromtation (e.g., "I give in easilly to people when I am pressured" $)$.

Related to compliance is the willingness to select a socially desirable response (Gudjonsson, 2003). This feature is important because in all pseudomemory paradigms, the social context plays a pivotal role (e.g. Hyman \& Billings, 1998). Consider, for example, the fictitious childhood event paradigm discussed earlier (e.g., Wadle et al., 2002). Here, participants are told that they are expected to remember increasingly more during the subsequent interview sessions. Participants may come to experience reports about additional memories as highly desirable in order to gain respect and approval. The Marlowe-Crowne Social Desirability Scale (SDS; Crowne \& Marlow, 1964) measures the tendency of individuals to present themselves in socially favourable terms and "thus, taps conformity in response to social pressure. Typical SDS items are "I am always careful about my manner of dress" and "No matter who I am talking to, I am always a good listener."

\section{PERSONALITY CHARACTERISTICS AND PSEUDOMEMORIES}

How, then, may these personality characteristics affect memory? It is not too farfetched to give some of the personality characteristics a place within the source monitoring framework, the last stage of the Hyman and Kleinknecht (1999) modell 
discussed earlier. A tentative taxonomy of personality characteristics and source monitoring is shown in figure 2.1 .

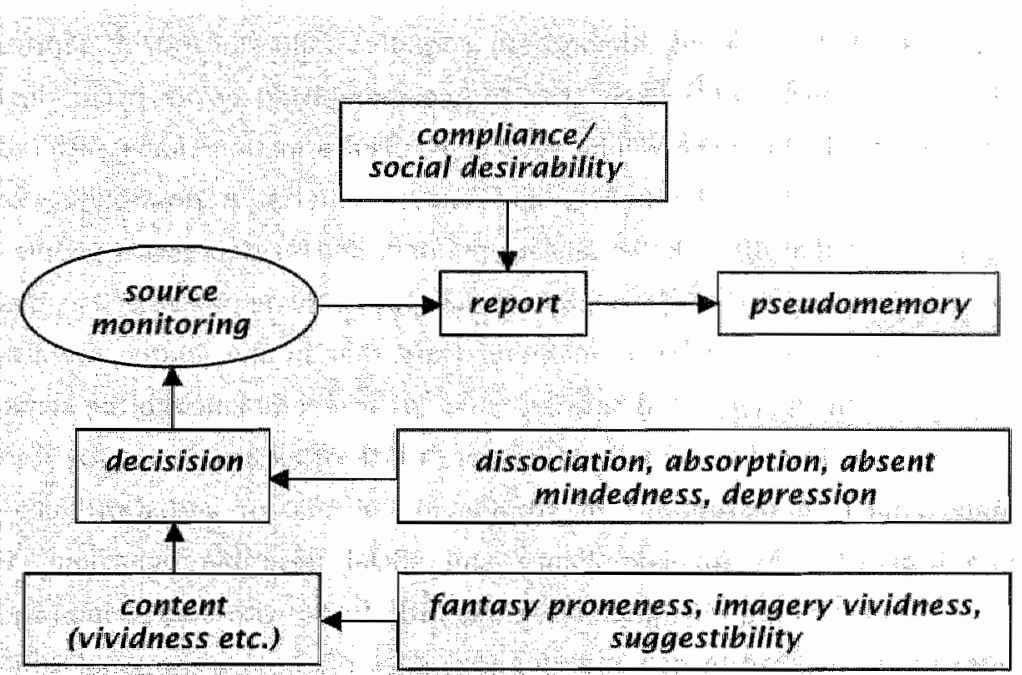

Figure 2.1: Integration of source monitaring and personality characteribus.

One could argue, though, that, for example, fantasy proneness or imagery vividness might come earlier into play as they can fuel plausibility judgements andfor memory construction. Meanwhile, in order to distinguish between intemally generated sources of recollective experiences (e.g. imaginations, fantasies) and externally generated sources of such experiences (e.g., actuall perceived events, others" recollections, media stories), cules are needed (johnson et al., 1993). Relative to imagined events, perceived events include an abundance of perceptual (e.g., colour, sound, smell) and contextual (e.g., spatial, temporal) information, semantic detail, and affective information (Eisen \& Lynn, 2001). However, when imagined events are experienced as clear and vivid as perceived 
events due to characteristics like fantasy promeness, imagery vividness, and suggestibility, source monitoring errors and relatedly, memory errors can emerge Furthermore, when few details of perceived events are recalled as a consequence of dissociation, absorption, cognitive failures, and/or depressive symptoms, it is also highly likely that source monitoring errors occur. In that case, people might be more willing to accept misinformation that is offered by others (e.g.: therapists, the police, and experimenters). A possibility closely related to this is that dissociative, absent minded, and/or depressive people rely on lax decision criteria when they have to evaluate whether a mental representation refers to a "real" memory. Note that in the source monitoring framework, internally generated sources show great resemblance to the semantic or gist traces as described by FTI. Moreover, a lack of external cules for sources is highly similar to disruptions of storage in episodic or verbatim traces as stipulated by FT. As for compliance and social desirable behaviour, their influence on developing false memories has little to do with source monitoring. They are more involved in demand characteristics of the experimental context, resulting in false alarms which are in that same context considered as false memories.

The tentative model depicted in figure 1 contains many parameters and causall relations. In the chapters that follow, we have not the ambition to test the merits of the model. Rather, the model tries to explain why we focus on certain personality characteristics. Obviously, only when these characteristics are found to be linked to pseudomemories, it becomes opportune to test causal relationships between memory and personality. 
CHAPTER 3

Absorption, Fantasy Proneness, and the False Fame Effect

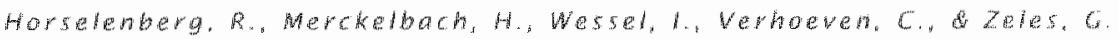
(stumilted for pablication). 


\section{ABSTRACT}

Participants tend to claim that nonfamous names refer to well-known people when they have previously been required to read these nonfamous names. This false fame effect originates from source monitoring errors. In two studies, we explored whether high levels of absorption or fantasy proneness are related to such source monitoring errors. In study 1 , undergraduates selected for their high or low scores on absorption $(N=39)$ underwent a famous names task. In study 2 , this task was carried out by undergraduates who were recruited for their high or low fantasy proneness scores $(N=40)$. While an overall false fame effect did occur, neither high absorption nor high fantasy prone participants were found to display a stronger false fame effect than control participants. In study 1 , there was, however, a modest correlation between self-reported depressive symptoms and the false fame effect. Our findings suggest that some memory illusions are so pervasive that they are not readily explained by personality traits contributing to source monitoring difficulties. The question arises therefore whether such memory illusions provide a good lab model for studying ellinical memory aberrations.

\section{INTRODUCTION}

Jacoby and colleagues (Jacoby, Kelley, Brown \& Jasechko, 1989) described a robust memory illusion that they dubbed the false fame effect. This effect can be obtained as follows. Participants are first required to read a series of nonfamous names. The next day, they are shown a list of names, consisting of the old nonfamous names, new nonfamous names, but also names referring to famous people (e.g., actors, writers, politicians, etc.). Participants are then asked to make fame judgements for these names. Under these conditions, a false fame effect will occur, which means that participants falsely identify previously studied (old) 
nonfamous names as famous. Apparently, participants are misled by the familiar sound of old nonfamous names.

Researchers agree that the false fame effect is a subtle example of a source monitoring error (Schacter, 1999). Source monitoring refers to a person's ability to remember the source from which information was acquired Johnson, Hashtroudi \& Lindsay, 1993). In case of the false fame effect, the source of familiarity of the old nonfamous names is forgotten, paving the road to false fame.

Interest in source monitoring has grown during the past few years, because it might account for certain clinical phenomena (e.g., Belli \& Loftus, 1994; Johnson \& Raye, 1998; Destun \& Kuiper, 1999). For example, Lipinski and Pope (1994) described some dinical cases inwolving serious source monitoring errors. Their patients frequently suffered from aggressive intrusions, yet under the influence of therapy they came to view these intrusions as recovered memories of real traumas. Thus, in these cases, the internal source of the intrusions was forgotten. A similar process might occur in people who take their vivid hypnagogic hallucinations as genuine memories (e.g., Rassin, Merckelbach \& Spaan, 2001). Other case vignettes involving a misinterpretation of internal mentation as aversive events can be found in Szücs, Jansky, Holló, Migléczi, and Halász (2003). Following this line of reasoning, it is conceivable that at least some recovered memories of traumatic chilldhood events originate from source monitoring errors. That is, it might well be that in some cases, imagery (intrusions, dreams, or fantasies) is experienced as a genuine recollection, because it has acquired a high degree of familiarity through previous therapeutical conversations (e.g., Belli Loftus, "1994).

Meanwhite, it is obvious that not every patient or research participant is susceptible to source monitoring errors and memory illusions (e.g. "Destun Kuiper, 1996; 1999). It is only a minority of persons, whose memory for sources becomes rapidly inaccessible, thereby making them vulnerable to certain types of memory illusions. Thus, finding a connection between personality characteristics 
and source monitoring errors would be relevant for our understanding of why certain people are more susceptible to develop pseudomemories than others. Some authors have argued that persons who are easily wrapped up in their imagery and fantasy are prone to source monitoring errors (Destun \& Kuiper, 1996; Hyman Blllings, 1998; Merckelbach, Muris, Horselemberg \& Stougie, 2000). Indeed, questionnaires measuring fantasy-related characteristics (e.g.. absorption, fantasy proneness) often address potentiall source monitoring errors. For example, the Tellegen Absorption Scale (TAS; Tellegen \& Atkinson; 1974) contains the following item: "While watching a movie, a TV show, or a play, I may become so involved that I may forget myself and my surroundings and experience the movie as if it were real and as if $\|$ were taking part in it". As another example; the Creative Experiences Scale (CEQ; Merckelbach, Horselenberg \& Muris, 2001) consists of items like "My fantasies are often as true to life" and "Sometimes I confuse my fantasies with real memories".

Whille the false fame effect is a straightforward llaboratory example of a source monitoring error, research on individual differences and the false fame effect is scarce. A number of studies found that the false fame effect is larger in older than in younger people (see for a review: Schacter, Koutstaal \& Norman, 1997). However, these studies sought to elucidate the neuropsychological underpinnings of source monitoring errors. In contrast, the present research was prompted by the question whether false fame phenomena might serve as a laboratory model for psychopathologlical memory illusions (e.g.x recovered memories of abuse, misinterpretation of hypnagogic experiences). In our opinion, a good laboratory analogue for such phenomena should be selective in the sense that it occurs in certain individuals, i.e., individuals who score high on trait characteristics like absorption and fantasy proneness. Note that there are good reasons to assume that absorption serves as an antecedent of certain types of memory illusions (Wilkinson \& Hyman, 1998; Winograd, Peluso \& Glover "1998). For example, Destun and Kuiper (1999) found that high absorption levels were accompanied by higher ratings for context and sensory characteristics of imagined events. On the 
basis of this finding, Destun and Kuiper $(1999 ;$ p. 185) argued that "if a highly absorbed individual"s memories of real and imagined events are both represented with a high degree of vividness, this individual might have increased difficulty discriminating between real and imagined events". Germane to this issue is also a study by McNally and co-worlkers (McNally, Clancy, Pitman \& Schacter, 2000), who examined personality profilles of women who had recovered memories of clhildhood abuse and control women. McNally and associates found that the recovered memory group had considerably higher scores on an absorption scale than control women. With these considerations in mind, study 1 examined whether scoring high on absorption (as indexed by the TAS) is related to a rellatively strong false fame effect (indicating a tendency to make source monitoring errors).

There are also strong indications that fantasy proneness makes people susceptible to pseudomemories (e.g., Merckelbach et al., 2000, 5panos, Cross, Dickson \& DuBreuil, 1993; Spanos, Burgess \& Burgess, 1994). A case in point is the study by Merckelbach et al. (2000) who found that participants scoring high on fantasy proneness tend to overendorse trivial childhood experiences presented to them relative to those scoring low on fantasy proneness. Thus, in study 2, we explored whether people high on fantasy proneness are more susceptible to the fallse fame effect than people low on fantasy proneness.

In the studies to be described below, undergraduate students scaring high or low on the TAS (study 1) or CEQ (study 2) were recruited. Participants also completed the Dissociative Experiences Scale (DES; Bernstein \& Putnam, 1986) which is the standard measure of trait dissociation. Trait dissociation is known to overlap with absorption and fantasy proneness and is often examined in the clinical context (e.g. Kihlstrom, Glisky \& Angiulo, 1994; Eisen \& Lynn, 2001). Furthermore, we collected information about depression levels of participants. This was done, because people with depressive symptoms tend to display a discrepancy between implicit and explicit memory (Roediger \& McDermott, 1992). That is, implicit memory performance (e.g., performance on priming tasks) of depressive persons 
is usually intact but they perform poorly on explicit memory tasks fe.g., recall, recogmition) that heavily draw on cognitive resources. As the false fame paradigm contains both implicit (1.e., repetition of nonfamous niames) and explicit (i.e., identification of the source) elements, we sought to explore whether there is a connection between depressive symptoms and the false fame effect.

\section{STUDY 1}

\section{METHOD}

PARTICIPANTS. A growp of 166 psychology undergraduates completed the TAS (see below). Next, participants with an extreme high or extreme low TAS score were selected. They were invited to participate in the experiment. Thus, the final sample involved a high $(n=20 ; 5$ men) and a low $(n=19 ; 7$ men) TAS group. The mean age of this sample was 19.2 vears $(S D=1.7$; range: $18-25$ years). The mean TAS score of the high group was $26.7(S D=3.1)$, while that of the low group was $7.8(S D=2.3)$. Undergraduates were paid a small financial compensation for their participation.

MATERIALS. The Tellegen Absorption Scale (TAS; Tellegen \& Atkinson, 1974; Cronbach alpha $=.84$ ) is a widely used measure of mental absorption (Kihistrom et al., 1994), which is defined as a disposition to have "episodes of total attention that fully engage one's representational (i.e., perceptual, enactive, imaginative, and ideational) resources" (Tellegen \& Atkinson, 1974; p. 268). It consists of 34 yes / no items that pertain to the tendency to become deeply involved (absorbed) in everyday activities. Items are summed to obtain a total score (range 0 - 34) with higher scores reflecting a stronger disposition to become absorbed. The Creative Experiences Questionnaire (CEQ; Merckelbach, Horselenberg Muris, 2001: Cronbach alpha $=.81$ ) is a 25 true/false items Dutch measure of fantasy proneness. CEQ ttems were derived from the extensive case descriptions of fantasy proneness provided by Wilson and Barber (1982). Typical examples are 
"In general, || spend at least half of the day fantasising and daydreaming" and "My fantasies are so vivid that they are like a good movie". The number of trueanswers is summed to yield a total score (range $0-25$ ) with higher scores indicating higher levells of fantasy proneness.

The Dissociative Experiences Scalle (DES; Bernstein \& Putnam, 1986; Cronbach alpha $=.89$ ) is a 28 -item self-report instrument that asks about experiences of amnesia, depersonalisation, derealization, absorption, and imaginative involvement. Participants indicate on $100-\mathrm{mm}$ visual analogue scales (VASs: anchors being $0=$ not at all; $100=$ very much) the extent to which they experiences these phenomena on a daily basis. Scores on the individual items are averaged to obtain a total DES score (range 0 - 100), with higher total DES scores indicating stronger dissociative tendencies.

The Beck Depression Inventory (BDI; Beck, Rush, Shaw \& Emery, 1979; Cronbach alpha $=.80$ ) is a self-rating questionnaire consisting of 21 items. It measures the extent to which behavioural manifestations of depression are present. Items are scored on a 4-point scale and ratings are summed to obtain a total score frange $0-63)$, with higher scores reflecting higher levels of depressive symptoms.

PROCEDURE. Before the experiment proper, extensive pillot studies were carried out in order to sellect adequate stimulus material. This resulted in a set of 160 names. Half of them referred to nonfamous persons; while the other half referred to moderately famous Dutch persons. Nonfamous and famous mames were matched on length of Christian and family name and on sex.

The experiment consisted of two phases. During phase 1, participants completed the CEQ DES, and BDI. After this, they were informed that the experiment was about pronunciation and that they had to read a series of 40 nonfamous names. Names were presented by a Compaq computer running Experimental Run Time System (ERTS; Beringer, 1996) on a Phillips Brilliance screen. Each name appeared for $2 \mathrm{~s}$ in lowercase letters with the initial letter of Christian and family name in capitals. Interstimulus time was 2 s. Participants were instructed to read the 
presented names aloud. Although a microphone was placed in front of them, no responses were recorded during phase 1.

Phase 2 started 24 hours after phase 1. Participants returned to the lab and were exposed to a series of 160 names: 40 old nonfamous names, 40 mew nonfamous names, and 80 famous names. Participants were instructed to indicate for every single name whether it was nonfamous or famous. To do $\mathrm{so}$, they had to press either the right or the left shift-key of the keyboard. Participants were explicity told that old nonfamous names would be presented along with new nonfamous and famous names. It was emphasized that they were not required to provide reasons for their subjective fame-judgements. When participants understood the instructions, they were given several practice trials. The same display device was used as in phase 1. A name was presented randomly from the whole pool and disappeared from the screen as soon als participants pushed one of the shiftkeys. This was followed by a $1 \mathrm{~s}$ blank screen before the next name appeared. This sequence continued until participants had given fame judlgements for all 160 names. The computer recorded each fame judgement. Within the low and high TAS-group, shift-keys (i.e., lleft vs. right) and old and new nonfamous names were counterbalanced. Thus, old nonfamous words for one group served as new nonfamous words for the other group and vice versa.

\section{RESULTS AND DISCUSSION}

Questionnaire and memory data are shown in Table 3.1. As can be seen, the high TAS-group also sicored higher on both CEQ [t $(37)=-5.7, p<.001]$ and DES [t $(37)=-2.6, p<.05]$ than the Iow TAS-group. However, the two groups did not differ in terms of self-reported depressive symptoms. 
Table 3.1: Mean scores of high and low TAS group on indwidual diffreme measures (stomdard deviations are giver in parentheses.

DES
CEQ

BDI

\section{High TAS $(n=20)$}

$25.6(8.9)$

\section{$10.0(3.9)$}

$6.7(5.7)$

\section{Low TAS ( $n=19$ )}

$10.9(5.6)$

4:0 (2.2)

$4.5(3.8)$

Note. TAS = Tellegen Absorption Scale: DES = Dissochative Experiences 5 calle; CEQ

- Creative Experience Questionnaire; $B D=$ Beck Depression Mventory: $=w$ 0.01 . twotailed.

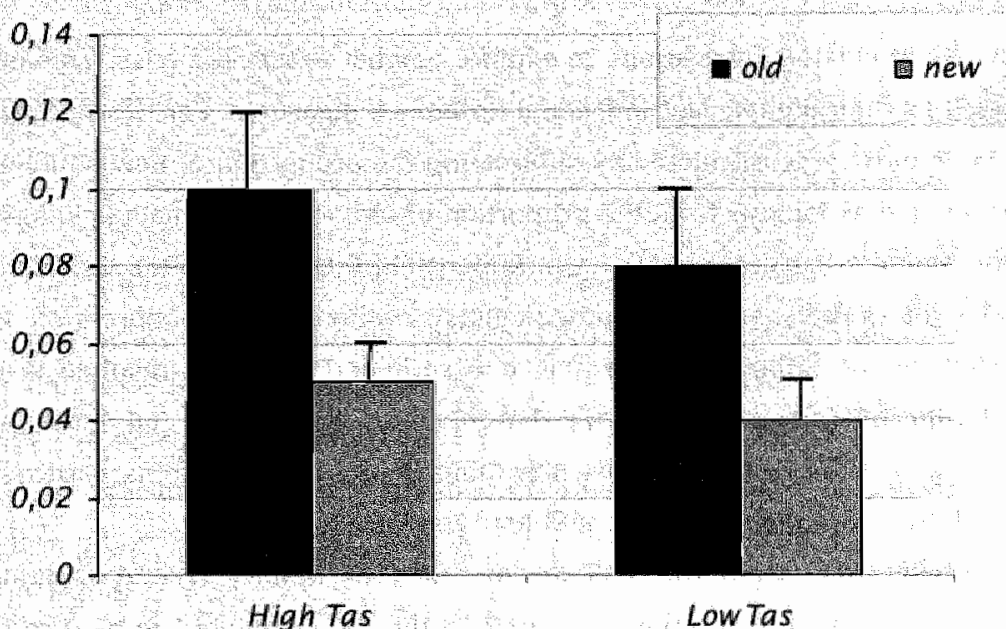

Figure 3.1: Proportions of old and hew nonfamous names falsely identifed as famous in study I (MSE's are shown with thars). 
In Figure 3.1 the proportions of old and new nonfamous names judged as famous are given: Proportions were calculated by dividing the number of names judged as famous by $40 . \mathrm{A} 2$ (group: high vs. low TAS) $\times 2$ (false fame: old vs. new nonfamous names) analysis of variance (ANOVA) with repeated measures on the last factor ylelded a highly significant false fame effect $[F(1,37)=15.3, p<.01]$. That is, $9 \%$ of the old nonfamous names were judged as famous, whereas only $4 \%$ of the new nonfamous names were judged as famous. Yet, the main effect of group did not attain significance $[F(1,37)<1.0]$ and neither was the critical interaction between group and false fame significant $[F(1,37)<1.0]$. Thus, no evidence was found to suggest that high TAS individuals display a stronger false fame effect (and, therefore, more source monitoring errors) than low TAS individuals.

Finally, we calculated correlations to explore to what extent the false fame effect is related to clinically relevaint individual difference measures. For this purpose, a false fame index was calculated by subtracting the proportion of new nonfamous names judged as famous from the proportion of old nonfamous names juidged as famous (range: -1 to .23 , see Rybash "Rubenstein \& DeLuca, 1997). Correlations between this index and dissociation, fantasy proneness, and depression were corrected for the influence of the selection variable (TAS). This resulted in only one significant correlation, namely that between depresision and false fame: partial $r(36) \cong 31, p<.05$. Thus, the more depressive symptoms participants reported, the more they were susceptible to the false fame effect.

The present study used the TAS as an index of fantasy-related mentation. However, the type of absorption measured by the TAS is thought to be related to reality absorption (i.e., becoming absorbed by external stimuli) ratheir than fantasy absorption (lie, becoming absorbed by internal sensations like dreams, intrusions etc.; Allen \& Coyne, 1995). The results of study I clearly show that absorption as tapped by the TAS does not modulate the false fame effect. Meanwhile, the driving force behind the false fame phenomenon is the 
misinterpretation of an internal sensation, namely the feeling that a name sounds familiar. Perhaps, then, it is fantasy proneness rather than absorption that is related to false fame. Admittedly, in study 1, fantasy proneness cowaried with high and low TAS scores, but this covariance might have lacked sufficient power to detect group differences in false fame due to fantasy proneness. The point is nicely illustrated by Hyman and Billings (1998). These authors found that dissociation (as measured by the DES), but not absorption (as measured by the TAS) predicted susceptibillity to pseudomemories, although DES and TAS were positively correlated with each other $(r=.59)$. This shows that dissociation, absorption, and fantasy proneness correlate imperfectly with each other. As the study by Rassin et al. (2001) shows that fantasy proneness is one distinct feature of people who tend to confuse dreams with memories, study 2 was conducted using participants selected on their fantasy pronemess scores.

\section{STUDY 2}

\section{METHOD}

PARTICIPANTS. A group of 396 psychology undergraduates completed the CEQ. Next, participants with an extreme high or extreme low CEQ score were recruited, resulting in a high ( $n=20 ; 4$ men) and a low ( $n=20 ; 3$ men) CEQ group. The mean age of this sample was 19.6 years $(\mathrm{SD}=1.7$; range: $18-24$ vears). The mean $C E Q$ score of the high group was $14.5(S D=3.1)$, while that of the low group was 2.3 $(S D=2.3)$. Participants were paid a small financial compensation.

MATERIALS. Participants completed the same questionnaires as in study 1 , with one exception. Instead of the DES, the DES-C (Wright \& Loftus, 1999) was used in study 2 . In non-clinical samples, the traditional DES produces a skewed distribution and this problem can be circumvented with the DES-C, whilch was specially developed for healthy samples. Item content and scoring of this 
questionnaire is similar to that of the original DES. Cronbach alpha's for TAS, DES-C, CEQ, and $B D \mid$ were $.90, .94, .91$, and .78 , respectively.

PROCEDURE. The same procedure and stimulus material was used as in study 1.

\section{RESULTS AND DISCUSSION}

As can be seen in Table 2, the high CEQ-group also scored higher on the TAS [t $(38)=-3.1, p<.005]$, DES-C [t $(38)=-5.4, p<.001]_{n}$ and BDI [t $(38)=-2.7, p$ $<.01]$ than the low CEQ-group.

Table 3.2: Mean scores of high and low CEQ grow on individual difference measures and proportions of old and new nonfamous names judged as famous in sudy 2 (standard deviations are given in parentheses.).

\begin{tabular}{ll} 
& High CEQ $(n-20)$ \\
\hline TAS * & $20.7(6.7)$ \\
\hline BES.C* & $40.4(16.1)$ \\
\hline BDI* & $6.8(4.6)$
\end{tabular}

\section{Low CEQ $(n=20)$}

$10.9(4,6$

\section{$24,9(15,4)$}

3.3 (3.3)

Nate: CEQ - Creative Experherces Scale; TAS Tellegen Absorption Scate: DES = Disociative Experiences Scale; BDI Beck Depression Inventory; $=p<0.01$, two-tailed.

Figure 3.2 shows the proportions of ald and new nonfamous names judged as famous. As was done in study 1, a 2 (group: high vs. low CEQ) $\times 2$ (false fame: old vs. new nonfamous names) ANOVA with repeated measures on the last factor was used, yielding a highly significant false fame effect $[F(1,38)=33.9, p<.01]$. That is, $6.5 \%$ of the old nonfamous names were judged as famous, whereas only $1.5 \%$ of the new nonfamous names were judged as famous. There was no 
significant main effect of group $[F(1,38)=1.2, p=.28]$ and neither was the critical interaction between group and false fame $[F(1,38)=2.3, p=.14]$ significant. Thus, we found no evidence to support the idea that high CEQ individuals show a stronger false fame effect than low CEQ individuals.

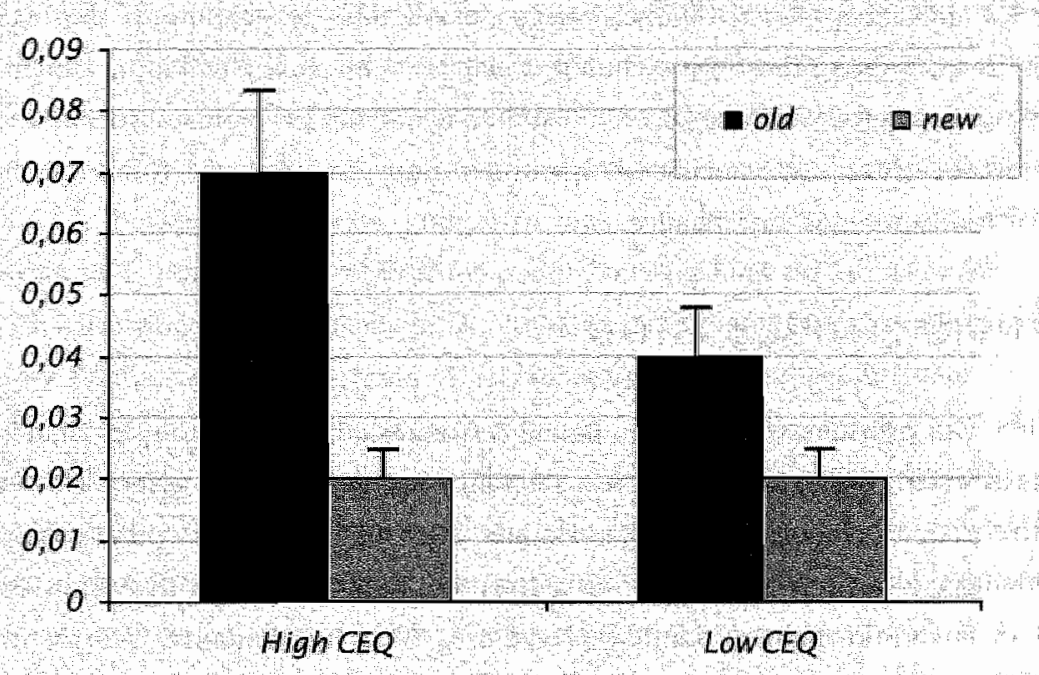

Figure 3.2. Proportions of old and new honfanous names falsely identified as famous ins sudy 2 (MSE's are show with t-bars).

As in study 1, a false fame index was calculated (range: -.2 to .3). Correlations between this index and absorption, dissociation, and depression were corrected for the influence of the selection variable (CEQ). This time, the association between false fame and self-reported depressive symptoms $(B D \mid)$ remained nonsignificant $(r=-.23, p=.35)$. Neither were the other correlations significant. 
OVERALL ANALYSIS. While both studies found robust false fame effects, we were unable to link this memory illusion to individual difference measures that are clinically relevant. One might argue that our failure is the result of a lack of statistical power. Therefore, we collapsed the data of study 1 and study $2(N)=$ 79) and calculated a set of correlations between the false fame index, on the one hand, and absorption fantasy proneness, and self-reported depressive symptoms, on the other. We excluded dissociation because the two measures we employed differed (DES ws. DES-C). To circumvent the problems associated with subject selection, we calcullated Spearman rank correlations. None of these correlations attained significance.

\section{GENERAL DISCUSSION}

In line with previous studies (e.g., Banaji \& Greenwald, 1995; Jacoby et al., 1989; Rybash et al., 1997), we obtained a straightforward false fame effect. However, contrary to our expectations, individuals high in absorption and/or fantasy proneness were not found to display a stronger false fame effect than individuals low in absorption and/or fantasy promeness. Thus, no evidence was found to suggest that individuals who are characterized by high levels of absorption and fantasy proneness are particularly susceptible to the type of source monitoring error that is tapped by the false fame effect. Only in study 1, we found a correlation between the magnitude of the false fame effect and one individual difference variable, namely self-reported depressive symptoms. It is true that depressive persons" poor performance is a recurring theme in studies relying on (explicit) autobiographical retrieval tasks (Merckelbach, Wessel \& Horselenberg, 1996; Van Vreeswijk \& De Wilde, 2004). These studies also suggest that reduced working memory capacity of depressed individuals might explain why the false fame effect is related with self-reported depressive symptoms. However, in our study 2, we could not replicate the correlation between false fame fllusion and depressive symptoms. Furthermore, when both studies were collapsed, no 
significant relation emerged. Therefore, we are reluctant to attribute much theoretical significance to this link.

It is obvious that pseudomemories in the clinical context le.g., misinterpretations of intrusions or hallucinations, false memories of childhood abuse) involve source monitoring errors (Brainerd, Reyna \& Poole, 2000; Hyman \& Kleinknecht, 1999). It is also evident that the false fame effect is a very pure laboratory manifestation of a source monitoring error (Multhaup, De Leonardis \& Johnson, 1999). Nevertheless, our data indicate that the false fame effect does not provide a good lab model for clinically rellevant memory aberrations (e.9., false memories, confusion between memories and intrusions). One distinct feature of such aberrations is that they are typical for people scoring high on fantasy proneness and/or absorption (e.g., McNally et al., 2000; Rassin et al., 2001). Yet, these traits are not related to the fallse fame effect, making this effect less relewant for the clinical domain.

What makes the false fame phenomenon attractive is that it is under total experimental control (i.e., the experimenter knows exactly whether or not source monitoring errors occur). Things are quite different with most autobiographical retrieval tasks (e.g., diary studies; Conte, 1999). On the other hand, the false fame effect represents a laboratory phenomenon with little or no self-relevance. Perhaps, them, our failure to detect links between absorption, fantasy proneness, and false fame has to do with the lack of personal involvement that is typical for the false fame task. Indeed, most studies documenting a link between individual differences and source monitoring errors are based on tasks that require participants to retrieve autobiographicall material (e.g., Hyman \& Billings, 1998; Porter, Yuille \& Lehman, 1999). A handful of studies relied on both types of tasks, - i.e., word lists and autobiographical memory tasks - , and noted that "performance on word lists may not be a good predictor of an individual's performance in everyday memory tasks because the two may be based on different underlying processes" (Wilkinson \& Hyman, 1998; p. 29; see also Platt et al., 1998). 
In the false fame illusion; it is a feeling a familiarity that confounds participants' source monitoring. On the basis of the current data as well as other studies (Wilkinson \& Hyman; 1998; Platt et al, 1998), we suspect that in clinically relevant memory illusions it is not familiarity but vividness, detailedness, and emotionality that contribute to source errors. It is here that traits like absorption, fantasy proneness, and dissociation might come into play. While the false fame effect is clearly relevant to practical issues like eyewitness testimony (e.g., Multhaup et al., 1999), it seems to be of less value to researchers looking for lab models of clinicall memory aberrations. 
CHAPTER 4

Imagining Fictitious Childhood Events:

The Role of Personality Characteristics

in Imagination Inflation

Chapler a is an adjated wasion of the following article. Horselenberg.

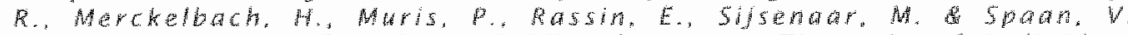

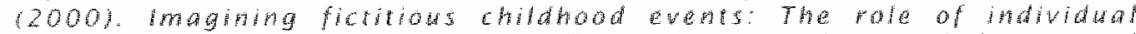

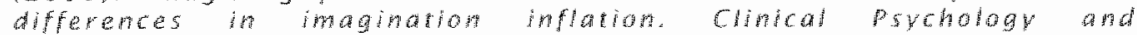
Psychotherapy.7.12g-137. 


\section{ABSTRACT}

Imagination inflation refers to the phenomenon that imagining a low probability childhood event promotes subjective confidence that the event actually happened. The present article describes two studies that addressed the issue of whether imagination inflation is related to certain personality characteristics (i.e., social desirability, imagery ability, and dissociation). In study 1 , students $(\mathbb{N}=34)$ rated the probability of 60 childhood events. Four weeks later, they came to the lab and were asked to imagine 4 low-probability childhood events. Next, new confidence ratings of target (i.e., imagined) and control items were collected. Students also completed measures of social desirability, imagery ability, and dissociation. While a higher percentage of increased confidence ratings was found for target items than for control items, the size of this imagination inflation effect was modest. Only imagery ability was found to be related to imagination inflation in that individuals with better imagery abilities clisplayed a larger imagination inflation effect. The procedure of study $2(\mathrm{~N}=45)$ closely

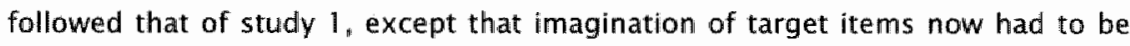
written down. Writing about a fictitious event generated a straightforward imagination inflation phenomenon, but this was not related to any of the personality characteristics. The discussion focuses on the extent to which imagination inflation may model therapy induced false memories.

\section{INTRODUCTION}

In their often cited study, Garry, Manning. Loftus, and Sherman (1996) claimed that pseudomemories might develop as a result of a simple imagination instruction. Garry and colleagues had participants rate the probability of a large number of possible childhood experiences. Next, the authors selected events that received low subjective probability ratings. Two weeks later, participants were asked to create detailed images of some of these low-probability events. Finally, 
participants again rated how confident they were that the events had happened to them. Imagination of the low-probability items produced an increased confidence that these events did happen, a phenomenon that the authors termed imagination inflation.

According to Garry et al. (1996; see aiso Heaps \& Nash, 1999; Paddock, Joseph, Chan, Terranova, Manning \& Loftus, 1998), imagination inflation can best be interpreted in terms of a source monitaring disruption. By this view, imagining a fictitious event increases familiarity with that event. To the extent that this increased familiarity is misattributed to the authenticity of the event, sourcemonitoring problems arise Johnson, 1988; Koehler, 1991; Coff \& Roediger; 1998), which may promote the subjective probability of imagined events.

In discussing the implication of their findings, Garry et al. (1996; p. 214) note that "when a mental health professional repeatedly encourages a client to imagine an abusive childhood event, these imagination activities may unknowingly promote a greater belief that particular episodes occurred. The search for fact may create a fiction." Two recent studies succeeded in replicating the imagination inflation phenomenon in undergraduate students (Heaps \& $\mathrm{Nash}_{*}$ 1999; Paddock et al., 1998). While this suggests that imagination inflation is a robust phenomenon, a number of issues can be raised that have to do with the origins and magnitude of this phenomenon. To begin with, it remains to be seen whether source monitoring fallures provide the most plausible explanation for imagination inflation. More specifically, one could argue that inflation of subjective confidence subsequent to imagination instructions is a function of participants" sensitivity to demand characteristics, i.e., their tendency to exhibit socially desirable responses. This point is important because the literature on eyewitness memory suggests that acceptance of misleading information might be related to participants eagerness to cooperate with the perceived purpose of the study (see for a review, Winograd, Peluso \& Glover, 1998). While it is true that recent experiments on individual differences in memory illusions failed to detect a connection between social desirability and memory distortion (Wilkinson \& 
Hyman, 1998; Winograd et al, 1998), to the present authors' knowledge, none of the published imagination inflation studies looked at the potential influence of social desirability. Thus, the current studies sought to examine to what extent the magnitude of the imagination inflation phenomenon depends on participants" social desirability tendencies.

Secondly, inspired by previous work showing that people with stronger dissociative tendencies and/or better imagery abilities are more susceptible to develop pseudomemories in response to misleading prompts, recent imagination inflation studies have looked at trait dimensions related to dissociation and imagery vividness. Whereas these studies found dissociative tendencies to be positively and significantly correlated with imagination inflation (Heaps \& Nash, 1999: Paddock et all, 1998), no evidence was found to suggest that individual differences in ilmagery vividness modulates this phenomenon (Heaps \& Nash, 1999). However, the connection between dissociation and imagination inflation reported by Heaps and Nash (1999) and Paddock et al. (1998) needs to be replicated. For one thing, correlations between dissociation and imagination inflation were only moderate $(r=.34$ and $r=.32$, respectively). Also, the Heaps and Nash (1999) study relied on a non-standard instrument for measuring dissoclative tendencies, while Paddock et al.'s (1998) findings are difficult to interpret because these authors correllated dissociative tendencies with residual imagination scores produced by a multiple regression analysis.

A third issue is that Garry et al. (1996) describe their findings in terms of percentages of participants with increased confidence ratings for imagined and control items. While the percentage of participants with increased confidence was reliably greater for imagined than for control items, it is not clear what the magnitude of this increased confidence was in terms of scale points. The replicational studies by Paddock et al. (1998, experiment 1; experiment 2) are subject to the same limitation. On the other hand. Heaps and Nash (1999) reported both percentages of participants with increased confidence and increases in scale points. For both parameters, significant imagination inflation 
effects were found, yet effect sizes seemed to be more substantial for percentages than for scale points $(.68$ versus .44$)$. Obviously, the hypothesis that imagining fictitious events may elicit pseudomemories about these events would gain in strength if it could be shown that imaginative activities produce large shifts on subjective confidence scales.

A fourth issue is whether imagination inflation effects are restricted to those situations in which participants engage in covert (i.e., silent) imagination of low probability events. More specifically, the question arises whether such effects may also be obtained with more therapeutically relevant techniques such as writing exercises.

With the aforementioned issues in mind, the present studies explored whether imagination inflation phenomena are related to certain personality traits (i.e., social desirability, imagery ability, and dissociation). In addition, an attempt was made to determine the magnitude of this phenomenon in terms of scale point shifts. In study 1, the imagination procedure closely followed that of Garry et al. (1996). In study 2 , a writing procedure was employed to elicit imagination inflation.

\section{STUDY 1}

\section{METHOD}

PARTICIPANTS. The final sample (see below) consisted of 34 psychology undergraduates (29 women) who volunteered to participate in experiment 1 . Their mean age was 20 years $(S D=4.4$; range: $17-43$ years). Participants were paid for their participation.

MATERIALS. A translated and adapted version of Garry et al."s (1996) Life Events Inventory (LEI) was used in the current study. This LEI version $(\alpha=.82)$ lists 60 items each describing a discrete childhood event that could have happened. Examples are: "Broke a window with my hand", and "Found a silver 
ring" Responidents indicated on 7 -point Likert scales how confident they were that the events happened to them before the age of $10,1=$ "definitely did not happen": $7=$ "definitely did happen"). Participants also completed widely used Dutch translations of the Social Desirability Scale (SDS; Crowne \& Marlow, 1964), the Questionnaire upon Mental Imagery (QMI: Sheehan, 1967), and the Dissociative Experiences Scale (DES; Bernstein \& Putnam, 198:6).

The SDS $(\alpha=.36)$ consists of 33 true/false items (e.g. "l never hesitate to help someone who is in distress") and is commonly used to measure the tendency to provide socially desirable responses across many situations. The llow Cronbach alpha reflects the relatively broad range of situations that the SDS samples.

The QMI $(\alpha=.91)$ is a 35 -item self-report instrument that aims at measuring individual differences in imagery ability. Examples are "How vividly and lively can you imagine the taste of salt" and "How vividly and lively can you imagine the sensation of a soar throat". Participants indicate on 7-point Likert scales $(1=$ "as perfectly clear as true"; $7=$ "I think about it, but I cannot imagine it") how vividly and lively they can imagine each item. A low overall score implies excellent imagery ability.

The DES $(\alpha=.93)$ consists of 28 items that pertain to dissociative phenomena (e.g., feelings of derealization, depersonalisation, disturbances in memory). Respondents indicate on $100 \mathrm{~mm}$ Visual Analogue Scales (VASs: $0=$ "not at all"; 100 "very much") the frequency with which they experience these symptoms. Scores on the individual items are averaged to obtain a total DES score. The hilgher the total DES score, the stronger the dissociative tendencies.

Procedure

Eighty-two Psychology undergraduates at Maastricht University completed the LEI. Next, a selection of items and participants was made. First, mean confidence score per item $(N=60)$ on the LEl was calculated and only those items that had average scores between 2 and 4 were selected. Additionally, only participants who did not have the maximum score (7) on one of the selected items were invited to participate in the experiment. This procedure resulted in a pool of 8 LEI 
events and 34 participants. The experiment proper took place 4 weeks after LEI (LEI1) data had been collected during regular classes.

Upon arrival in the lab, participants completed the SDS. Next, they were told that the experiment was about individual differences in imagery ability. This was followed by an imagination task that involved 4 pre-selected LEl items (e.g. " You found a beautiful silver ring"). The other 4 selected items served as control items (see below). Imagination and control items were counterbalanced across participants. That is, imagination items of one half of the participants served as control items for the other half and vice versa. Imagination instructions given to the participants closely followed those of Garry et al. (1996). Thus, the experimenter introduced each imagination item by reading a few sentences describing the context of the event (e.g." "You"re playing outside the house. Your mother just told you that within half an hour, dinner will be ready"). Participants were given 20 to 60 secs to imagine this context. Subsequently, they answered a set of questions that pertained to their imaginations (e.g., "With whom are you playing?"; "Is it evening?"). The purpose of these questions was to encourage participants to elaborate their fantasy. The experimenter then read the pertinent part of the event that corresponded to the selected LEl item (e.g., "As you are playing outside, your attention is attracted by a glistering object lying on the ground. You pick it up; it's a beautiful silver ring") and participants were again instructed to imagine this as completely as possible. Following this, participants answered some questions about the event (e.g. "What will you do with the ring"). Each of the 4 imagination items was subjected to this procedure. Next., participants completed the QMI and DES. Finally, participants filled out the original LEI (LEI2). When a subject noticed that $s$ /he had already completed this list, the experimenter said that the other LEI (LEII) had been lost.

DATA ANALYSIS. Changes in subjective confidence from LEll (baseline) to LEI2 (post-experimental) for the imagination items were compared to those for matched control items. This was done in three different ways. First, the approach 
of Carry et al. (1996) was followed which consists of calculating for each imagination and control them the percentage of participants with increased, decreased, or unchanged probability ratings. Second, as this approach is not informative about the magnitude of subjective probability changes, a 2 (LEII versus LEI2) $\times 2$ (imagination versus control items) Analysis of Variance (ANOVA), with both factors being repeated measures, was performed on the subjective probability data. Third; Pearson product moment correlations were computed between imagination inflation effects and individual difference measures (i.e., SDS, QMI, and DES).

\section{RESULTS}

Figure 4.1 shows percentages of participants with increased, decreased, and unchanged subjective probability ratings for imagination and control items. Paired $t$-tests (with items as cases) revealed no difference between imagination and control items with regard to percentage decreased ratings $[t(7)<1.0]$. However, percentage of unchanged ratings were higher for control items than for imagined items $[t(7)=-1.90, p=.05]$ As well, imagination items tended to have a higher percentage of increased confidence ratings than control items. While this difference reached only borderline significance $[t(7)=1.62, p=.07]$, the effect size was large $(r=.52)$ and corresponds to that reported by others (e.g., Clancy, McNally \& Schacter, 1999). 


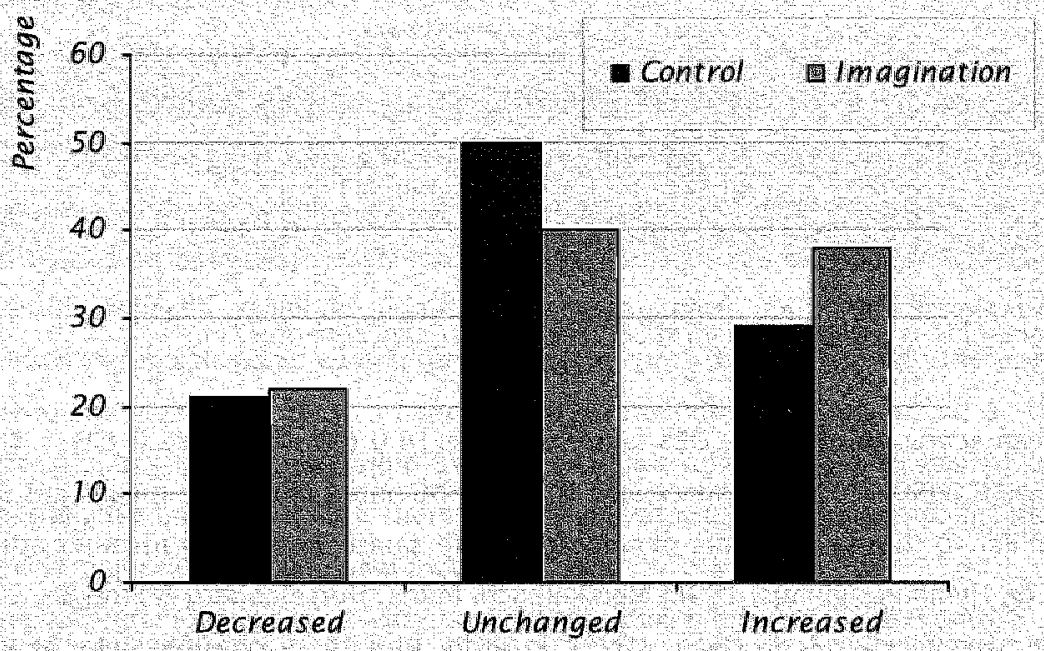

Figure 4.1: Mean percentages of participants $(N=34)$ with decreased, unchanged. and incrased probability ratings for control and imagination items.

Mean probability ratings for imagination and control items on LEII and LEI2 are shown in Table 1. The ANOVA yilelded a significant main effect of LEI $[F(1,33)=$ $7.21, p=.011$, which indicates a robust repetition effect. That is, irrespective of imagination, asking twice about the same events increased the subjective probability of these events. Neither the main effect of imagination, nor the criticall interaction of $L E \mid$ and imagination reached significance: both $F$ 's $(1,33)<1.0$. Thus, the ANOVA yielded no evidence for an ilmagination inflation effect in terms. of scale point shifts. 


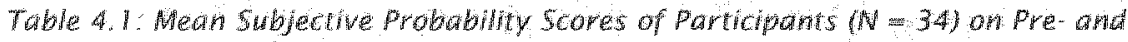
Post experimental Imagination and Control tems of the Life Event inventon (LE). Shamdard Devidions are given Between Parentheses.

$\begin{array}{ll} & \\ \mathrm{LEII} \\ \mathrm{LEl}\end{array}$

\section{Mraginationitems}

$2.4(.9)$

$2.8 .01 .0)$

\section{Control items}

$2.4(1.0)$

$27(7)$

Note: LEI is pre-experimental LEI, LEL is post-experimental LEI.

Mean scores on the SDS, DES, and QMI were $16.0(\mathrm{SD}=4.2), 25.0(\mathrm{SD}=14.1)$, and $8.8 .9(5 D=22.8)$, respectively. It should be noted that these means are quite similar to the mean scores of undergraduate samples reported in other studies (e.g., Hyman \& Billings, 1998; Merckellbach, Muris, Horselenberg \& Stougie, 2000; Aleman, Boecker \& de Haan, 1999). In order to explore possible links between these measures and imagination inflation, an index of imagination inflation was calculated by subtracting the change in ratings on control items from that on imagination items. This index provides the best estimate of imagination inflation as it controls for repetition effects. Next, Pearson product-moment correlations were computed between imagination inflation and personality traits. There was no correlation between imagination inflation and the tendency to give social desirable answers $(r=.04)$ Neither was there a connection between imagination inflation and dissociative tendencies $(r=-.03)$. The only correlation that attained significance was that between imagination inflation and imagery ability: $r=-$ $0.34 \mathrm{p}=.05$. Note that the correlation was in the expected direction. That is, the higher the imagery abillity (i.e., lower QMI scores), the stronger the imagination inflation effect.

\section{DISCUSSION}

The results of study 1 can be summarised as follows. To begin with, the imagination inflation phenomenon described by Garry et al. (1996) was partially 
replicated. That is, the percentage of participants with increased subjective probability ratings tended to be higher for imagination items than for control items, while the percentage of unchanged probability ratings was higher for control than for imagination items. Second, when the magnitude of this effect (i.e., mean scale point changes rather than percentages of participants with increased confidence ratings) was taken into account, no convincing evidence for an imagination inflation phenomenon was found. At this level of analysis, only a repetition effect attained significance: irrespective of the imagination

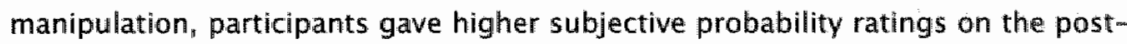
experimental LEI (LEI2) than on the pre-experimental LEI (LEI1). Third, at the within-subjects level, imagination inflation was not related to social desirability or dissociative tendencies. Yet, there was a significant though modest connection between imagery ability and imagination inflation.

In line with previous studies (Garry et al."1996; Heaps \& Nash, 1999; Paddock et al., 1998), the current results indicate that imagining low-probability events enhances confidence that the events had in fact occurred. Meanwhile, the magnitude of this effect appears to be small when one looks at scale point shifts rather than percentages of participants. This is reminiscent of Heaps and Nash' (1999) finding that effect sizes of imagination inflation are higher for percentages than for scale values. Does this mean that the practical (e.gl, clinical) implications of imagination inflation are limited? Not necessarily. One could argue that imagination inflation, though fairly tame in the laboratory, might conceivably create powerful effects in thase clinical settings where imagination exercises are carried out repeatedly and are aimed at ambiguous autobiographical events. Support for this line of reasoning comes from recent work of Goff and Roediger (1998). These authors noted that when participants imagine performing actions (e.g., "bounce the ball"), they subsequently remember that they had actually carried out these actions and this effect increases with the number of imagination exercises. 
The present data show that shifts in subjective confidence ratings of imagination items are not controlled by social desirability tendencies. This makes an interpretation of imagination inflation in terms of demand characteristics and social desirability less likely. In contrast; imagery vividness was found to be linked to imagination inflation. While this result is difficult to reconcile with Heaps and Nash's (1999) failure to detect an association between imagery ability and imagination inflation $(r=-.06)$, it is in line with earlier studies showing that individuals with vivid imagery are more likely to make source monitoring errors (Dobson \& Markham, 1993) and to produce false recognition responses on word list tasks (Wilkinson \& Hyman, 1998; Winograd et al. 1998). In more general terms, these studies converge upon the notion that persons with good imaginary abilities are more susceptible to memory illusions.

Unlike previous imagination inflation studies (Heaps \& Nash, 1999; Paddock et al., 1998), we were unable to find a correlation between dissocilative tendencies and imagination inflation. We have no obvious explanation for this discrepancy, except that, as noted in the introduction, previous studies reported relatively moderate correlations and rellied on operationalisations of dissociation and imagination inflation that are not particularly straightforward. As an aside, it should be noted that in the domain of memory illusions, a number of follow-up studies specifically addressed the connection between dissociation and pseudomemories. Many of them failed to find such a connection between these two parameters (e.g. Mazzoni, Loftus "Seitz \& Lynn, 1999; Platt, Lacey, lobst \& Finkelman, 1998; Spanos, Burgess, Burgess, Samuels Blois, 1999). Perhaps, then, dissociative tendencies are only a weak predictor of memory illusions and it requires considerable statistical power to demonstrate such a connection.

The question arises why the imagination inflation phenomenon found in the present study remained a moderate effect. There are two possible reasons for this. First, participants' imaginations were based on scenarios developed by the researchers. From a social-psychological point of view, such an approach cannot be expected to induce strong commitments of participants to their imaginations. 
Writing about a fictitious event might provide a much stronger manipulation (e.g., Spanos, 1996). A second factor that may have cointributed to the fragile nature of the imagination inflation effect found in Study 1 is that the post-experimental. LEI items were identicall to the baseline LEI items. To the extent that participants want to make a consistent impression in their answers to the LEI items, this may have counteracted imagination inflation effects.

With these two issues in mind, study 2 was conducted. Study 2 relied on an imagination inflation task that required a more active involvement of the participant. More specifically, a witing exercise was used. Thus, participants were instructed to write brief, but plausible sitories about lowmprobability LEI events. Next, participants completed a post-experimental LEI (LEI2) that also included paraphrased versions of the pre-experimental imagination items. These additional items were included to reduce consistency tendencies:

\section{STUDY 2}

\section{METHOD}

PARTICIPANTS. Forty-five participants (30 women) participated in study 2. Their mean age was 17 years $(S D=1.1$; range: $16-20$ years). Some participants were psychology undergraduates, but the majority of them were high school students recruited through advertisement in a local paper. Participants received a small financial compensation for their participation.

MATERIALS. Two weeks before the experiment took place, participants completed the LEI ( $\alpha=.83$; see study 1). For practical reasons, the procedure of calibrating items for each participant deviated from that in study 1. Most importantly, the sample in study 2 was too small to allow selection of items on the basis of excluding participants. Therefore, ittems that had an average score between 2 and 4 in study 1 were selected (see for a similar procedure, Paddock et al., 1998). This resulted in a pool of 12 possible imagination items with an 
average subjective probability rating of $2.2(\mathrm{SD}=1,2)$. From this pool, the experimenter selected 4 magination items for each participant individually, using the criterion that none of the selected imagination ittems had a score of 6 or higher for that particular participant. Selection of control items from the pool of 48 remaining LEU items took place affer the experiment. Control items were matched on mean pre-experimental subjective probability ratings assigned to the imagination items. As in study 1 , participants also completed the SDS $(\alpha=.43)$, DES $(\alpha=.95)$, and QMI $(\alpha=.87)$.

PROCEDURE. Two weeks after they had completed the LEl at home (LEl1), participants were invited to come to the laboratory. Participants were told that the experimenters were interested in creatiwe writing. They were encouraged to imagine the pre-selected items and write their imaginations down. More specifically, each imagination trial started with a card on which the pertinent item was printed. The instruction was as follows: "Try to imagine yourself actually experiencing the event you have just read. Experience this imaginary event as vividly and fully as you can. Write your imaginations down on the piece of paper in front of you. Describe as vividly and fully as possible all your imaginations." This instruction was repeated for each imagination item. Following the imagination trials, participants completed the SDS, DES, and QMI. Finally, the LEI was administered for a second time (LEI2). Twelve items were added to the LEI2. These items were paraphrases of the 12 potential imagination items and were positioned in such way that they preceded the original imagination items. Examples of paraphrased items are "I took something from a store without paying for it" (original item: "I stole sweats in a shop") and "I said to my parents that I didn't feel good, so I didn't have to go for a school exam" (original item: "I pretended to be sick, so $\|$ didn't have to go to school $\left.{ }^{*}\right)$. When participants indicated that they had already completed the LEll, the experimenter replied that they initially had received the wrong version of the questionnaire. 


\section{RESULTS}

Following Garry et al. (1996), percentages of participants with increased, decreased, and unchanged probability ratings were calculated for imagimation and control items, separately. However, given the different procedure of selecting imagination and control items, paired t-test would be inappropriate for the data obtained in this study. Therefore, Chi-square tests were carried out. Imagination and control items did not differ with regard to percentage of participants with decreased probability ratings $[18.3 \%$ and $20.6 \%$, respectively; $\chi 2(1)=.28, p=.69]$. Yet, imagination items had a lower percentage of participants with unchanged ratings than control items [43.9\% and $62.2 \%$, respectively; $\chi 2(1)=12.15, p=.001]$, while the reverse was true for the percentage of increased ratings $137.8 \%$ and $17.2 \%$, respectively; $\left.\chi^{2}(1)=19.07, \mathrm{p}=.001\right]$.

Average subjective probability ratings for imagination and control items on LEI and LEI2 are shown in Table 2. A 2 (LEI1 versus LEI2) $\times 2$ (imagination versus control) ANOVA, with both factors being repeated measures, was performed on these data. This ANOVA yielded a significant main effect of imagination $[F(1,44)$ $=6.94, p<.05]$. Overall, imagination items had higher probability ratings than control items. Most importantly, the critical interaction of LEI and imagination reached significance $[F(1,44)=7.84, p<.01]$, indicating a reliable imagination inflation effect. There was no significant repetition effect of $L E \mid[F(1,44)=2.01, p$ $=.161$. 
Table 4.2: Mean Subjectwe Probability Scores of Participants (N = 45) an pre and Postedperimental Imagination. Parathrased Imaghation thems, and Control hems of the Life Event Inventory (LEd). Standard Deviations are given aetween Parmanthes.

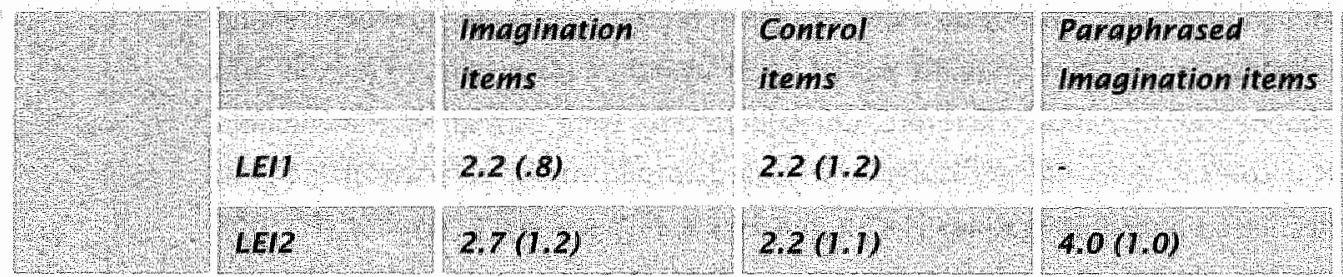

Note: LEII is preexperimental LEI: LEL is postexperimental $L E$.

Mean scores on the SDS, DES, and QMIl were highly comparable to those obtained in Study 1: 18.6 (SD = 4.4), 16.2 $(S D=13.4)$, and $92.7(S D=18.6)$. There was no significant relation between imagination inflation (calculated as pre- to post-test changes on imagination items corrected for repetition effects on control items; see Study 1$)$ and the tendency to give social desirable answers $(r=-.20, p>.10)$. Neither was there a connection between imagination inflation and dissociative tendencies $(r=-.18)$. Curiously enough, the connection between imagination inflation and imagery ability found in Study 1 was not replicated in this study $(r=$ .20).

The right column of Table 4.2 shows mean confidence ratings of the paraphrased LEI2 items. Note that the paraphrased imagination items had a relatively high mean confidence rating, that is, a rating that exceeds the midpoint of the scale (i.e., 3.5). Subjective probability ratings of paraphrased imagination items were higher than those on LEI2 control items $[\mathrm{t}(44)=-9.11, \mathrm{p}<.001]$ and also exceeded those on LEI2 imagination items $[\mathrm{t}(44)=-5.66, \mathrm{p}<.001]$. These findings suggest that a straightforward imagination inflation effect occurred for the paraphrased imagination items. To explore whether imagination inflation for paraphrased items was related to SDS, DES, and QMI, imagination inflation was redefined as confidence changes from imagination items on LEIII to paraphrased 
items on LEI2 corrected for changes on control items. However, no significant correlations were found between imagination inflation defined in this way and personality characteristics (all $r^{x} s<.20$, all $p^{*} s>.10$ ).

\section{DISCUSSION}

The findings of study 2 can be summarised as follows. To begin with, writing about a fictitious event led to a reliable imagination inflation phenomenon, both in terms of percentages of participants with increasing confidence ratings and mean increases on the 7 -point probability scalle. Second, no evidence was found to suggest that this imagination inflation phenomenon is linked to social desirability characteristics. Neither were there indications that the phenomenon is. linked to dissociative tendencies or imagery vividness. Third, imagination inflation was even more evident with paraphrased versions of the imagination items, suggesting that participants" tendency to respond in a consistent manner may, indeed, counteract the imagination inflation phenomenon.

Differences in sample characteristics and item selection prechude direct comparisons between study 1 and study 2. Nevertheless "results suggest that study 2 demonstrated a much stronger version of the imagination inflation phenomenon than study 1. Thus, the present findings support Spanos' (1996) claim that writing about fictitious events may foster subjective confidence in those events (see also Destun \& Kuiper, 1996). But why would writing about imaginations produce a more convincing imagination inflation phenomenom than does the sort of sillent imagination exercise used in study 1 ? Two possibilities suggest themselves. One is that writing produces a "public record" (Spanos, 1996: p. 100). This, in turn, may create a stronger commitment than the silent imagination sessions of study 1 . Interestingly, effects of writing about counterattitudinal beliefs have been well researched in social psychology. A number of studies on cognitive dissonance have demonstrated that when people are asked to write an essay about a counter-attitudinal view without being paid for this, they subsequently express more agreement with that view (e.g., Cohen, 1962). A 
second poissibility has to do with a more technical issue, namely that the imagination procedure followed in study 1 consisted of prompts formulated by the experimenters, while the procedure of study 2 was not structured in this way. Thus, it may well be the case that the procedure of study 2 allowed for more idiosyncratic and, therefore, more plausible imaginations.

As in study 1, no evidence was found to support an interpretation of imagination inflation in terms of participants' sensitivity to experimental demands. In both studles, uncreases in confidence for imagination items were not related to participants' SDS scores. Accordingly, it is unlikely that imagination inflation is an artefact caused by participants" tendency to comply with the demands of the experiment. While study il found a significant, though modest, connection between imagery ability and the imagination inflation phenomenon, such a connection was not replicated in study 2. This implies that the correlation between imagination inflation and imagery vividness is not a robust one. On the other hand, like study 1 , study 2 failed to obtain a significant correlation between dissociative tendencies and imagination inflation. We return to this issue in the general discussion.

Study 2 demonstrates that when paraphrased imagination items are employed, the imagination inflation effect is not only significant, but also crosses the midpoint of the confidence scale (i.e., 3.5). Perhaps, then, experimental set-ups that rely on identical pre- and post-experimental LEls produce an underestimation of the imagination inflation phenomenon. Note, however, that the post-experimental LEI in the current study did not include paraphrases of control items. A more rigorous test of the idea that identical pre- and postexperimental LEls unduce consistency tendencies "thereby reducing imagination inflation effects, would involve direct comparisons between paraphrased control and imagination items. One could argue that the relatively high confidence ratings of paraphrased imagination items are simply the result of the fact that these items repeat the content of standard imagination items of LEII. This would imply that the heightened probability ratings on paraphrases reflect a repetition 
effect. However, such an interpretation is flawed on several counts. First, it leaves unexplained why ratings on paraphrased items were quite high. The magnitude of the repetition effects usually is in the order of .3 scale points (e.g. Brown \& Nix, 1996) which is considerably smaller than the 1.7 scale points increase found for paraphrases in the current study. Another problem with this explanation is that it is difficult to reconcile with the absence of a repetition-effect for control items (cf. supra). Why would such an effect become manifest during LEI2 only for paraphrases of imagination items, but not for control items? After all, control items of LEI2 were identical to control items of LEI 1 , whereas paraphrases of LEI2 were just what they were: paraphrases. A related issue is that the LEL 2 was designed in such way that paraphrases preceded the pertinent imagination items. Consequently, an explanation in terms of repetition effects would dictate a huge confidence increase for the imagination items and a relatively small increase for the paraphrases. Yet, as a matter of fact, the opposite pattern occurred, which casts doubts on a repetition-effect account.

\section{GENERAL DISCUSSION}

Taken together, the present studies provide support for the idea that imagining a low-probability childhood event promotes subjective confidence in that event. In general, then, the current findings accord well with those reported by Garry et al. (1996), Heaps and Nash (1999), Paddock et al. (1998), and Clancy et al. (1999). It should be added, though, that the magnitude of this effect remained small in Study 1. A more conwincing effect was obtained in Study 2 , but here imagination was combined with writing exercises. This suggests that a single and covert act of imagination results in robust, but relatively small shifts of subjective confidence, while huge effects may be produced by writing imaginations down.

Plainly, the effects of writing an imagination down bears relevance to clinical settings. Over the past few years, writing exercises thave become a common treatment intervention for individuals with traumatic experiences (e.g., 
Pennebaker, 1993; see also Littrell, 1998). The beneficial effects of this intervention on health parameters are well-established (e.g., Greenberg, Wortman \& Stone, 1996). However, writing exercises have also been advocated as a vehicle for memory recovery. For example, a survey among licensed psychotherapists conducted by Poole, Lindsay, Memon; and Bull (1995) revealed that a considerable percentage of surveyed psychotherapists had used journaling as a technique to help clients recover memories of sexual abuse. In their scholarly review on recovered memories, Lindsay and Read (1994; p. 301) noted that they were "particularly concerned about cases in which the instructions for journaling suggest that writers should strive for a non-critical, stream-of-consciousness flow, writing down whatever comes to mind without stopping to evaluate it". The results of study 2 show that Lindsay and Read's concern is not misplaced.

Dissociative tendencies as indexed by the DES (Bernstein \& Putnam, 1986) have been found to be linked to suggestibility (Merckelbach, Muris, Wessel \& Van Koppen, 1998; Wolfradt \& Meyer, 1998), fantasy proneness (Merckelbach, Muris \& Rassin, 1999" Rauschenberg \& Lynn, 1995), and the propensity to develop pseudomemories (Hyman \& Billings, 1998). There is also some evidence that dissociative tendencies may be related to imagination inflation (Heaps \& Nash, 1999. Paddock et al., 1998, Clancy et all., 1999). From thils perspective, it is surprising that the present studies failed to obtain significant correlations between dissociation and imagination inflation. We can only speculate about the reasons for these null findings. One possibility is that the relation between dissociative tendencies and memory distortions is not as impressive as some authors have suggested. This position is suppiorted by the fact that a number of recent studies found no (Mazzoni et al, 1999; Spanos et al., 1999; Platt et all, 1998) or only a small (e.g., Eisen \& Carlson, 1998) correlation between DES and the tendency to generate illusory memories. It is hard to escape the conclusion that broad trait measures of dissociative tendencies (e.g., DES) and imagery ability (e.g., QMI) provide only imperfect operationalisations of source monitoring decisllons involved in discriminating between real and pseudomemories. 
Therefore, future studies should carry out more fine-grained analyses to establish which aspects (e.g., subscales, factors) of dissociation and imagery ability tap source monitoring aspects (see for an example, Wilkinson \& Hyman, 1998).

Another possibility is that imagination inflation is a metamemory rather than a memory phenomenon. That is, it is conceivable that as a result of imagination exercise(s), people change their belief about the probability of target items but do not necessarily develop pseudomemories about these items. To the extent that individual differences in dissociation and imagery ability are linked to pseudomemories rather than metamemory beliefs, one would not expect to find strong correlations between imagination inflation and these personality traits. Clearly, this point warrants further study.

The present findings along with those of Garry et al. (1996), Goff and Roediger (11998), Heaps and Nash (1999), Paddock et al. (1998), and Clancy et al. (1999) converge on the notion that imagination inflation is a real phenomenon that bears relevance to clinical practice. Obviously, the issue of what is inflated during imagination inflation requires further study. In addition, it would be worthwhile to run parametric studies that examine whether imagination inflation can, indeed, be maximalized with paraphrased items. In more general terms, the precise interplay between imagination inflation, source monitoring decisions " and personality aspects awaits clarification. 


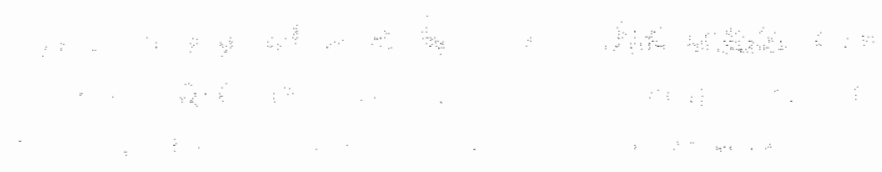


CHAPTER 5

Personality Characteristics and the Accuracy of Autobiographical Memory

Chapter 5 is an adjusted wersion of the article Horselenbers, $R$.

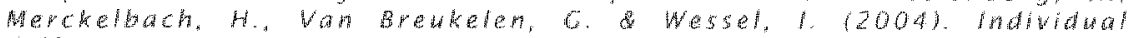
differences in the accuracy of abtoblographical memory. Clintical psychalagy and Psychotheraty. 11, 168.176. 


\section{ABSTRACT}

In recent literature on "false memories", autobiagraphical memory distortions are often liriked to manipulations such as hypnosis or imagination. However, Barclay and Wellman (1986) demonstrated that such distortions might also occur more or less spontaneously. The current study sought to replicate this phenomenon. In addition, it examined whether certain personality characteristics, (i.e., fantasy proneness, dissociation, absorption, suggestibility, and depression) might contribute to such spontaneous pseudo-memories. Volunteers $(N=38)$ kept a diary of self-selected, outstanding events for a two-week period. Six months later, they were unexpectedly given a recognition test consisting of original memories and several types of foils. Participants performed relatively well on the recognition task, although they had some difficulties differentiating original items from foil-items. Curiously enough, fantasy proneness was related to superior recognition performance.

\section{INTRODUCTION}

It has long been recognized that autobiographical memory bears strong relevance to psychotherapy (e.g., Bonanno, 1990). One straightforward example of this is the use of autobiographical writing exercises during psychotherapeutic treatment (e.g., Pennebaker \& Memon, 1996). Historically, the psychotherapeutic probing of clients recollections have been portrayed as a form of mental archaeology in which the therapist uncovers step by step the autobiographical truth of a client (Bonanno, 1990). We now know that this "archaeological metaphor" is misleading and that clients" recollections are coloured by therapist's questions and interpretations. But what about spontaneous memory illusions? Schoutrop, Lange, Hanewald, Duurland, and Bermond (1997) found that a majority of their participants recovered new memories when they wrote about their childhood traumas. How accurate are such spontaneous recoveries? And what does it mean 
that people may benefit from writing about other people's trauma (see for examples, Lepore \& Smyth, 2002)? Does it imply that these people spontaneously come to accept other people's trauma as their own narrative truth?

There are only a handful of studies that address these issues. One of the most compelling studies is that by Barclay and Wellman (1986) in which participants were asked to record everyday autobiographical events over a 4-month period. After this recording phase, participants were invited to perform a recognition task that consisted of original items and foil items. Original records corresponded to participants" own records, while foils were distracters (i, $e_{\text {, }}$ altered records or records from other participants). Barclay and Wellman (1986) found that autobiographical recollections become surprisingly inaccurate over time. After some weeks, many of the participants failed to identify original items as their own memories, a failure which involves an omission error (i.e., forgetting). Moreover, participants made, albeit on a smaller scale, commission errors in that they accepted foils as their own autobiographical memories. From a methodological point of view, the Barclay and Wellman paradigm was rather innovative. Unlike the classic diary experiments (e.g., Linton, 1975; Wagenaar, 1986) where experimenter and subject are one and the same, the Barclay and Wellman procedure is suitable for testing normal and clinical samples. Also, its reliance on foils to assess memory accuracy in a systematic manner might provide important information.

The results of Barclay and Wellman (1986) inform what has been dubbed the "recovered memory debate". In this debate, some authors have emphasized the effects of external factors (e.g., psychotherapy) on the development of pseudomemories (see for an overview, Destun \& Kuiper, 1996). A number of experimental studies $d_{0}$ indeed, show that treatment techniques such as imagery, journaling, dream interpretation, and hypnosis may lead to pseudomemories (e.g., Garry \& Polaschek, 2000; Horselenberg et al., 2000; Mazzoni \& Loftus, 1996, 1998; Spanos, Burgess, Burgess, Samuels \& Bois, 1999). The Barclay and Wellman (1986) findings indicate that even in the absence of such 
treatment techniques, pseudo-memories may occur. Thus, it seems that at least in some participants, pseudo-memories might develop more or less spontaneously (see also Rassin, Merckelbach \& Spaan, 2001).

Merckelbach, Wessel; and Horselenberg (1997) tried to replicate the study of Barclay and Welliman (1986). They also found that autobiographical memory is far from accurate in that participants made omission and commission errors. In addition, they explored individual differences in memory accuracy. This issue could only be addressed in a preliminary fashion because of their small sample size $(N=10)$. Nevertheless, they found some evidence that depressive symptoms are associated with higher frequencies of pseudo-memories (i.e., accepting foils). To some extent, this link between depressive symptoms and pseudo-memories is in accordance with studies showing autobiographical deficits in depression (Williams, 1992). In short, Williams and colleagues (Williams, Stiles \& Shapiro, 1999) argue that dlepressed people's avoidance of painful thoughts lead to a generic retrieval style that produces overgeneral (i.e., non-specific) memories. This lack of specificity may make depressive people susceptible to memory distortions. Meanwhile, most research on individual differences in susceptibility to pseudo-memories has focused on traits such as dissociation (e.g." Hyman \& Bilings, 1998; Winograd, Peluso \& Glover, 1998), absorption (e.g., Drivdahl \& Zaragoza, 2001; McNally, Clancy, Schacter \& Pitman, 2000), fantasy proneness (e.g., Merckelbach, Muris \& Rassin, 1999), and suggestibility (e.g., Gudjonsson, 1992; Kassin, 1997) rather than depression.

The concept of reality monitoring proposed by Johnson, Hastroudi, and Lindsay (1993) provides a framework for understanding how certain personality traits might contribute to the development of pseudo-memories (see also: Loftus, 1997). In short, reality monitoring refers to the ability of people to discriminate between memories of external events and memories of internal events (e.g., dreams, fantasies, imaginations). Pseudo-memories occur whenever an individual misinterprets memories of internal events as memories of external events. Basically, there are two pathways along which such pseudo-memories might 
arise. To begin with, pseudlo-memories might occur because internal events have characteristics that are typical for real memories. Thus, to the extent that memories of internal events are very detailed, have a strong sensory loading, and are reconstructed without much cognitive effort, people might easily come to misinterpret them as real memories. A second pathway has more to do with criterion setting. Clearly, people have to rely on criteria to determine whether at given memory has the characteristics of a real (i.e., external) or an internal event. As a result, pseudo-memories might be the consequence of endorsing a liberal criterion for discriminating between memories of real and memories of imagined events.

Turning now to how personality traits may relate to reality monitoring, one could speculate that certain traits endow internal events with features that are usually typical for memories of external events. Fantasy proneness, dissociation, and absorption might be examples of such traits. Note, in passing, that there is a substantial overlap between these traits (Kihlstrom, Glisky \& Angiulo, 1994; Merckelbach. Horselenberg Muris, 2001). Thus, it may well be the case that people high on fantasy proneness, dissociation, and/or absorption are susceptible to pseudo-memories because they misinterpret their detailed imagery as real memories. On the other hand, some individuals might be susceptible to pseudo-memories because they adopt liberal criteria and, perhaps, suggestibility and depression might be key features that characterize such individuals. After all, reality monitoring decisions consume cognitive resources and assume a certain amount of self confidence, yet, cognitive resources of depressed people are relatively limited, while their self-confidence is low. Suggestible people also suffer from a lack of self-confidence (e.g., memory distrust; Gudjonsson, 1992). Under these circumstances, it is conceivable that participants show a positive responsie bias in that they easily come to accept correct, but also incorrect, items as their memories.

Over the past few years, several studies have looked at how personality characteristics such as fantasy proneness and dissociation interact with certain 
manipulations (e.g, imagination) to produce pseudo-memaries (e.g., Heaps \& Nash, 1999; Paddock et al., 1999). However, with a few exceptions (Candel, Merckelbach \& Kuifpers, 2003, Rässin et al, 2001), lltttle work has been done on spontaneous pseudo-memories and the personality characteristics that might be involved in such memorles. The current study relied on the Barclay and Wellman (1986) paradigm to evaluate the contribution of fantasy proneness, dissociation, absorption, suggestibility, and depression to the occurrence of spontaneous pseudo-memories. A signal detection approach was used to determine whether fantasy proneness, dissociation, and absorption are linked to signal sensitivity (i.e., differentiation between targets and foils), whille suggestibility and depression are linked to response bias.

\section{METHOD}

\section{PARTICIPANTS}

Participants were 38 undergraduate psychology and health sciences students ( 30 women) who volunteered to participate in the current study. Their mean age was 21.1 years (range $19-27$ ). They were paid for their participation.

\section{MATER\|ALS}

Participants completed the Creative Experiences Questionnaire (CEQ; Merckelbach et al. 2001), the Dissociative Experiences Scale (DES; Bernstein, \& Putnam, 1986), the Tellegen Absorption Scale (Tellegen \& Atkinson, 1974), the Gudjonsson Suggestiblity Scale (CSS: Gudjonsson, 1997), and the Beck Depression Inventory (BDI; Beck, Rush, Shaw \& Emery, 1979).

The CEQ $(\alpha=.74)$ is a 25 item yes/no index of fantasy proneness. CEQ items. were derived from the extensive case descriptions of fantasy proneness provided by Wilson and Barber (1982). Typical CEQ-items are: "In general, I spend at least half of the day fantasizing or daydreaming" and "My fantasies are so vivid that 
they are like a good movie". Yes-answers are summed to yield a total CEQ score with higher scores indicating higher levels of fantasy proneness.

The DES $(\alpha=.89)$ consists of 28 items that pertain to dissociative phenomena (e.g.x feelings of derealization, depersonalization, disturbances in memory). Respondents indicate on $100 \mathrm{~mm}$ Visual Analogue Scales (VASs: $0=$ not at all: $100=$ very much) the frequency with which they experience these symptoms. Sample items are: "Some people have the experience of feeling that their body does not seem to belong to them. Mark the line to show what percentage of the time this happens to you" or "Some people have the experience of finding themselves in a place and having no ldea how they got there. Mark the line to show what percentage of the time this happens to you". VAS-scores are averaged to obtain a total DES score with higher total DES scores indicating stronger dissociative tendencies.

The TAS $(\alpha=.81$ ) is a widely used measure of mental absorption (Kihlstrom et al., 1994), which is defined as a disposition to experience "episodes of total attention that fully engage one's representational (i.e., perceptual, enactive, imaginative, and ideational) resources" (Tellegen \& Atkinson, 1974; p. 268). it consists of 34 yes/no items that address the tendency to become deeply involved (absorbed) in everyday activities. Sample items are: "The sound of a voice can be so fascinating, that I can listen to it endlessly" and "I like to watch the changing of cloud shapes". Items are summed to obtain a total TAS score with higher scores reflecting a stronger disposition to become absorbed.

The CSS (version $1 ; \alpha=.62$ ) consists of a short story that is read out to the participants and 20 specific questions about the story. Fifteen of these questions convey misleading information about the story. The extent to which an individual gives in to the leading questions constitutes that individual"s Yield score (maximum score $=15$ ). Having answered the 20 questions, participants are told in an authoritative manner that they made a number of mistakes and that all questions have to be answered for a second time. The number of times that participants change their answers constitutes their Shift score (maximum score $=$ 
20). Yeld and Shift scores are summed to obtain a total GSS score (maximum score $=35$. A number of other parameters can be derived from the CSS, but for practical reasons (i.e, extensive test sessions), the present study only focused on total CSS seores.

The $\mathrm{BD}(\alpha=.88)$ is a self-rating questionnaire consisting of 21 items that address behavioural manifestations of diepression. Sample items are: "I am so sad and unhappy that I can't bear it anymore" and "I totally lost interest in other people". Items are scored on a 4-point scale (range: 0-3) and scores are summed to obtain a total score, with higher scores reflecting higher levels of depressive symptoms.

\section{PROCEDURE}

Participants were asked to provide brief, but complete descriptions of three selfselected outstanding events each day, for 14 consecutive days. This resulted in 42 records for each participant. They were instructed to describe the events in a fixed format. All records had to specify "context" (i.e., place), "event" (i.e., what happened), and "affective evaluation"(i.e., emotional reaction to the event).

After 6 months, participants were linvited to participate in a study involving a computer task. They were not informed about the real purpose of the experiment and underwent a surprise recognition test. This tesit consisted of 40 items: 10 Items were literal transcriptions of records written by participants, whereas the other 30 items were foils. There were 3 types of foils. Ten foll items consisted of original records of the participant in which the context was radically changed by the experimenter (context-foils), 10 items involved original records of the participant in which the evaluation was radically changed by the experimenter (evaluation-foils), and 10 items were original records of other participants (other-foils). Foils containing distortions deliberately made by the experimenter deviated strongly from the original records, but remained plausible. Thus, implausible modifications as well as wague, but possibly correct paraphrases of the original context or evaluation descriptions were avolded (see for a detailed 
description of the procedure: Barclay \& Wellman, 1986; Merckelbach et al.. 1997). Participants were informed that the recognition test consisted of original and foil records. For each item of the recognition test, participants indicated what type of item they thought was presented, resulting in 4 possible responses: original, context-foil, evaluation-foil, or other-foil. In addition, they rated on a $100 \mathrm{~mm}$ Visual Analogue Scale (VAS: $0=$ not confident at all; $100=$ absolutely confident) how confident they were about their answers. Following this, they completed the earlier mentioned questionnaires.

\section{RESULTS}

\section{HITS AND FALSE ALARMS}

Table 5.1 shows mean proportions of hits (i.e., original items identified as authentic memories) and fallse alarms (i.e., foil items accepted as authentic memories). The proportion of hits (.78) was comparable to that reported by Merckelbach et al. (1997), whereas overall, the mean proportion of false alarms was higher than that found by Merckelbach et al. $(1997): .35(S D=.28)$ versus $.19(\mathrm{SD}=.15)$, respectively. A one-way Analysis of Variance (ANOVA) with Greenhouser-Geisser correction made it clear that proportions false alarms significantly differed between the 3 foil categories [F $(2,35)=81, p<.001$ ]. A post-hoc analysis (Bonferroni corrected) revealed that context-folls elicited more false alarms than evaluation foils, which, in turn, induced more false alarms than other-foils (all $p^{\prime} s<.01$ ).

Table 5.1 also shows confidence ratings of participants for hits and false alarms. An ANOVA with Greenhouser-Geisser correction was carried out showing that confidence ratings differed over the 4 response categories (original, contextevaluation-, and other-foil) $[F(3,34)=4.5, p<.05]$. A post-hor analysis (Bonferroni corrected) indicated that hits and false alarms on context- and evaluation-foils had similar confidence ratings, whereas confidence for fallse 
alarms on other-foils was lower than that for the other 3 response categories ( $p$ $<.0011$.

Table s. 1 : Propontions of his fon original hems) and false alarms con context. eviluation- and other foiss of participants $(N=38$ ) during recognition testing Confidence ratings are also shown. Standard devations are in parentheses.

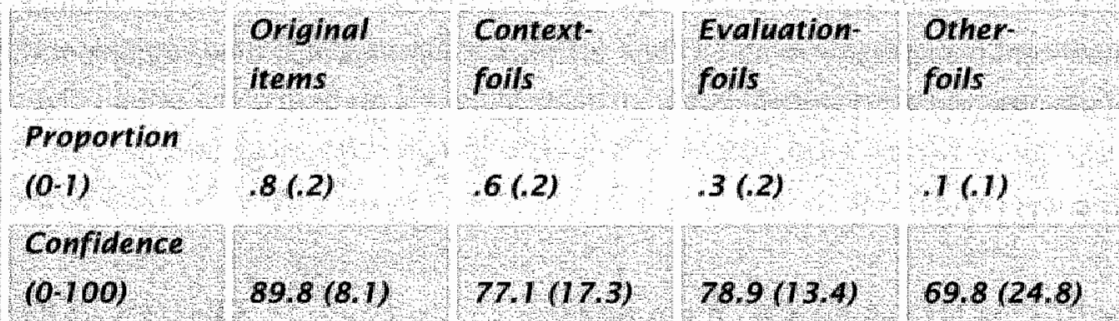

\section{DISCRIMINATION AND RESPONSE BIASI}

Because participants were given 4 types of recognition items to which they could react with 4 types of responses (i.e., the item is an original, a context-foil, a evaluation-foil, or an other-foil), our data consist of a 4 (item) by 4 (response) contingency table with 40 observations for each person. Usually, signal detection analysis relles on 2-choice response tasks for deriving common discrimination $(\mathrm{Pr})$ and response bias $(\mathrm{Br})$ indexes. Therefore, we calculated alternative measures for discrimination and response bias for each participant.

Cohen's Kappa was used as a measure of discrimination. That is, we calculated the amount of agreement between type of response and type of recognition item

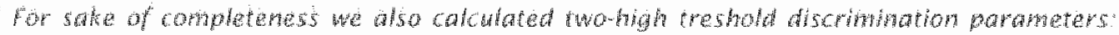

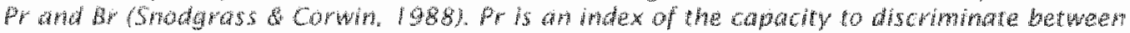

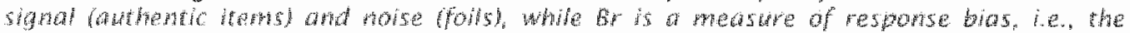

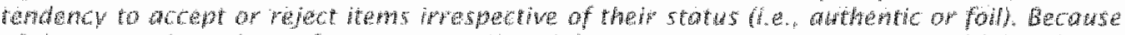

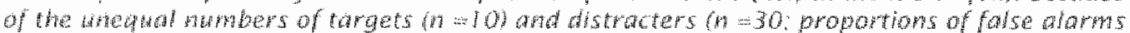

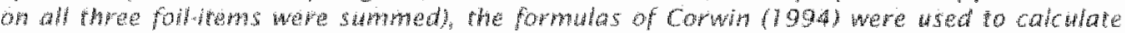

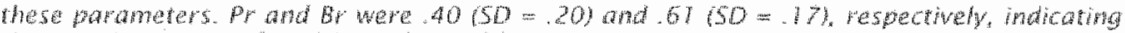

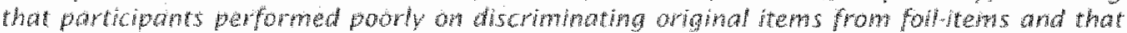

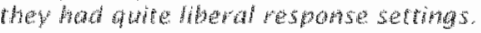


(i.e., correctly classifying recognition items). Similarly to Pr, Kappa corrects the observed hit rate (proportion agreement) for its expected value under guessing. As an index of response bias (similar to $\mathrm{Br}$ ), we used a Chi-Square to evaluate deviations of the observed response distribution from the expected response distribution for accurate responders. Since all 4 types of recognition items were presented 10 times, an accurate responder is expected to give each responsetype 10 times. Under the null hypothesis of no bias, the measure has a ChiSquare distribution with $\mathrm{df}=3$.

Average Kappa was $.58(S D=.74)$, a value that indicates average performance. Thus, participants were able to discriminate between the 4 types of records at a madest level. A significant Chi-Square indicated response bias, that is "a preference for some responses above others. Setting alpha at 0.01 with a mean Chi-Square of $8.39(S D=5.67)$, almost a quarter of the participants showed a significant response bias. Two outliers (extremely high Chi-Squares) even classified more than half of their original and context-foil items as other-items.

\section{INDIVIDUAL DIFFERENCES}

Mean scores on CEQ, DES, TAS, CSS, and BDI are given in Table 5.2. To explore the contribution of individual difference measures to memory accuracy, Pearson correlations between these measures and discrimination and response bias indices were calculated (see Table 5.2). It appeared that only fantasy promeness. (CEQ) was related to both indices. That is "individuals high on fantasy prone performed better on this recognition task. There were no relations between individual difference measures and confidence ratings. ${ }^{2}$

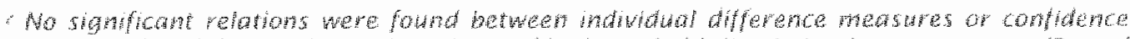

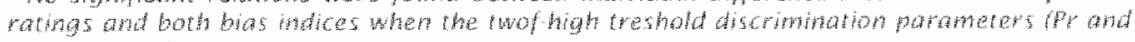
(15) wers 4 sed. 


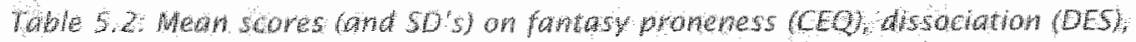

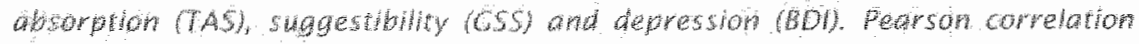

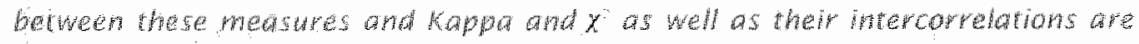
also hown.

\begin{tabular}{|c|c|c|c|c|c|c|c|c|}
\hline & $M$ & SD & Kappa & $x$ & DES & TAS & $\sigma s$ & $B D I$ \\
\hline CEQ & 6.7 & 3.8 & $38^{\prime \prime}$ & $-44^{213}$ & .41 & .61 & 19 & $39^{2}$ \\
\hline DES & 18.0 & 10,7 & .19 & 1.11 & & 25 & .08 & 06 \\
\hline TAS & 14,6 & 5.7 & 29 & 21 & & & .03 & 25 \\
\hline GSS & 7.7 & 3.2 & 801 & .17 & & & & .08 \\
\hline BDI & 6.7 & 6.9 & 19 & .25 & & & & 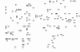 \\
\hline
\end{tabular}

\section{DISCUSSION}

The present study examined two issues. First, we sought to replicate earlier findings on spontaneous distortions in autobiographical memory (Barclay \& Wellman, 1986; Merckelbach et al., 1997) in a larger sample. Second, the contribution of individual difference variables to memory was explored. As for the first issue, our results indicate that memory accuracy over a 6 -month time interval was found to be far from perfect. As in the Barclay and Wellman study (see also Merckelbach et al., 1997), participants recognized on the average about 80 of their original diary records, but also made commission errors by accepting foil records as their own. Commission errors or false allarms were not evenly distributed over different types of foil items. That is, participants seemed to have more difficulties rejecting context-foils than rejecting evaluation- or otherwfoils.

The fuzzy-trace theory (FTT; Brainerd, Reyna \& Poole, 2000) offers a theoretical framework for interpreting the spontaneous memory distortions found in this 
study. According to this theory, target events are simultaneously stored in verbatim (episodic or item specific) and gist (semantic) traces. Both traces elicit different types of subjective impressions. Whereas verbatim traces go together with feelings of specific recollection, gist traces go hand in hand with a global impression of familiarity. These feelings, in turn, support all-or-none or graded similarity judgments. However, verbatim traces rapidly decay over time (i.e., withim days; e.g., Koriat, Goldsmith \& Pansky, 2000), whereas gist traces are resistant to decay. When time passes, people will increasingly use global gist traces to reconstruct their memories. Thus, the high false alarm rattes on context- and evaluation-foils can be explained by the 6-month interval, in which verbatim traces decayed "but vague feelings of familiarity based on gist traces still existed. In this light, the low false alarm rates on other-foils may be interpreted as the result of inconsistencies between these foils and gist traces.

As was the case in the Barclay and Wellman study (1986; see also Merckelbach et al..., 1997), confidence ratings for hits and false alarms on context- and evaluation-foils did not differ, although participants were less confident about their false alarms on other-foil items. This indicates that "in general, false alarms go hand in hand with high confidence scores. In Barclay and Wellman's (1986; p.101) words: "People are more confident about the exact nature of events occurring in their life than they should be." The type of task affects this owerconfidence. It is a well-established fact that recognition tasks produce strong confidence-accuracy discrepancies (Robinson \& Johnson, 1996). Overconfidence is also a function of ease of retrieval (see for example Kelley \& Lindsay, 1993). The lower confidence ratings on other-foil items might be an indication that participants had relatively more difficulties retrieving this type of item.

The second issue that was explored in the present study pertained to the association between autobiographical memory distortions and the individual difference measures of fantasy proneness" dissociation, absorption, suggestibility, and depression. Note that the mean scores on these measures come close to those reported in earlier studies (e.g., Merckelbach et al., 1999; 
Horselenberg, Merckelbach, \& Josephs, 2003; Gudjonsson, 1997). Intercorrelations between these individual difference measures also replicated patterns found in previous studies. For example, as was the case in Horselenberg et als $5(2003)$ study dissociation and fantasy proneness were found to correlate significantly. Likewise, as in the Lynn and Rhue (1986; see also Platt, Lacev, lobst \& Finkelmian, 1998) study, fantasy proneness and absorption were associated with each other. On the other hand, suggestibility was not related to any of the other measures, while depression only correlated with fantasy proneness.

A counter-intulive relationship between fantasy proneness and memory performance was found. That is, participants high on fantasy proneness were superior in discriminating between targets and foils, and they also exthibited reduced response bias. One possible explanation for this finding is that autobiographical records of high fantasy prone people are somehow different in their linguistic or marrative construction compared to records of low fantasy prone people: Indirect evidence for this comes from a recent study (Merckelbach, 2004) in which high and llow fantasy prone people were asked to write dlown a fabricated story. The stories of high fantasy prones were judged by blind raters (i.e., psychologists) as being more convincing than those of low fantasy prones, a finding that must have something to do with the way in which high fantasy prones construct their narratives. Thus, it might well be the case that in the current study, high fantasy prone participants could rely on a broad variety of stylistic features to identify their original records. Clearly, this issue warrants further study.

We anticipated that individual differences would modulate source monitoring. Yet with the exception of fantasy proneness (cf. supra), none of the individual differences tapped in the current study, was rellated to memory distortions. This mull finding can be interpreted in the light of the task employed in the current study. Recognition does not require individuals to elaborate on certain memory traces, and so involvement of source monitoring decisions might be minimal. in contrast, recall tasks require intensive use of source monitoring processes. 
Interestingly, Candel et al. (2003) found that individuals high on DES displayed more commission errors (i.e., false alarms) in a free recall task. On a related note, one could argue that individual differences in memory distortions occur primarily when individuals are exposed to post-event misinformation during an experiment (e.g., Platt et al „, 1998).

The present findings, along with those of Barclay and Wellman (1986) and Merckelbach et al. (1997), conwerge on the notion that spontaneous autobiographical distortions are a common phemomenon. Yet, the present study found no evidence for individual difference variables contributing to this phenomenon. It may well be that such variables only matter with implausible (e.g., UFO-abductions; Bartholomew, Basterfield \& Howard, 1991; Horselenberg \& Merckelbach, submitted) rather than plausible memory commissions. A case in point is the study by Spanos, Cross, Dickson, and DuBreuil (1993) who showed that fantasy proneness is not related to UFO experiences per se, but to the unusual physical sensations of such experiences, with high fantasy prones reporting more bizarre experiences. Such an effect is also found in people reporting previous-life memories. Thus, in their study on people undergoing regression therapy and hypnosis, Horselenberg and Merckelbach (submitted; see also chapter 7) found that high fantasy prone subjects reported more eccentric previous-life memories than did low fantasy prone people. Clearly, a more detailed understanding of who is likely to make commission errors and under what conditions awaits clarification.

Trierweiler and Donovan (1994; p. 301) rightly remarked that "memories of interpersonal events in a client's life are the grist for the psychotherapeutic mill". Our results show that people's memories of their diary descriptions of such events are far from perfect. They not only forget a surprising proportion of their diary notes (omissions), but they also sometimes come to accept notes that are not their own (commissions). This, then, is another demonstration that narrative truth is quite different from historical truth (Bonanno, 1994). Psychotherapists 
CHAPTER 5

are well advised to take this point into account, even when they make use of such relatively passive tools as writing exercises. 
CHAPTER 6.1

Personality Characteristics and False Confessions: A Conceptual Replication of Kassin and Kiechel (1996)

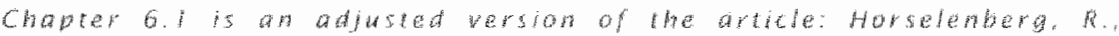

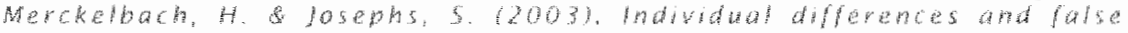

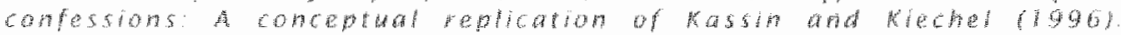
Psychology, Crime and law, 9. 1- 


\section{ABSTRACT}

In their study, Kassin and Kiechel (1996) falsely accused students of causing a computer cirash and found that $69 \%$ of them were willing to sign a false confession, $28 \%$ internalized guilt, and $9 \%$ confabulated details to support their false beliefs. The authors interpreted these results to mean that false confessions can be easily elicited. Howewer, in their study, false confessions were explicitly not associated with negative consequences. The current study examined whether false incriminating evidence may elicit false confessions in undergraduate students when such confessions are explicitly associated with financial loss. We also explored whether individual differences in compliance, suggestibility, fantasy-proneness "dissociation, and cognitive failures are related to false confessions. The large majority of participants $(82 \%)$ were willing to sign a false confession. In about half of the participants, false confessions were accompanied by internalization and confabulation. There was no evidence that individual differences modulate participants' susceptibility to false confessions. Taken together, our study replicates previous findings of Kassin and Kiechell.

\section{INTRODUCTION}

Although confession evidence plays an important role in criminal proceedings this topic has received relatively fittle attention from experimental psychologists (Kassin, 1997). Meanwhile, especially false confessions warrant systematic study because, as a number of well documented case studies show (e.g., Wright, 1994; Gudjonsson, Kopelman \& Mackeith, 1999), their legal ramifications might be farreaching. Research about the incidence of self-reported false confessions among prison inmates has yielded estimates that vary from $0.6 \%$ (Cassell, 1998) to 12\% (Gudjonsson, \& Sigurdsson, 1994). Yet, little is known about the precise situational and interpersonal antecedents of such confessions. 
Several authors (Kassin \& Wrightsman, 1985; Kassin, 1997; McCann, 1998; Wakefield \& Underwager, 1998) have pointed that there are at least three distinct types of false confessions. The first type is the voluntary false confession that involves spontaneous self-incriminating statements made without external pressure. The second type is the coerced-compliant false confession. In these cases, suspects have the private bellef that they are innocent, but nevertheless confess in order to secure a benefit (e.g., promises of immunity) or to avoid a threatened harm or an aversive state (e.g., abstinence symptoms). The third type is the coerced-intermalized false confession. Here suspects actually come to believe that they are guilty of a non-committed crime. While this type seems rather counter-intuitive, psychiatric literature offers many anecdotal reports illustrating such internalized false confessions (see, for a review, Gudjonsson, 1992). To some extent, internalized false confessions overlap with one particular category of memory illusions, namely illusions known as "false" memories (e.g., Loftus, 1993).

However, whereas false memories usually refer to autobiographical recollections of fictitious childhood events that suddenly occur in the context of psychotherapy (e.g., Gudjonsson, 1997), internalized confessions may pertain to relatively recent episodes and, by definition, occur within a legal context. Over the past 5 years or so, a considerable number of laboratory studies have sought to identify factors that may contribute to the development of false mentories. In general, this research has been successful in that it has identified certain interventions (e.g., false feedback, imagery, journaling) that may elicit false memories in a nontrivial minority of healthy subjects (e.g., Hyman, \& Pentland, 1998; Garry, Manning. Loftus \& Sherman, 1996; Horselenberg, Merckelbach, Muris, Rassin, Sijsenadir \& Spaan, 2000; chapter 4).

In contrast, little work has been done on the experimental analysis of internalized false confessions. With the exception of the older study by Bem (1966), only the recent experiment of Kassin and Kiechel (1996) addressed the issule of internalized false confessions. These authors invited 75 undergraduates to 
participate in what was introduced as a computer task. It was stressed that during the task, participants should not hit the ALT-key. After 1 minute, thie computer supposedly crashed and the experimenter accused participants of having pressed the forbidden ALTwey. The experimenter then asked participants to sign a standardized confession $l^{a l}$ hit the ALT-key and caused the program to crash. Datia were lost"y. Signing this confession was interpreted as evidence for the compliant type of false confession. To determine whether internalization of the false confessions had occurred, a confederate who waited outside the lab and who had overheard the commotion, asked participants what happened and recorded their reply. If participants expressed guilt for the computer crash, this was taken as evidence for an internalized false confession. Two variables were systematically manipulated, namely pace of the computer task (slow versus fast) and false incriminating evidence (absent or present), resulting in four experimental conditions. The false incriminating evidence condition consisted of a seemingly independent confederate who claimed that s/he had seen the participant hitting the ALT-key. In the absence of a witness and with a slowly paced task, $35 \%$ of the participants signed the confession form (compliance) while none of them expressed guilt for the computer crash (0\% internalization). In the absence of a witness, but with a fast task, these percentages increased to 65 $\%$ and $12 \%$, respectively. When a witness was introduced in the context of a slowly paced task percentages increased even further to $89 \%$ and $44 \%$, respectively. Finally, the combination of a witness and a fast paced task induced compliance and internalized false confessions in the large majority of participants, percentages being $100 \%$ and $65 \%$ respectively. Accordingly, the authors concluded "that the presentation of false incriminating evidence - an interrogation ploy that is common among the police and sanctioned by many courts - can induce peoplle to internalize blame for outcomes they did not produce" (Kassin \& Kiechel, 1996; p.127).

Although the pioneering work of Kassin and Kiechel (1996) bears relewance to the issue of false confessions, several critical points can be raised. To begin with, in 
the Kassin and Kiechel (1996) studly, a supposedly non-involved and independent peer of the participant provided false incriminating evidence. However, in real life interragations such an independent witness will be rare. A more plawsible scenario is one in which an authority figure claims to possess privileged knowledge that might be incriminating. Secondly, in the Kassin and Kiechel (1996) study, participants' confessions had no immediate and explicit negative consequences. Again, this is very unlike the situation during a police interrogation. Here, a confession will produce a cascade of effects, one of which might be conviction, and therefore, punishment.

With these points in mind, the current experiment made an attempt to replicate the Kassin and Kiechel (1996) findings. However, the following procedural changes were made. First, all participants were exposed to an experimenter who claimed to possess incriminating evidence. Second, participants were aware of the fact that if they decided to sign a confession, this would result in a $80 \%$ reduction ( $\$ 2$ instead of $\$ 10$ ) of the financial fee they would receive for their participation in the experiment.

A subsidiary aim of the present study was to explore to what extent individual difference variables contribute to experimentally induced false confessions. Previous research has found tentative evidence that high sicores on the Gudjonsson Compliance Scale (GCS; Gudjonsson, 1989; 1991) are related to false confessions. For example, Sigurdsson and Gudjonsson (1996) noted that prison inmates who claimed to have made false confessions had significantly higher GCS scores than a control group. This suggests that individual differences in compliance contribute to false confessions of the coerced-compliant type (Gudjonsson "1992). Sigurdsson and Gudjonsson (1996) also found evidence that false confessions of the coerced-internalized type are specifically linked to heightened suggestibility as indexed by the Gudjonsson Suggestibility Scale (GSS; Gudjonsson, 1984). Similarly, in their case study, Santtila, Alkiora, Ekholm, and Niemi (1999) described the example of a defendant charged with robbery who 
made a coerced-internalized false confession, presumably because he was highly suggestible:

Other traits that may make people more susceptible to false confessions are fantasy proneness, dissociation, and self-reported cognitive failures. Germane to thils issue is research showing that fantasy proneness, dissociation, and/or cognitive failures predict individuals" tendency to develop pseudomemories (e.g. Hyman, \& Billing, 1998; Merckelbach, Muris, Rassin, \& Horselenberg, 2000; Winograd, Peluso, \& Glover, 1998; but see also chapters 3,4 , and 5 ; Spanos, Burgess, Burgess, Samuels \& Blois, 1999).

In sum, then, the current study examined to what extent false incriminating evidence presented by an experimenter elicits false confessions in undergraduate students, even when such confessions are associated with financial loss. Our study also explored whether compliance, suggestibility, fantasy proneness, dissociation, and cognitive failures predispose individuals to exhibit false confessions.

\section{METHOD}

\section{PARTICIPANTS}

Participants were 34 undergraduate psychology students (all women). Their mean age was 18.6 years (range $18-22$ years). As a result of previous testing sessions, we had access to the compliance, suggestibility, fantasy proneness, dissociation, and cognitive fallures scores of the participants in the current study. These psychometric data had been obtained some 8 months before the current study was conducted. Participants were told that they would participate in an ergonomic study that evaluated the effectiveness of new keyboard configurations. They were paid for their participation. 


\section{MATERIALS}

As part of individual testing sessions that took place some 8 months before the experiment proper, participants completed the Gudjonsson Compliance Scale (GCS; Gudjonsson, 1989), the Gudjonsson Suggestibility Scalle (GSS; Gudjonsson, 1984), the Creative Experiences Questionnaire (CEQ; Merckelbach, Horselenberg, \& Muris, 2001), the Dissociative Experiences Scale (DES; Bernstein, \& Putnam, 1986), and the Cognitive Failure Questionnaire (CFQ; Broadbent, Cooper, Fitzgerald, \& Parkes, 1982).

The GCS ( $\alpha=.72$ ) is a self-report questionnaire consisting of 20 true/false statements that have to do with the way in which individuals may deal with conflicts and confrontation (e.g., "I give in easily to people when 1 am pressured."). Responses are totalled with higher scores reflecting a stronger tendency to comply.

The GSS (version 1; $a=.60$ ) consists of a short story and 20 specific questions about the story. Fifteen of these questions convey misleading information about the story. The extent to which an individual gives in to the leading questions constitutes that individual's. Yield score (maximum score $=15$ ). Following the 20 questions, participants are told in an authoritative manner that they made many mistakes and that all questions have to be answered for a second time. The number of times that participants change their answers constitutes their Shift score (maximum score $=20$ ). Yield and Shift scores are summed to obtain a total suggestibility score (maximum score $=35$ ). A number of other parameters can be derived from the GSS, but for practical reasons (i.e., extensive test sessions), the present study only focused on Yield-, Shift-, and total suggestibility scores.

The CEQ $(\alpha=.70)$ is a 25 item yes/no index of fantasy proneness. The CEQ items were derived from the extensive case descriptions of fantasy proneness provided by Wilson and Barber. Typical CEQ-items are: "In general I spend at least half of the day fantasizing or daydreaming" and "My fantasies are so vivid that they are like a good movie". Yes-answers are summed to yielld a total CEQ score. High scores indicate fantasy proneness. 
The DES $(\alpha=.86)$ consists of 28 items that pertain to dissociative phenomena (e.g. feelings of derealisation, depersonalisation, disturbances in memory). Respondents indicate on $100 \mathrm{~mm}$ Visual Analogue Scales (VASs: $0=$ not at all: $100=$ very much) the frequency with which they experience these symptoms. VAS-scores are averaged to obtain a total DES score. Higher total DES scores indicate stronger dissociative tendencies.

The CFQ $(\alpha=.83)$ is a 25 -item self-report instrument that measures the frequency of everyday lapses and minor blunders (e.g., "Do you forget appointments?"). Subjects indicate on 5-point scales how often they have experienced each cognitive failure in the past month (anchors: $0=$ never; $4=$ very often). Scores are summed to obtain a total CFQ score, with higher scores indicating a higher frequency of self-reported cognitive failures.

For the computer task, a DELL PC was used running Experimental Run Time System (ERTS; Beringer, 1996). Stimuli appeared on a 17-inch screen in lower case in yellow colour against a grey background. Responses were recorded on line to correct for actually hitting the SHIFT-key. None of the participants hit the SHIFT-kev.

\section{PROCEDURE}

To increase the credibility of the cover story, participants completed several forms concerning their typing abilities, typing performance, and problems they previously encountered with various keyboard arrangements. Participants were told that they were assigned to a control group and, therefore, had to carry out a task on a standard keyboard. Following this, they were instructed to type as quickly and accurately as possible various letters appearing on the screen. Participants were told that they should not touch the SHIFT-key, because touching that key would result in a fatal computer crash and total loss of data. To make the possibility of a computer crash more plausible the letter $Z, X$, and $A$ (which are all located near the SHIFT-key) were presented on some trials. In total, 96 stimuli were presented before the computer crashed. 
After the computer crash, the experimenter accused participants of having touched the SHIFT-key and insisted that she had seen it happened with ther own eyes (false incriminating evidence). Next, the experimenter invited participants to sign a hand-written confession stating - and this was stressed explicitly by the experimenter - that the data were lost because the participant hit the SHIFT-key and that she (i.e., the participant) would therefore lose $80 \%$ of her financial fee. If participants refused to sign the confession form, the experimenter once again encouraged them to sign it. The experimenter then left the room and advised the participants to think for while about what had happened. After 5 minutes, a confederate entered the room. He explicitly stated that he was not associated with the ongoing experiment. The confederate asked participants what was going on. Participants' answers were recorded verbatim. Finally, the experimenter reentered and fully debriefed the participants and asked them not to discuss the experiment with their colleagues.

\section{RESULTS}

Of the 34 participants, $27(82 \%)$ signed the confession, $14(42 \%)$ exhibited internalization (i.e., expressed the belief that they were fully responsible for the computer crash) and $19(58 \%)$ exhibited confabulation (i.e., gave detailed information about when, why, and how they hit the SHIFT-key). Note that participants more often displayed confabulation than internalization. This has to do with our definitions of these two constructs that allow for the possibility that a participant is not fully convinced of the fact she had touched the SHIFT-key, but does make up a story about what could have happened. Percentages of internalization and confabulation are conservative because only straightforward statements about personal responsibility and about when, why, and how the SHIFT-key was touched were accepted as evidence for internalization and confabulation, respectively. 
Mean scores on the GCS, GSS-Yield, GSS-Shift, GSS-total, CEQ, DES, and CFQ were $10.3(\mathrm{SD}=3.7), 3.4(\mathrm{SD}=2.3), 5.8(\mathrm{SD}=2.9), 9.2(5 \mathrm{D}=3.3), 7.8 \mathrm{(SD}=$ $3.7), 20.0(\mathrm{SD}=9.7)$, and $46.2(\mathrm{SD}=10.7)$, respectively. These scores come close to those reported by previous studies for undergraduate samples (e.g., Gudjonsson, 1997; Merckelbach, Muris, \& Rassin, 1999; Merckelbach et al., 2000).

To explore the contributions of individual difference variables to coerced confessions (i.e., signing a form), intermalizations, and confabulations, 3 separate Multivariate Analysis of Variance (MANOVA) were carried out. Each MANOVA followed a 2 (signed versus not signed or internalized versus not internalized or confabulated versus not confabulated) $\times 5$ (individual difference variables) setup. No evidence was found to support that people who sign, intermalise, and/or confabulate differ from people who do not sign, internalise, and/or confabulate with respect to individual difference measures obtained in the current study: all $F$ $(1,25)$ 's $<1.5$, all $p$ 's $>.2$ for signing and all $F(1,29)^{\prime} s<2.1$, all $p$ 's $>.15$ for internalizing and confabulating. Mean scores on the individual difference variables are given in Table 6.1.1. 


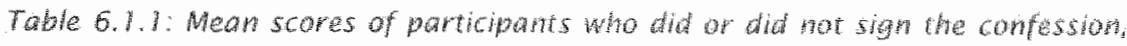
did or did not intermalize, and did or did not comfabulate on comphance rocs.

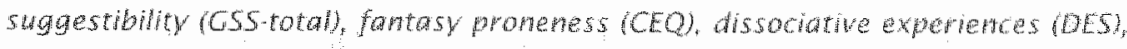
and cognitive failures (CFOL. Stantard devations are given beween warembeses.

\begin{tabular}{|c|c|c|c|c|c|c|}
\hline & $\begin{array}{l}\text { signed } \\
(n=21)\end{array}$ & $\begin{array}{l}\text { Not } \\
\text { signed } \\
(n=6)\end{array}$ & $\begin{array}{l}\text { Inter } \\
\text { nalized } \\
(n=13)\end{array}$ & $\begin{array}{l}\text { Not } \\
\text { mtern. } \\
(n=18)\end{array}$ & $\begin{array}{l}\text { confa } \\
\text { bullated } \\
(n=18)\end{array}$ & $\begin{array}{l}\text { Not } \\
\text { Confab. } \\
(n=r 3)\end{array}$ \\
\hline GCS & $\begin{array}{l}9.7 \\
(3.8)\end{array}$ & $\begin{array}{l}10,7 \\
(2,2)\end{array}$ & $\begin{array}{l}9.8 \\
(3.8)\end{array}$ & $\begin{array}{r}10.3 \\
(3.6)\end{array}$ & $\begin{array}{l}10.6 \\
(3.7)\end{array}$ & $\begin{array}{l}9.4 \\
(3.5)\end{array}$ \\
\hline GSS & $\begin{array}{l}9.7 \\
(3.6)\end{array}$ & $\begin{array}{l}8.5 \\
(2.7)\end{array}$ & $\begin{array}{l}7.4 \\
(3.2)\end{array}$ & $\begin{array}{l}8.8 \\
(3.4)\end{array}$ & $\begin{array}{l}7.7 \\
(3.0)\end{array}$ & $\begin{array}{l}9.0 \\
(3.8)\end{array}$ \\
\hline$C E Q$ & $\begin{array}{l}7.3 \\
(3.7)\end{array}$ & $\begin{array}{l}9.5 \\
(3.8)\end{array}$ & $\begin{array}{l}6.9 \\
(3.9)\end{array}$ & $\begin{array}{l}8.1 \\
(3.5)\end{array}$ & $\begin{array}{l}8.4 \\
(3.7)\end{array}$ & $\begin{array}{l}6.5 \\
13.5\end{array}$ \\
\hline DES & $\begin{array}{l}19.7 \\
(10.6)\end{array}$ & $\begin{array}{l}24,7 \\
(9.9)\end{array}$ & $\begin{array}{l}16.5 \\
(6.4)\end{array}$ & $\begin{array}{l}22,5 \\
(11.5)\end{array}$ & $\begin{array}{l}19.1 \\
(10.3)\end{array}$ & $\begin{array}{l}21,2 \\
(9.9\end{array}$ \\
\hline$C F Q$ & $\begin{array}{l}46.2 \\
(12.3)\end{array}$ & $\begin{array}{l}44,2 \\
(9.1)\end{array}$ & $\begin{array}{l}45.3 \\
(13.1)\end{array}$ & $\begin{array}{l}46.8 \\
(9.3)\end{array}$ & $\begin{array}{l}45 \\
(10.5)\end{array}$ & $\begin{array}{l}47.8 \\
(11,6)\end{array}$ \\
\hline
\end{tabular}

\section{DISCUSSION}

The main results of the current study can be catalogued as follows. First, in keeping with the Kassin and Kiechel (1996) study, the large majority of our participants were willing to sign a false confession. Second, in about half of them false confessions were accompanied by internalization (42\%) and/or confabulation (58\%). Third, no evidence was found to suggest that individual differences in compliance tendencies, interrogative suggestibility, fantasy proneness, or dissociation modulate participants' susceptibility to false confessions.

Our results provide a fine replication of the Kassin and Kiechel (1996) findings. These authors reported overall percentages of $69 \%, 28 \%$, and $9 \%$ for compliance, internalization, and confabulation, respectively. We obtained somewhat higher 
percentages $(82 \%, 42 \%$, and $58 \%$, respectively), even though in our study, signing a false confession implicated financial losis. The fact that Kassin and Kiechel found owerall lower percentages of false confessions might have to do with their instruction to participants to try to recollect how the computer crash did happen. In contrast, we asked our participants about what could have happened. However, our results demonstrate that normal participants can be manipulated to sign a false confession even when such an act has straightforward neglative consequences. Our results also indicate that this effect does not depend on participants being confronted with a supposedly independent witness who presents false incriminating evidence. Negative feedback by an experimenter who is clearly involved and who claims to have seen the pertinent act suffices to elicit false confessions in a majority of participants. All in all, our results underline Kassin and Kiechel's $(1996 ;$ p.126) words "that the presentation of false incriminating evidence can induce people to internalize blame for outcomes they did not produce".

A more disappointing aspect of the present study is that we found no evidence that the tendency to exhibit false confessions is modulated by individual difference variables. Intercorrelations between these variables were quite similar to those in previous work. For example, dissociation (DES) was positively and significantly associated with cognitive failures (CFQ; $r=.53)$ and fantasy proneness (CEO; $r=31$ ) which replicates findings reported by Merckelbach et al. (1999). Likewise, cognitive fallures and interrogative suggestibility were positively associated with each other $(r=38)$, a finding that was also reported by Merckelbach et al. $(2000)$. These correlations demonstrate that the quality of our Individual difference data was good.

Nevertheless, individual difference variables were unable to predict the various aspects of false confessions. This null finding can be interpreted in several ways. One possibility is that after a time lapse of eight months, our individual difference data may have become unreliable. However, research shows that the test-retest reliability over longer time periods for the questionnaires used in this 
study are quite good (GCS: $r=.88$; Gudjonsson, 1997; GSS: $r=.83$; Gudjonsson, 1997; CEQ: $r=$ „95; Merckelbach et al., 2001; DES: $r=.78$; Putnam, Chu \& Dill, 1992; and CFQ: $r=.83$; Merckelbach, Muris, Nijman \& De Jong, 1996). Another possibility is that false confessions in the laboratory are primarily context dependent and have little to do with personality traits. This possibility receives some support from the recently published work of Spanos and co-workers (1999). These authors found that a large majority of participants develop false memories about infancy when they are exposed to certain conditions (e.g., an authoritative person who creates clear expectations about the occurrence of such memories) and that personality traits like dissociation and fantasy proneness do not, or only to a modest degree, predict false memory reporting. Thus, these findings seem to imply that environmental conditions rather than traits run the show. Of course, such external conditions might also include situationally induced risk factors like druggs and alcohol abuse or withdrawal (Gudjonsson, 1992; see also Santtila et al., 1999).

On the other hand, several case studies about false confessions made during criminal proceedings strongly suggest that personality traits like suggestibility and /or compliance are involved in the development of false confessions (see for examples: Gudjonsson, 1999a,b). Likewise, laboratory studies of for example, Hyman and Billings (1998) and Winograd and associates (1998) found evidence that, when it comes to the development of false memories, personality traits do matter. We suspect that personality traits come in to play when false confessions have severe consequences for the individual involved. Under such circumstances, one would expect that false confessions become a low-frequency phenomenon. It may well be the case that only under extreme conditions, trait factors predict who is going to display this phenomenon. Clearly, this issue warrants further study. In more general terms, it is important to clarify the antecedents of false confessions as knowledge about these antecedents may inform forensic practice. 


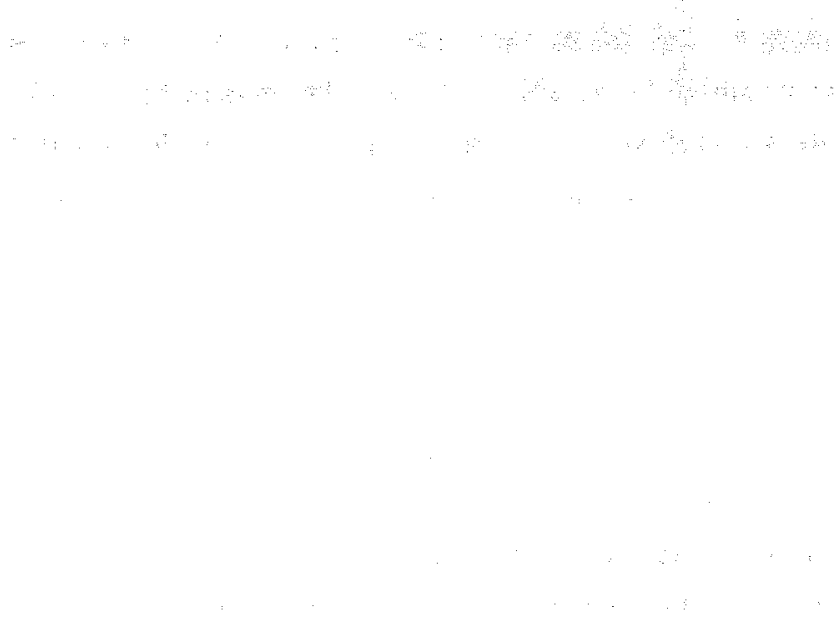


CHAPTER 6.2

False Confessions in the Lab:

Do Plausibility and Consequences

Matter?

Chaper 6.2 is an adjuted version of the article: Horselenberg. R.

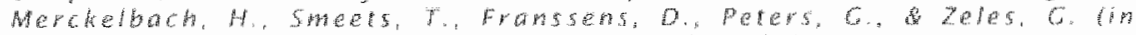

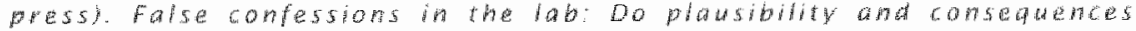
mater?. Psichology. Crime and in. 


\section{ABSTRACT}

The present paper describes three studies that examined false confessions in the laboratory. Study $1(\mathrm{~N}=56)$ and $2(\mathbb{N}=9)$ relied on the by now classic computer crash paradigm introduced by Kassin and Kiechel (1996). Study $3(N=12)$ employed a novel paradigm in which undergraduate participants were falsely accused of exam fraud. Our data indicate that false confessions do occur, even when conditions become more ecologically valid. Furthermore, we explored whether individual differences in compliance, suggestibility, fantasy proneness, dissociation, and cognitive failures are related to false confessions. Of these, only fantasy proneness was associated with false confessions.

\section{INTRODUCTION}

Throughout the history of legal practice "triers of fact have attributed much evidentiary weight to confessions (Kassin \& McNall, 1991; Kassin \& Sukel, 1997; Kassin \& Wrightsman, 1985). In general, confessions have greater impact on judicial decisions than eyewitness testimonies (Kassin \& Neumann, 1997). Germane to this issue are those individuals who have been wrongly convicted on the basis of their false confessions (for a review, see Gudjonsson, 2003). Estimates of the base rate of false confessions vary. Whereas Cassell (1996) argued that they have a relatively low base-rate, Gudjonsson and Sigurdsson (1994; see also Sigurdsson \& Gudjonsson, 1996) found that 12\% in their sample of Icelandic prison inmates clamed to have falsely confessed. Although this latter finding might be an overestimation, Bedau and Radelet (11987) moted that false confessions constitute a real problem in the sense that their consequences are farmpaching. These authors analyzed 350 miscarriages of justice and in at least $10 \%$ of these cases, false canfessions played a crucial role. Recently, Scheck, Neufeld and Dwyer (2000) reported a false confession incidence of $22 \%$ in their Innocence Project, which supports the conclusions of Bedau and Radelet (1987). 
The large scale surveys of Gudjonsson and colleagues (Gudjonsson, Sigurdsson, Bragasson, Einarsson \& Valdimarsdottir, 2004; Gudjonsson, Sigurdsson \& Einarsson, 2004) among college and university students found self-reported base rates of $2.8 \%$ (false confessions to police officers) and $8.8 \%$ (false confessions to parents and teachers).

In a recent extensive review, Gudjonsson (2003) proposed a modified taxonomy for false confessions. This taxonomy intends to take into account critiques on the classifications introduced by Kassin and Wrightsman (i.e., voluntary, coercedcompliant, and coerced-internalized false confessions; Kassin \& Winghtsman, 1985) and by Ofshe and Leo (i.e., voluntary, coerced-compliant, stresscompliant non-coerced-persuaded, and coerced-persuaded false confessions; Ofshe \& Leo, 1997). In short, Gudjonsson suggests that for a better understanding of the various false confession types, the term "coerced" should be redefined as "pressured" and that the source of pressure should be categorized as either internal or externall. Accordingly, the following classification of false confessions can be made. To begin with, there is the volluntary false confession, where pressure stems from an internal source. This source refers to the individual having internal motives ( $\mathrm{g}_{\mathrm{g}}$, to protect a significant other or a morbid desire for notorietyl to confess falsely. A second type of false confession is the pressured-compliant, where the source of pressure may be either caused by custodial (e.g., during a police interrogation) or non-custodial circumstances. Non-custodial pressure originates from people other than police officers (e.g., peers, cell mates, customs and immigration officers, undercover police officers). It is important to note that with this type of confession, the person does not believe that he or she committed the crime confessed. A third type of false confession is the pressured-internalized type. Here, suspects actually come to believe that they are guilty of a crime they did not commit. Again, the source of pressure can be either custodiall or non-custodial.

Kassin and Kiechel (1996) examined whether analogues of the various false confession types may occur under laboratory conditions. These authors 
instructed their undergraduate participants to copy letters that were presented on a computer screen. Participants were told not to touch the Alt-key because otherwise the computer would crash. During the task, the computer did crash and participants were falsely accused of having toucthed the forbidden key. Next, participants were asked to sign a written confession and they were approached by a confederate of the experimenter who presented as a naive subject. This confederate asked the participant about what happened. Kassin and Kiechel found that many participants (depending on the precise conditions, between 35 and $100 \%$ were willing to sign a written confession. A smaller portion of them (depending on the conditions, between 0 and 65\%) apparently had internalized their false confessions because they related to the confederate how they had touched the forbidden Alt-key.

Several studies (Candel, Merckelbach, Loyen \& Reyskens, 2005; Forrest, Wadkins \& Miller, 2002; Forrest \& Wilson, 2003; Horselenberg, Merckelbach \& Josephs, 2003; Klaver, Gordon Rose \& Lee, 2003; Lee, Klaver \& Gordon Rose, 2003; Redlich \& Goodman, 2003) have replicated the basic findings of Kassin and Kiechel (1996). For example, Candel and colleagues (2005) used the Kassin and Kiechel paradigm to examine false confessions in young children and found that $36 \%$ of the children falsely confessed having touched a forbidden computer key. As well, $89 \%$ of the falsely confessing children had internalized their confession (see also Redllich Goodman, 2003). Forrest et al.'s (2002) study focused on whether stress may contribute to laboratory induced false confessions. These authors reported that stress did not affect false confession and internalization rates in women, but it did so in men. When stress was absent, women tended to confess and internalize more than did men. The results of Lee et al. (2003) parallel those of Forrest et al. (2002). That is, Lee and colleagues (2003) reported a heightened rate of false confessions for women (80\%) compared to men (20\%). Yet, this gender difference was only evident for signing confessions "not for internalization rates. Forrest and Wilson (2003) examined the effects of rumination about past events (e.g., reminding someone of his or her criminal 
history) on false confessions. Although they came up with high overall rates of false confessions and internalizations ( $90 \%$ and $46.3 \%$, respectively), no effect of rumination could be demonstrated.

Horselenberg et al. (2003" chapter 6.1) studied whether negative consequences (i.e., monetary penalties) would reduce false confession rates. These authors found that, despite monetary penalties, the large majority of their participants (82\%) were willing to sign a false confession (see also Redlich \& Coodman, 2003). They also noted that in about half of their participants, false confessions were accompanied by internalization and confabulation. In a large sample $(\mathrm{N}=204)$ of undergraduates, Klaver et al. (2003) studied the effects of interrogation strategies (i.e., maximization or minimization) on false confession rates. Half of their participants were interrogated emphasizing the accidental nature of the act and blaming the sensitivity of the keyboard (i.e., minimization). During interrogations of the other half, the significant loss of data and the supervisor's irritation was emphasized (i...e, maximization). Within both conditions, some participants were accused of having pressed the more plausible Alt-key, while others were accused of having touched the rather implausible Esc-key. More confessions were signed in the minimization condition than in the maximization condition (156\% and $30 \%$, respectively). Furthermore, when plausibility was low, confession rates dropped dramatically. More specifically, when participants were accused of having plessed the Alt-key, 59\% signed a confession. However, when they were accused of having hit the Esc-key, 13\% signed a confession.

In sum, then, experimental studies suggest that there are many factors that may contribute to a false confession. Case studies have shown that these factors can best be grouped into two classes, mamely situational and personal factors. Situational factors include, for example, the interrogation process itself (Leo \& Ofshe, 1998), the techniques used by the police (Gudjonsson, 2003), overzealousness of police officers (Bedau Putnam, 1996), or presentation of false evidence (e.g., statements supposedly made by an accomplice or a staged eyewitness identification; Kassin, 1997). Personal factors that may increase 
susceptibility to false confessions are naivete, stress, anxiety, fatigue, low intelligence (e.g., mental disorders), young age, interpersonal trust " compliance, suggestibillty " and alcohol or drug use (Kassin, 1997, Gudjonsson, 2003).

In case reports about false confessions, compliance and suggestibility have received much attention (e.g., Gudjonsson, 2003). However, experimental studies using Kassin and Kiechel's paradigm yielded little or no evidence for the idea that compllance or suggestibility modulates participants' susceptibility to confess falsely (e.g. Candel et al., 2005; Horselenberg et al., 2003; Lee et al., 2003). Perhaps, these null findings have to do with the fact that extremely compliant or suggestible individuals are seldomly found among undergraduates. A related point is that sample sizes in this research domain are often limited. Interestingly, Redlich and Goodman (2003) found some tentative evidence that especially those particlpants who yielded to misleading questions were prone to falsely confess. In more general terms, it is fair to conclude that most laboratory work on false confessions has looked at situational factors (interrogation techniques, effects of false evidence, etc.), while relatively few studies systematically looked at relevamt personality traits.

Besides compliance and suggestibility, there are other individual difference measures that might be relevant to false confessions. Candidates that have some prima facie plausibility are fantasy proneness, dissociation, and self-reported cognitive failures. The point here is that at least some types of false confessions (e.g., the pressured-internalized type; Gudjonsson, 2003; Ost, Costall \& Bull, 2001) can best be considered as pseudomemories. There is an extensive llterature showing that fantasy proneness, dissociation, and/or cognitive failures predict an individulal's tendency to develop pseudomemories (e.g " Candel, Merckelbach, Kuijpers, 2003; Hyman \& Billings, 1998; Merckelbach; Muris, Rassin \& Horsellenberg, 2000; Ost, Vrij, Costall \& Bull, 2002; Winograd, Pelluso \& Glover, 1998; but see also chapters 3,4,5; and 6.1). It should be noted that these traits overlap to some extent (Kihlstrom, Glisky \& Angiulo, 1994; Merckelbach, Horselenberg \& Muris, 20011. There are good reasons to believe that, through 
suggestion or imagery, these traits act so as to endow internal events with features that are usually typical for "real" memories (i.e, memories of external events: Merckelbach et all, 2001). Thus, it may well be the case that, because they misinterpret their detailed imagery or fantasies about their involvement in a crime as real memories, people high on fantasy proneness, dissociation; and/on cognitive failures are susceptible to false confessions. Alternatively, individuals high on these traits may interpret their lack of robust memories about the crime as an indication that they must have repressed these memories. This line of reasoning comes close to what Gudjonsson and Mackeith (1982) have termed memory distrust.

The present paper describes three studies which attempted to elicit false confessions in a laboratory situation. Using Kassin and Kiechel's paradigm; study 1 manipulated the plausibility of the accusation (pressing the Windows-key versus the F12-key). We tried to replicate Klaver et al.'s (2003) finding that low plausibility goes hand in hand with a relatively low false confession rate. Following the same paradigm, study 2 focused on the severity of consequences. What happens when participants are accused of having caused a computer crash and they know that confessing means paying for the damage? Horselenberg et al."'s (2003: chapter 6.1) results seem to indicate that even under these circumstances, many participants falsely confess (see also Redlich \& Coodman, 2003). In order to create an ecologically valid situation, participants in study 3 were accused of cheating on an exam. We expected that, since cheating is less frequent than wrongfully touching a computer-key and as it involved severe consequences, this accusation would drastically reduce the number of false confessors in comparison to other studies. The studies to be described below are not intended to unravel the precise causal antecedents of the various false confession types. Rather they seek to give a solid empirical proof of false confessions under laboratory conditions. In all three studies, we explored whether compliance, suggestibility, fantasy proneness" dissociation, and cognitive failures predispose individuals to falsely confess. 
We are, of course, aware of the ethicall aspects of our studies Laboratory studies on false confession require careful planning and so we sought in an early stage the advice of our ethical committee. After extensive discussions, all three studies were approved by the standing ethical committee of the Faculty of Psychology at Maastricht University. Before the studies began, participants signed an informed consent in which it was explicitly stated that they had the right to withdraw from the study whenever they wanted to. Furthermore, after the studies, all participants were debriefed thoroughly and this was done in two ways: they were told about the ideas and procedures behind each study, but they also received a letter in which detailed background information was given. Most importantly, we decided beforehand that we would discontinue a study whenever participants became too distressed. In that case we also had a scenario that specified how participants had to be reassured and which other measures had to be taken. For study 3 , we decided that we would give participants a follow-up debriefing after approximatelly 5 months. In addition, by pre-testing participants we were able to exclude high anxious individuals from participation in study 3 . Nevertheless, after we had run a limited number of participants in studies 2 and 3, we decided to call these studies to a halt. The manipulations were experienced by some participants and experimenters as too upsetting.

\section{STUDY 1}

\section{METHOD}

PARTICIPANTS Participants were 72 undergraduate psychology students. After the study, all participants were given an exit interview in which they were asked whether they had known all along that the computer task was fake. It was explicitly stated that acknowledging this would not result in any consequences. Of all participants, 16 were discarded from further analysis as they saw through the experimental setmup. Thus, the remaining sample consisted of 56 participants ( 46 women). Their mean age was 20.6 years (range $18-33$ years). 
MATERIALS. Participants completed the Gudjonsson Compliance Scale (GCS; Gudjonsson, 1989), the Gudjonsson Suggestibility Scale (GSS1; Gudjonsson, 1984), the Creative Experiences Questionnaire (CEQ; Merckelbach, Horselenberg \& Muris, 2001), the Dissociative Experiences Scale-C (DES-C; Wright \& Loftus. 1999), and the Cognitive Failures Questionnaire (CFQ; Broadbent, Cooper, Fitzgerald \& Parkes, 1982).

The GCS $(\alpha=.45)$ is a self-report questionnaire consisting of 20 true/false statements that have to do with how individuals deal with conflicts and confrontation (e.g.", "I give in easily to people when I am pressured."). Responses are summed up to obtain a total score, with higher scores reflecting a stronger tendency to comply.

The GSS (version 1) comprises a short story that is read out loud to participants. This is followed by 20 specific questions about the story. Fifteen of the questions. convey misleading information about the story. The extent to which an individuall gives in to leading questions constitutes the Yield score (range $0-15$ ). The other 5 questions measure memory performance. Following the 20 questions, participants are told in an authoritative manner that they made many mistakes and that all questions have to be answered for a second time. The number of times a participant changes his/her answers constitutes the Shift score (range 0 20). Yield and Shift scores are summed to obtain a total suggestibility score (range $0-35$ ), with a higher score indicating higher interrogative suggestibillity. A number of other parameters can be derived from the GSS, but for practicall reasons the present study only focused on total suggestibility scores.

The CEQ $(\alpha=.75)$ is a 25 item yes/no index of fantasy proneness. The CEQ items were derived from extensive case descriptions of fantasy proneness provided by Wilson and Barber (1982). Typical CEQ-items are: "In general, I spend at least half of the day fantasizing or daydreaming" and "My fantasies are so vivid that they are like a good movie". Yes-answers are summed to obtain a total CEQ score, with higher scores indicating higher fantasy proneness levels. 
The DES-C $(a=95)$ consists of 28 items that pertain to dissociative phenomena (e.g.; feelings of derealisation, depersonalisation, disturbances in memory). Respondents indicate on 1 -pioints scales (anchors: $0=$ much less than others; 10 - much more than others) how often they have these experiences compared to others. Scores are averaged to obtain a total DES score. Higher total DES scores indicate stronger dissociative tendencies.

The CFQ $(\alpha=.77)$ is a 25 -item self-report instrument that measures the frequency of everyday lapses and minor blunders (e.g.; "Do you forget appointments?"). Participants indicate on 5-point scales how often they experienced each cognitive failure in the past month (anchors: $0=$ never; $4=$ very often). Scores are summed to obtain a total CFQ score, with higher scores indicating a higher frequency of self-reported cognitive failures.

For the computer task, a DELL PC was used running a program in MS-DOS. Stimuli appeared on a 17 -inch screen in lower case in yellow colour against a grey background. Responses were reconded online to correct for participants actually hitting the Windows- or F12-key. None of the participants actually hit these keys.

PROCEDURE. Participants were randomly assigned to one of two groups. All participants were told that they were contributing to an ergonomic study evaluating the effectiveness of new keyboard configurations. They were also tolld that they were randomly assigned to one of three keyboard conditions. To increase the credibility of the cover story, participants completed several questionnaires about their typing abilities, typing performance, and problems they previously encountered with various keyboard arrangements. They also completed the CEQ, DES-C, and CFQ. All participants were then informed that they were assigned to a controll group and, therefore, had to carry out a task on a standard keyboard. Subsequently, they were instructed to type as quickly and accurately as possible various letters appearing on the screen. Depending on their condition, participants were instructed that they should refrain from 
touching either the Window-key or the F12-key and that touching this key would result in a fatal computer crash and complete loss of data.

After the computer had crashed, the experimenter faisely accused participants of having touched the forbidden key and insisted that she saw it happening with her own eyes (i.e., false incrimimating evidence). Next, the experimenter invited participants to sign a hand-written confession stating - and this was stressed explicitly by the experimenter - that the data were lost because the participant had hit the forbidden key. If participants refused to sign the confession form, the experimenter once again encouraged them to sign it. The experimenter then left the room and advised the participants to think for a while about what had happened. After about $5 \mathrm{~min}$, a confederate entered the room and explicitly stated that he was not associated with the ongoing experiment. The confederate asked participants what had happened. Participants" answers were later written down by the confederate, so as to derive a measure of internalization. Finally, the experimenter re-entered and fully debriefed participants and asked them not to discuss the experiment with their colleagues. Approximately two years later participants were once again invited to the laboratory to complete the GCS and CSS. The reason for this considerable time interval was twofold. First of all, with this period, we tried to avoid carry-over effects from the false confession experiment to the GCS and GSS. In contrast to the CEQ, DES-C, and CFQ, it is easy for participants to see that the GCS and GSS are highly relevant to the false confession experiment. Secondly, gathering GCS and GSS data two years later mimics real world conditions. After all, during a judicial procedure, it takes months before an expert witness comes into play (Gudjonsson, 2003). The disadvantage of this set-up was that only 34 participants could be reached and were willing to complete the GCS and the CSS.

\section{RESULTS AND DISCUSSION}

Results showed that confession rates were highest $(77 \%)$ in the high plausibility condition (i.e., the Windows-key) and were lowest (58\%) in the low plausibility 
condition (1.e. F12-key). This difference, however, was not significant: Fisher's exact $\mathrm{p}=.16$, two-tailed. Interestingly, internalization only occurred in the Windows key condition with $26 \%$ of the confessors showing internalization during their conversation with the confederate: Fisher"s exact $p=.01$, two-tailed. Table 1 shows mean scores on the GCS, GSS, CEQ, DES-C, and CFQ. These scores are well in line with those reported by previous studies using undergraduate samples (e.g., Cudjonsson, 1997; Merckelbach et al., 2000). To explore whether individual difference variables were related to absence or presence of false confessions (iie, signing the confession form), group means within each condition (i.e., F12- versus Windows-key) were compared, using independent samples t-tests. No significant differences between confessors and nonconfessors were found (all t's $<1.2$; all p"s $>.10$ ). Yet, when the data were collapsed across conditions, a significant difference between confessors and non-confessors with reglard to their CEQ scores was found $I t(54)=2.32, p=$ .02]. That is, false confessors scored higher on fantasy proneness than nonconfessors (means being 7.8 and 5.8 , respectively). No other significant group differences in individual difference measures emerged. Given the fact that there were only 6 participants who internalized, we did not compare internalizers versus others with respect to mean individual difference scores.

In line with a number of previously mentioned studies, aur results show that it is relatively easy to make participants confess, irrespective of the plausibility of the key they allegedly hit. Apparently, the sheer presence of a pseudo-eyewitness who claims to have seen that the participant touched the forbidden key is enough for many to confess. However, plausibility does affect internalization rates. Only when the act was plausible, participants tended to internalize the false confession (i.e., came to believe their fallse confession). Whereas, the internalization rate was lower than that found in chapter 6.1 (26\% versus $42 \%$, respectively), the figure of $26 \%$ accords well with the overall internalization rate $(28 \%)$ reported by Kassin and Kiechel (1996). Importantly, some tentative evidence was found suggesting a 
relationship between fantasy proneness and false confessions. No other significant connections were found.

Table 6.2.1: Mean scores of partichans in study i in each conditon, who did on

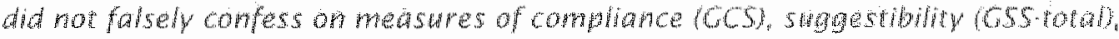

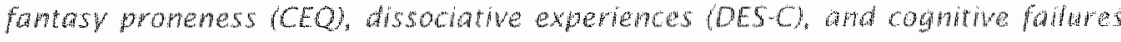
(CFQ) standard deviations (SD) are given between pavertheses.

\begin{tabular}{|c|c|c|c|c|}
\hline & \multicolumn{2}{|l|}{ F12key $(N=26)$} & \multicolumn{2}{|c|}{ Windows key $(N=30)$} \\
\hline & $\begin{array}{l}\text { Nont } \\
\text { confessors } \\
(n=11)\end{array}$ & $\begin{array}{l}\text { Folse } \\
\text { Confessors } \\
(n=15)\end{array}$ & $\begin{array}{l}\text { Nom } \\
\text { confessors } \\
(n=7)\end{array}$ & $\begin{array}{l}\text { False } \\
\text { Confessors } \\
(n=23)\end{array}$ \\
\hline $\mathrm{GCS}^{\circ}$ & $(S D=7,5, n=8)$ & $\begin{array}{l}8.8 \\
(S D=3.9, n=9)\end{array}$ & $\begin{array}{l}7.5 \\
(S D=7, n=2)\end{array}$ & $\begin{array}{l}9.2 \\
(S D=1.8, n=15)\end{array}$ \\
\hline $\begin{array}{l}\text { GSS } \\
\text { shift }\end{array}$ & $\begin{array}{l}2.6 \\
(S D=1,4, n=8)\end{array}$ & $\begin{array}{l}3.2 \\
(s D=4,1, n=9)\end{array}$ & $\begin{array}{l}1 \\
(S D=1,4, n=2)\end{array}$ & $\begin{array}{l}2,3 \\
(\mathrm{SD}=2, n=15)\end{array}$ \\
\hline CSS & $\begin{array}{l}7.6 \\
(S D=7,5, n=8)\end{array}$ & $\begin{array}{l}6 \\
(S D=5.2, n=9)\end{array}$ & $\begin{array}{l}3.5 \\
(S D=4.9, n=2)\end{array}$ & $\begin{array}{l}5.8 \\
(S D=3,1, n=15)\end{array}$ \\
\hline CEQ & $6(S D=2.8)$ & $8.1(S D=4.9)$ & $5.4(S D=1,6)$ & $7.7(5 D=3,9)$ \\
\hline DES-C & $\begin{array}{l}42.4 \\
(S D=10.9)\end{array}$ & $\begin{array}{l}40.3 \\
(S D=71.9)\end{array}$ & $\begin{array}{l}35.1 \\
(S D=15.8)\end{array}$ & $\begin{array}{l}40.6 \\
(S D=13.9)\end{array}$ \\
\hline SFQ & $\begin{array}{l}56 \\
(S D=8.6)\end{array}$ & $\begin{array}{l}53.7 \\
(S D=10.6)\end{array}$ & $\begin{array}{l}59.7 \\
(S D=8.6)\end{array}$ & $\begin{array}{l}54,3 \\
(50-7,4)\end{array}$ \\
\hline
\end{tabular}

"Oue to missing data, the number of participants differs from rotal $N$.

Aithough experimental studies have shown that it is relatively easy to elicit false confessions, critical points have been raised with regard to the traditional Kassin and Kiechel paradigm. For example, Forrest et al. (2002) argued that a computer crash does not involve any consequences apart from embarrassment. In contrast, falsely confessing to a crime usually leads to penalties of all sorts. With this in 
mind, we accused participants in study 2 of having caused the computer to crash and then they were told to pay for the damage.

\section{STUDY 2}

\section{METHOD}

PARTICIPANTS. Participants were 13 undergraduate psychology students. Of these, 4 were excluded after exit interviews had made it clear that they knew from the start the cover story was fake (e.g. because they had been warned). Thus, the remaining sample consisted of 9 participants ( 6 women) with a mean age of 19.6 years (range $18-21$ years).

MATERIALS. The same materials as in study 1 were used. Cronbach a's for the GCS, CEQ DES-C, and CFQ were .46, .59, 93 , and .84, respectively. As in study 1, GCS and GSS data were gathered approximately 2 years after the computer crash manipulation. We were able to locate 8 participants.

PROCEDURE. The procedure of study 1 was closely followed. Participants were told not to touch the "plausible" Windows-key. After the computer had crashed, they were told that they had to sign a written confession stating that they were being held accountable for the financial costs of the crash they had caused. Participants were told that costs would amount to about $€ 250$. 
Table 6.2.2. Mean scores of participants in stwhy 2 an measures of complance

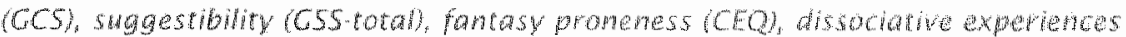

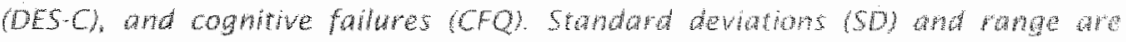
given between porentheses.

\section{Non confessors $(n=8)$}

\begin{tabular}{|c|c|c|}
\hline Gss-shift & $1.7(S D=2.0$, range: $02, n=7)$ & 6 \\
\hline $655^{\circ}$ & $5.4(S D=4,7$, range: $1-15, n=7)$ & 11 \\
\hline CEQ & $6.8(S D=3.2$, range: 3.11$)$ & 5 \\
\hline$D E S-C$ & $33.7(5 D=13.5$, range: 1152$)$ & 39.3 \\
\hline CFQ & $60.9(S D=10.9$, range: $44-76)$ & 64 \\
\hline
\end{tabular}

\section{False confessor $(n=1)$}

"Dowe tomissing dara, the number of partcipants differs from total $\mathrm{N}$

\section{RESULTS AND DISCUSSION}

Results can be summarized as follows. One participant was willing to sign a confession (11\%). In her conversation with the confederate, this participant did not show signs of internalization. Given the small sample size, formal statistical analysis was impossuble. For this reason, only descriptive data about the individual difference measures is given (see Table 2 ). Compared to mean scores of non-confessors, the false confessor had a higher 655 score, and, to a lesser extent, higher DES-C, and CFQ scores. However, the participant who falsely confessed did not have an elevated fantasy proneness score.

Whereas earlier studies relying on Kassin and Kiechel's paradigm found false confession rates up to $100 \%$, the false confession rate in the current study (11\%) was considerably lower. In any case, the figure of $11 \%$ is much lower than the $77 \%$ obtained in the high plausibility condition of study 1. Except for the consequences of confessing, study 2 and the high plausibility condition of study 
1 were highly comparable in terms of participant characteristics (e.g., age, educational level), procedure and so on. Therefore, we compared false confession rates, using the Fisher exact probability test. This yielded a significant difference (p. $=001$; two-tailed), indicating that articulating the consequences of failse confessions reduces the rate of this type of confession. In fact, the rate of $11 \%$ comes close to what has been found in field studies (Gudjonsson \& Sigurdsson, 1994; Sigurdsson \& Cudjonsson, 1996). Klaver et al."s (2003) laboratory study allso reports such low rates when a low plausibility event and minimization techniques were combined. Together, these data suggests that how people perceive the consequences of confessing may be a crucial determinant of whether or not they are going to confess (see also Kassin \& McNall, 1991).

of course, one could argue that the low false confession rate found in the current study cast doubts on the assumption that normal, healthy people can be easily brought to falsely confess. Note, however, that the undergraduates in our study were intelligent and critical participants. The simple fact that one of them falsely confessed, while accepting the consequences, demonstrates in our opinion that even in such populations, false confessions may arise. Still one could maintain that the typical Kassin and Kiechel experiment suffers from a lack of ecological validity (Inbau, Reid, Buckley \& Jayne, 2001). Being involved in an ergonomic study, in which one is falsely accused of having touched a key, is not what normally might happen to undergraduates. With this in mind, study 3 was conducted. Here, participants were accused of cheating on an exam for which they would be excluded from future exams. 


\section{STUDY 3}

\section{METHOD}

PARTICIPANTS. Twenty-two university undergraduate students served as participants. Six of them were excluded after exit interviews had made it clear that they had been familiar with false confession research. All in all, 16 participants ( 7 women) with a mean age of 19.4 years (range: $19-25$ years) participated in what they thought was a study on intelligence and certain personality variables. Participants were first screened on the Dutch version of the State Trait Anxiety Inventory-trait (STAI-t; Van der Ploeg, Defares \& Spielberger, 1980). It was anticipated that participants with a STAI-t score higher than 46 the third quartile) might experience the manipulation as too stressful. Consequently, 4 participants were not invited to take part in the next phase of the study, leaving 12 participants in the final sample. Undergraduates received 1 course credit for participating in this study.

MATERIALS. The same materials as in study 1 and 2 were used, except that now the DES (Bernstein, \& Putmam, 1986) instead of the DES-C was used. Cronbach $\alpha$ 's for the GCS, CEQ, DES, and CFQ were .41,.51, .91, and .91, respectively.

PROCEDURE. Participants were approached by an experimenter, carrying a stack of papers including the test materials and a sketch version of an upcoming exam. The experimenter showed the participants to the experimental room. Upon entering, he put the papers with the exam on top of the desk in clear sight of the participants. He then asked participants to sit down and briefly explained the goall of the study (e.g., "You are required to fill in two questionnaires and then complete the Raven's Intelligence Test"). After the participants had signed a consent form, the experimenter left the room, "forgletting" the stack of papers with the exam still on top of them. Participants began filling out the 
questionnaires. When they started with the intelligence test, the experimenter returned with the excuse that he had left some papers on the desk.

While leaving again, the noticed that one of the corners of the exam booklet was creased (i.e., false incriminating evidence). He then turned around and asked the participant whether s/he had looked in the exam, accusing the participant of having cheated. Initially, all participants denied the allegation. The experimenter left the room, saying that he was going to discuss further proceedings with the

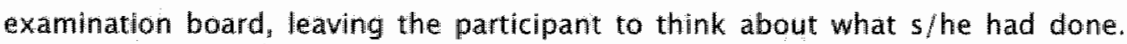
Approximately 5 min later, the experimenter returned saying that the examination board was in a meeting and right now had no time to discuss the issue with the participant. The experimenter then wrote down a statement (i.e." "I peeked at the exam and therefore committed exam fraud") and again accused the participant, arguing that the creased corner was clear evidence and that the examination board had informed him that refusing to confess would result in the participant not being permitted to take any upcoming exams until further notice. Participants were told that signing the confession would prevent the exclusion from the exams.

To explore whether participants would exhibit internalization, a confederate acting as if he were the next participant entered the room saying that he had been waiting for $15 \mathrm{~min}$. The experimenter acknowledged this, excused himself and left the room to get the course credit form. The confederate asked the participant why things had taken so long. If the participant said to have actually peeked at the exam, this was scored as internalization. All sessions were videotaped using two hidden cameras to verify that participants did not peek at the exam (but see below). Finally, all participants were extensively debriefed and explicitly instructed mot to talk with other students about the experiment as it would be of vital importance that future participants were naive as to the goal of the study.

In order to obtaim GCS and CSS data, participants were asked 5 months later if they were willing to participate in another experiment. To ensure that 
participants were in no way biased, the "second experiment" was introduced as separate and unrelated study and with another experimenter obtaining the data. Aglain, participants were thoroughly debriefed after this second session.

\section{RESULTS AND DISCUSSION}

of the 12 participants, one participant falsely confessed (8\%), while another participant actually did browse the exam, but did not read it. This participant confessed, albeit that she denied the browsing part and reported later that in her experience, she had falsely confessed (e.g., false denier). There were no indications that these participants had internalized their confessions. Given the small number of false confessors, no statistical analysis could be performed on individual difference measures. Therefore, the scores of these two individuals were compared to the data obtained from non-confessing participants by examining their individual scores (see Table 6.2.3).

Table 6.2.3: Mean scores of partidinats in study 3 on measures of complande (GCS), suggestibility (CS5-total, fantasy proneness (CEO), diswociatre experiences (DES), and cognitive fallures (CFO). Standard devations (SD) and range are given beween parentheses.

\begin{tabular}{|c|c|c|c|}
\hline & $\begin{array}{l}\text { Non } \\
\text { confessors } \\
(n=10)\end{array}$ & $\begin{array}{l}\text { False } \\
\text { confessor } \\
(n=1)\end{array}$ & $\begin{array}{l}\text { False } \\
\text { denier } \\
(n=1)\end{array}$ \\
\hline ccs & $8.5(S D=1.8$, range: $S=11)$ & 11 & 14 \\
\hline Gss.shift & $5.1(S D=2.1$ range: $2-9)$ & 3 & 1 \\
\hline GSS & $10.3(S D=3.7$, range: 5.18$)$ & 10 & 2 \\
\hline CEQ & $5.4(S D=2.4$ range: 2.9$)$ & 11 & 3 \\
\hline DES & $15.8(S D=10.5$, range: $3.6-42.7)$ & 18.8 & 8.2 \\
\hline CFQ & $64.1(S D=12.1$, range: $41-75)$ & 49 & 67 \\
\hline
\end{tabular}


Relative to non-confessors, the participant who falsely confessed and the false denier appeared to have elevated CCS scores. However, the false denier also had a low score on the GSS. The false confessor exhibited a different pattern. Compared to non-confessors, he had raised scores on the GSS and CEQ.

For the judicial context, falsely confessing to exam fraud is more ecologically valid than is falsely confessing that one has touched a forbidden key. This has to do with the element of, what lawyers term, mens rea, i.e., the presence of explicit intent to do what one is not supposed to do (Kassin \& Kiechel, 1996). Inspecting an exam that is not supposed to be inspected is purposeful behaviour. Touching a forbidden key might be an unintended sidei-effect of routine behaviour. The current study shows that even in a small sample of non-anxious and intelligent undergraduates, some people can be manipulated so as to falsely confess to evidently wrongful behaviour. Interestingly, there was also a false denier. Thus, the current paradigm is not only useful for studying false confessions and true denials, but also to explore false denials. Gudjonsson (2003) has recently pointed out that false denials form an interesting phenomenon. In large Icelandic college and university student samples, Gudjonsson (Gudjonsson et al., 2004a; 2004b) showed that about $14 \%$ of those who had been interrogated by the police reported that they had falsely denied.

\section{GENERAL DISCUSSION}

Our studies provide additional evidence for the clailm that one can induce false confessions in healthy, intelligent adults by using subtle tactics. That is, clever undergraduates falsely confessed in the laboratory, even if implausible acts, serlous consequences, or "mens rea" were involved. When serious consequences were involved, confession rates, as predicted, were lower and showed a remarkable resemblance with figures obtained in field studies (e.g.. Gudjonsson \& Sigurdsson, 1994; Sigurdsson \& Gudjonsson, 1996). 
There are good reasons to believe that in the real world, false confessions are strongly linked to interrogation tactics used by the police. Thus, Kassin and Wrightsman $(1985 ;$ p. 77$)$ have argued that pressured-compliant confessions are likely to occur with "powerful and highly salient techniques of social control". Alternatively, internalizations are expected when "more subtle, less coercive" techniques are used. In our studies, interrogations lasted only a few minutes, with participants being accused approximately twice. These accusations were accompanied by false incriminating evidence (e.g., eyewitiness or creased comer). All in all, the tactics used in the present studies were relatively mild compared to, for example, the techniques recommended by some interrogations manuals (e.g., Kassin, 1997). Nevertheless, our participants experienced the whole procedure as stressful. This may have contributed to the pressured-compliant confessions.

Clearly, our findings can also be related to the idea that people's choice to falsely confess or not depends on a cost-benefit analysis they make (Kassin \& MCNall, 1991). So, in the face of the interrogation tactics with which they were confronted (e.g., false evidence etc.), participants will have made an analysis of costs and benefits of confessing. Indeed, during informal interviews after the experiment, most confessors stated spontaneously that their confession was based on a weighing of pros and cons. For example, in our third study, the false confessor was convinced that eventually, the examination board would conclude that the accusations were unreasonable. So, he saw his confession as an easy way to escape from a painful situation.

In study 1, low plausibility was not related to a significantly lowered false confession rate. However, it was only with high plausible accusations that internalization of false confessions occurred. This is reminiscent of Pezdek, Finger, and Hodge"s (1997) work, which showed that full-blown false memories are easier to elicit when the target event is highly plausible (e.g., lost in a shopping mall) than when the target is a low-probability event (e.g., having had a rectal enema). 
A subsidiary aim of the present studies was to explore the relationship between false confessions and individual difference measures of compliance, suggestibility, fantasy pronemess, dissociative experiences, and cognitive failures. Note that the mean scores on these measures come close to those reported in earlier studies (Gudjonsson, 1997; Horselenberg, Merckelbach, Van Breukellen \& Wessel, 2004; Platt, Lacey; lobst \& Finkelman, 1998). Of these measures, only fantasy proneness appeared to be consistently related to false confessions, although in study 2, we also found same tentative evidence for heightened suggestibility levels (i.e., GSS) in the person who false confessed (see also Redlich \& Goodman, 2003).

At first sight, it seems odd that fantasy proneness rather than compliance (as indexed by the GCS) is related to false confessions. After all, the large majority of false confessions that we obtained were of the pressured-compliant type (Gudjonsson, 2003). That is, in only a few cases, we found indications that false confessors really came to believe their confessions (i.e., internalized their confession). On the basis of false memory literature, one would expect fantasy proneness to be related to such pressured-internalized confessions, as they can be conceptualized as full-blown false memories (see also Ost et al., 2001). One way to look at the connection between fantasy proneness and false confessions is to assume that the various types of false confessions (i.e., pressured-compliant and pressured-internalized) do not represent distinct categories, but rather points on a continuum. It may well be the case that an excellent ability to fantasize about a forbidden act contributes via reality monitoring problems to false confessions. Yet, these reality monitoring problems may not be robust and severe enough to be manifested in internalization. At low intensities, they might only give rise to doubts about one's memory and a pressured-compliant confession. With further interrogation and as fantasy-related reality monitoring confusion about the forbidden act grows, such a pressured-compliant confession may develop into a pressured-internalized confession, This point clearly warrants further study. 
On theoretical grounds, one could argue that compliance is related to pressuredcompliant false confessions, whereas suggestibility is related to pressuredinternalized false confessions (Gudjonsson, 2003). However, research addressing this issue has yielded mixed results. While it is true that several case (see for an overview, Gudjonsson ${ }^{2}$ 2003) and field studies (e.g., Gudjonsson \& Sigurdsson, 1994: Sigurdsson \& Gudjonsson, 1996) found evidence for a connection between compliance, suggestibility, and false confessions, recent work by Gudjonsson (Gudjionsson et al., 2004a; 2004b) falled to find any reiationship between these variables. Such a null finding was also reported in chapter 6.1. These authors speculated that individual differences in compliance and suggestibility may only come in to play when severe consequences of confessing are involved. Although our study 2 and 3 met this criterion, they did not yield impressive cues that false confessors are extremely compliant and suggestible individuals. One could, of course, counter that sample sizes in these studies were very small. But, then, in real court cases, the numbers are always small and the question arises to what extent compliance and suggestibility scores of a suspect convey diagnostic information about the probability of a false confessilon. This issue remains unanswered and warrants further study.

Some limitations of the present studies must be acknowledged. A major concern. besides the ethical issues, is the small sample size in studies 2 and 3 . We decided to stop these studies because some participants became distressed by the procedures. The small sample sizes make it difficult to be very precise about the prevalence rates of false confessions in the laboratory and they make it impossible to speculate about the causal antecedents of false confessions. Future studies should focus on the causality issue. Another shortcoming of our studies is their reliance on undergraduate participants. Thus, it would be highly informative to conduct false confession experiments with, for example, forensic patients, i.e., people who probably have elevated compliance and suggestibility scores. 
In sum, then, do false confessions occur when plausibility is low and consequences are serious? The answer is: Yes, they do. There are intelligient and healthy undergraduates who falselly confess under these circumstances. 
CHAPTER 7

Fantasy Proneness and Dissociative Experiences in Adults with Previouslife Memories

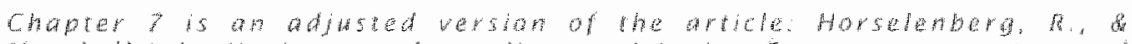

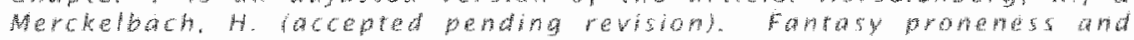
dissociative experiences in adtits with previouslife memories.

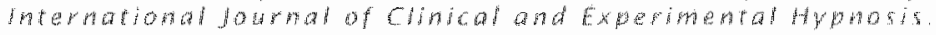




\section{ABSTRACT}

This study addresses the relationship between dissociative experiences, as measured by the Dissociative Experiences Scale (DES; Bernstein \& Putnam, 1986), and fantasy proneness, as measured by the Creative Experiences Questionnaire (CEQ; Merckelbach, Horselenberg \& Muris, 2001) in adults reporting previous-life memories. To this end, we recruited 43 clients from two private practices specialized in reincarnation therapy. As in previous studies, fantasy proneness and dissociation were correlated with each other. However, while the sample displayed elevated levels of fantasy proneness, their dissociation levels were quite normal. As well, fantasy proneness was related to the eccentricity of previous-life memories. Our data suggest that dissociative symptoms only contribute to implausible memory reports when they overlap with fantasy proneness.

\section{INTRODUCTION}

Although there is now considerable evidence from clinical as well as non-clinical studies that self reported childhood trauma goes hand in hand with elevated levels of dissociation, the interpretation of this relationship has lead to some controversy (e.g., Merckelbach \& Muris, 2001). Whereas many authors (e.g., Putnam et al., 1996) conceptualise the trauma-dissociation link in terms of direct causality (i.e., dissociation as coping strategy to handle traumatic childhood memories), other authors have argued that the causal directions implied might be more complex (e.g., Frankel "1996; Merckelbach, Horselenberg \& Schmidt, 2002; Giesbrecht \& Merckelbach in press). They pointed out that dissociative symptomatology overlaps with fantasy proneness (Hyman \& Billings, 1998; Silva \& Kirsch, 1992), and other personality traits like cognitive failures (Merckelbach, Muris, Horselenberg \& Stougie, 2000) and suggestibility (Ost, Fellows \& Bull, 1997: Wolfradt \& Mever, 1998). Under some circumstances (e.g., suggestive 
interviewing; hypnosis), these mediating traits may not only contribute to an exaggeration of self-reported trauma, but may even serve as antecedents of trauma self-reports (Merckelbach et al., 2002).

One clear limitation of most studies emphasizing the overfap between dissociative symptoms, on the one hand, and fantasy proneness and other traits (e.g., suggestibility), on the other, is that they relied on non-clinical samples. Thus, it remains to be seen whether the association between dissociative symptoms and fantasy promeness can be replicated in persons who seek help for their mental health problems. One particularly fruitful approach would be to explore the link between trauma reports, fantasy proneness, and dissociation in samples reporting memories of unlikely events. Recently; Clancy, McNally, Schacter, Lenzenweger, and Pitman (2002) followed this approach and examined people claiming to have been abducted by aliens. Interestingly, compared to controls, participants with memories of alien abduction had higher scores on mental absorption, which is a close cousin of fantasy proneness (Kihlstrom. Glisky \& Angiulo, 1994), but not on dissociation. This finding is reminiscent of that reported by Spanos, Cross, Dickson, and DuBreuil (1993) who also found that fantasy proneness plays a mediating role in UFO experiences. To be more specific, these researchers reported that UFO believers scoring high on fantasy proneness tended to have more elaborated UFO experiences than those scoring low on fantasy proneness. Unfortunately, 5 panos and co-workers did not focus on how dissociative symptoms relate to UFO experiences.

A category of memories that has hardly been studied systematically is that of previlous-life memories (see for a review, French, 2003). Spanos, Menary, Gabora, DuBreuil, and Dewhirst (1991) conducted a study in which they gave participants hypnotic suggestions to regress beyond birth to a previous life. As expected, those participants with relatively strong mental imagery abilities (e.g., fantasy pronenessi) generated more previous-life experiences. This finding was supported by a subsequent study of Spanos, Burgess, and Burgess (1994). Especially the high fantasy prone participants were found to produce detailed 
memories of previous lives under hypnosis and had difficulties separating fantasy from reality. Again, the authors did not focus on the possible contribution of dissociation. Such a relation was studied by Haraldsson and associates 2000; see also Haraldsson, 1995; 2003) in children in Sri Lanka who claimed memories of a previous-life. Whereas these authors did include a measure of dissociation, they failed to look at the contribution of fantasy proneness. The authors noted that their sample exhibited a heightened level of dissociation, as measured by the Child Dissocilation Checklist. Note that there is a distinct difference between these spontaneously reported previous-life memories and those produced by hypnotic regression. "The findings of Haraldsson, however, accord well with survey results by Ross and Joshi (1992). These authors showed that paranormal experiences, among which knowledge of past lives, are rellated to heightened levels of dissociation.

Taken together, the studies cited above provide some evidence that claims of paranormal experiences are connected to heightened levels of fantasy proneness and/or dissociative experiences. So far, no study looked at how these two constructs relate to each other in people with mentall health problems who claim paranormal experiences. The current study explored this relationship in a sample of people who reported previous-life memories during the course of reincarnation therapy. We expected that these people would show raised scores on dissociation and fantasy proneness. Furthermore, we hypothesised that the eccentricity of their previous-life memories would go hand in hand with elevated fantasy proneness and dissociation scores.

\section{METHOD}

\section{PARTICIPANTS}

Data were collected from 2 private practices specialised in past-life regression therapy to treat panic symptoms, psychosomatic complaints, and depressive feelings. In tatal, 43 of their clients (28 women) volunteered to complete a set of 
questionnaires and to answer a series of demographic items. Their mean age was 43.6 years (range 26 - 70 years). Before clients completed standard measures of dissaciation and fantasy proneness, we asked them a set of questions about their therapy. On average, participants had had 12.4 regression therapy sessions (rangle 2-50 sessions). More than half (i, $e_{2}, 58 \%$ ) of the participants said that they firmly believed that previous lives do exist. With the exception of one client, all clients recovered at least 5 distinct previous-life memories. Forty percent of the clients were convinced that these memories were accurate and reflected past realities. Eighty-eight percent of the past-life accounts were highly aversive and pertained to negative events (e.g., war experiences, murder, and illness).

\section{MATERIALS}

To assess their llevels of fantasy proneness and dissociation, participants completed the Creative Experiences Questionnaire (CEQ; Merckelbach, Horselenberg \& Muris, 2001) and the Dissociative Experiences Scale (DES; Bernstein \& Putnam, 1986), respectively. The CEQ $(\alpha=.81)$ is a 25 item yes/no self-report scale. Its items were derived from the extensive case descriptions of fantasy proneness provided by Willson and Barber (1982). Typical items are: "As a child, I could very easily identify with the main character of a story of movie" and "I can recall many accurrences before the age of three". The DES $(\alpha=, 87)$ consists of 28 items that pertain to dissociative phenomena (e.g., feelings of derealization, depersonalization, disturbances in memory). A sample item is: "Some people have the experience of driving a car and suddenly realizing that they don't remember what has happened during all or part of the trip. Mark the line to show what percentage of the time this happened to you". Respondents indicate on $100 \mathrm{~mm}$ Visual Analogue Scales (VASs: $0=$ not at all: $100=$ very much) the frequency with which they experience these symptoms.

Participants were also asked to write down one typical past-life memory that they had recovered during therapy. Whereas some participants gave relatively mundane descriptions (e.g., "I was an old woman, became ill, and died"), others 
came up with Romanesque summaries (e.g., There was a poisoned arrow shot in one of my eyes because I stole jewellery from Cleopatra"). Five blind raters, all of them psychologists, were asked to indicate on a $100 \mathrm{~mm}$ Visual Analogue Scale (VAS: 0 not at all. 100 very much) to what extent the previous-ife memory descriptions were eccentric. The average inter-rater correlation was .51 (range $37-.65 ;$ all $p ' s<.05$ ). Scores of the raters were averagled for further use.

\section{RESULTS}

Mean scores on the CEQ and DES were $9.2(\mathrm{SD}=4.7)$ and $12.8(\mathrm{SD}=8.2)$, respectively. Note that the CEQ scores were raised and were comparable to fantasy proneness levels that have been reported for patients with borderline personality psychopathology (Merckelbach, ampo \& Hardy, in press). On the other hand, the mean DES score was not raised and was highly similar to the average population score (i.e., 11.6 ) reported by Van Jzendoorn and Schuengel (1996).

Table 7.1: Pearson correlations between dissociation (DES), fantasy proneness (CEQ) and eccentricity of previous life memories.

\section{CEQ}

$.33^{t}$

$32^{\circ}$

\section{DES}

.26

DES

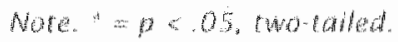

Table 7.1 shows Pearson correlations between fantasy proneness, dissociation, and the eccentricity of previous-life memories. As can be seen, there was a significant correlation between CEQ and DES, although the magnitude of this correlation was modest. As well, fantasy proneness, but not dissociation, was 
related to the eccentricity of previous-life memories. That is, the more eccentric previous-life memories, the higher the CEQ score.

\section{DISCUSSION}

Our findings show that reports of previous-life memories are accompamied by ellevated levels of fantasy proneness. Furthermore, fantasy proneness was found to be related to how eccentric these reports were judged by others. It is worthy to note that the large majority $(88 \%$ ) of these memories pertained to highly aversive events.

In our sample clients undergoing regression therapy, we replicated the wellestablished link between fantasy proneness and dissociation (e.g., Merckelbach et al., 2000; 2002). However, in contrast to what we anticipated, there were no elevated levels of dissociative symptoms in our sample, nor were dissociative symptoms related to the eccentricity of previous-life memories. In undergraduate samples, a positive relation between dissociation and experimentally induced false memories is often, albeit not consistently, reported (i.e. "Eisen \& Carlson, 1998; Hyman \& Billings, 1998, but see also: Ost, Vrij, Costall \& Bull, 2002: chapters $3,4,5,6.1$, and 6.2). Yet, in clinical samples, this relation seems to be more fragile. For example, Clancy et al. (2002) found that their sample of people reporting alien abductions displayed normal dissociation levels.

As was true for the studies of Parnell (1988) and Spanos et al. (1991: 1993), fantasy proneness was found to be linked to reports of unlikely events. Spanos and colleagues $(1993 ;$ p. 631$)$ argued that prior beliefs are necessary for this category of memories and that fantasy promotes "confusion between intermally produced images and sensations and externally events (e.g. experiences that occurred at night and in association with sleep)". A slight majority of our participants (58\%) had firm a priori belleves about previous-life memories, and so, our data are in line with the idea that fantasy proneness fosters prior beliefs, which in turn contribute to recovered memories of unlikely events. In addition, 
once people have such memories, fantasy proneness might determine how eccentric these memories are.

The current study showed that reports of previous life memories are related to fantasy proneness, but not to dissociative symptoms, although these traits do overlap to some extent. This suggests that there might be different varieties of dissociative symptoms, namely those that include fantasy proneness and those that do not (e.g., Kihlstrom et al., 1994). In this context it is interesting to note that some authors (e.g, Barrett, 1992) have made a distinction between two types of highly hypnotizable participants: fantasisers and dissociators. The first type would recover rich and vivid pseudomemories under hypnosis, while the second exhibits amnesia for their hypnotic experiences. Obwiously, our sample of regression therapy clients had more fantasisers than dissociaters. In more general terms; our data suggest that dissociative symptoms do contribute to reports of unlikely traumatic events, but only so if these symptoms include fantasy proneness. This would explain why studies have come up with such inconsistent results when they tried to link dissociative levels to participants' propensity to develop false memories. 
CHAPTER 8

General Discussion 


\section{INTRODUCTION}

Two issues inspired the studies presented in this thesis. The first concerned techniques for eliciting pseudomemories. The other whether certain personality characteristics play a modulating role in the occurrence of such memories. In this chapter, the main results of the various studies will be summarised and some concluding remarks will be drawn. Furthermore, future research directions will be discussed.

\section{PSEUDOMEMORIES AND PERSONALITY CHARACTERISTICS}

When students read out names of non-famous individuals, and the next day are asked to indicate whether the names presented on a computer screen belong to famous or non-famous people, they tend to attribute fame to the names they read out the day before. This so-called false fame effect is a memory illusion, but no evidence was found that it is related to fantasy proneness, absorption, or dissociation. Study 1 (chapter 3) did, however, find a modest correlation between self-reported depressive symptoms and the false fame effect. After imagining a fictitious childhood event, students rate the plausibility of this imagined event higher than they did before the act of imagining. This memory illusion is known as the imagination inflation effect. Here, individuals with better imagery abilities were found to display a larger imagination inflation effect (study 1 , chapter 4). In a surprise recognition task of their own diary records, students perform relatively well. However, when foil-items were given, their performance dropped significantly. Surprisingly, fantasy proneness was related to superior (i.e., more accurate) recognition performance (chapter 5 ). When falsely accused, a disturbing proportion of students were willing to accept guilt, falsely confessed, and started to believe that they carried out the forbidden act, even when they were aware of the consequences related to their confessions. Some indications were found that 
fantasy proneness was associated with false confessions (chapter 6.2). Adults reporting previous-life memories had elevated levels of fantasy proneness. Furthermore, the more eccentric these memories were, the higher participants scored on fantasy proneness (chapter 7).

Taken together, our studies demonstrate a point that many prominent researchers - among them Elizabeth Loftus $(2003 \mathrm{a}, \mathrm{b})$ - have made: it is not very difficult to create pseudomemories in a healthy, critical, and smart students. As Loftus $(2004, p .147)$ puts it: "There is now ample evidence that people can be led to believe that they experienced things that never happened [...] [or] can be led to believe in experiences that are highly unlikely to be true le.g., witnessing demonic possession, being abducted by aliens [...])."

The studies presented in this thesis also demonstrate another issue, namely our failure to find key personality characteristics that might explain why some people are more susceptible to pseudomemories than are others. Why was it so hard to pinpoint such characteristics? And when correlations between pseudomemories and personality characteristics occurred, why were they so inconsistent? There are three points that should be considered. Firstly, not all paradigms used in the current studies might have been sensitive enough to detect individual differences. Secondly, the inconsistent findings might have to do with the content of the distorted memories. The final consideration concerns the fact that the majority of the studies reported relied on student samples. These points will be briefly discussed in the following paragraphs.

\section{SENSITIVITY OF PARADIGMS}

The question can be raised whether typical laboratory studies, such as the DRM paradigm (see chapter 2 for details) or the false fame procedure, possess enough ecological validity to serve as an analogue to what happens in a therapeutical setting (Freyd \& Cleaves, 1996; Pezdek. 1994). After all, many recowered memories emerge during psychotherapy (Van Koppen \& Merckelbach, 1999) and 
they are the impetus for studying pseudomemories in the laboratory to begin with (e.g., Lindsay \& Read, 1994, Poole, Lindsay, Memon \& Bull, 1995). When certain laboratory paradigms fall to serve as an analogue of real-life pseudomemories, can they then be sensitive enough to study personality characteristics?

A common expllanation for the memory illusions obtained with the DRM paradigm is that they are based on a feeling of famillarity (Blair, Lenton \& Hastie, 2002). in chapter 3 , the false fame paradigm was used to elicit pseuldomemories. Basically, the false fame effect occurs because source monitoring is corrupted through vague feelings of familiarity. Accordingly, it is a very pure laboratory manifestation of a source monitoring error and, in some respects, is comparable to the DRM paradigm. However, it is safe to assume that in clinically relevant pseudomemories, it is vividness, detaildness, and emotionality rather than sheer famillarity that contribute to source monitoring errors The personality characteristics that were measured bear relevance to vividness, detailedness, and emotionality (Destun \& Kuiper, 1996), but is not at all obvious that they promote feelings of familiarity. Thus, in retrospect, the false fame paradigm might not be very suitable to study the link between personality characteristics and memory illusions in student samples.

Increased familiarity is also said to play a role in the effects of imagining (see chapter 4), but imagination has an element of content. Although imagining mimics reality in that it is an often used procedure in therapy (e.g.. Poole, Lindsay, Memon \& Bull, 1995; Health Council of the Netherlands, 2004), the imagination inflation paradigm is not a genuine memory distorting paradigm. Rather it is a procedure that creates a shift in subjective confidence whether a fictitious childhood event occurred before the age of 10 years (e.g. Garry. Sharman, Wade, Hunt \& Smith, 2001). More precisely, subjective confidence inflation reflects a belief, not a full-blown pseudomemory. Several authors (Scoboria, Mazzoni, Kirsch \& Relyea, 2004; Smeets, Jellicic, Horselenberg \& Merckelbach, in press) have suggested that a belief follows a plausibility 
judgement, but precedes memory creation (see also Hyman \& Kleinknecht, 1999). So, we suspect that the personality characteristics that were focused upon are more geared to the content of (pseudo-) memories than to subjective confidence. With this in mind, the imagination inflation paradigm would gain in sensitivity if the effects of imagining would be studied with other outcome measures than just subjective changes in confidence. For example, what would happen if participants imagined that they experienced a frightful moment with a spider when they were young and they would later have to perform a Behavioural-Approach Test (BAT; Arntz, 1993)? Would a change in subjective confidence have implications for behaviour? And would fantasy-related personality characteristics modulate such an effect?

It was expected that the degree of manipulation of participants' memories would be important for making the role of personality characteristics visible. In this thesis, the intensity of the manipulation was raised, thereby making the paradigms more sensitive to the potential effects of such characteristics: Indeed, when studying false confessions and highly unlikely memories (created by hypnotic manipulations of a therapist), fantasy proneness turned up as a correlate of memory illusions.

\section{CONTENT OF MEMORIES}

Another possibility that warrants consideration is that personality characteristics do or do not come into play depending on the content of the manipulated memories. Perhaps, then, connections between fantasy proneness, dissociation, and so on and pseudomemories only become evident with autobiographical themes. Tentative evidence for this line of reasoning can be found in the work of Platt, Lacey, lobst, and Finkelman (1998). These authors compared performance on the DRM paradigm with performance on an autobiographicial memory task referring to the O.J. Simpson-trial. Although memory distortions on both tasks were strongly correlated with each others, the contribution of personality 
characteristics to distortions was only evident in the case of autobiographical recollections such that memory distortions were positively related to absorption scores. We hasten to add that this is not the full explanation, a point illustrated by Whinson and Hyman (1998; experiment 2). These authors also contrasted performance on an autobiographical task with the DRM paradigm and related both tasks to personality characteristics. First of all, Wilkinson and Hyman failed to find a relationship between memory performance on one task and that on the other task. Secondly, they reported that different aspects of dissociation were related to either source judgements for the autobiographical memory task or intrusions during recall of the word list task. Note that the study of Platt et all. (1998) relled on a task tapping personally irrellevant flash bulb memories, whereas Wilkinson and Hyman (1998) used autobiographical material which was personally relevant.

Germane to this issue of autobiographical memory is the recent work of McNally and co-workers (Clancy, MCNally \& Schacter, 1999; MCNally; Clancy, Pitman \& Schacter, 2000; MCNally, Clancy \& Schacter, 2001). These authors inwited wamen reporting repressed (e.g., they believed they had been sexually abused), recovered (e.g., they reported sexual abuse after periods of having been unable to remember this), or continuous. (e.g., they had always remembered the sexual abuse) memories of childhood sexual abuse to their laboratory. There can be little doubt that these autobiographical memories were personally relevant. The authors showed that participants from the recovered and repressed group scored significantly higher on absorption and dissociation than those reporting continuous memories, who, in turn, scored higher on these measures than a control group reporting no sexual abuse. When participants from the recovered memories group were given a guided imagery task (Clancy et al., 1999), though, they failed to exhibit the traditional imagination inflation effect in contrast to the controls. Furthermore, when engaged in a directed forgetting task (e.g., participants were instructed to either forget or remember words presented on a computer screen; McNally et al., 2001), they performed similarly to controls (see, 
for a replication: Geraerts, Smeets, Jelicic, Van Heerden \& Merckelbach, submitted). By and large, these studies show that people with recovered or repressed memories score differently on various personality measures compared to controls. What these studies do not demonstrate is that these personality correlates are causally involved in the creation of (pseudo-) memories. Also, it was impossible to determime whether the recovered or repressed memories were genuine or false.

To overcome this problem, Clancy, McNally, Schacter, Lenzenweger, and Pitman (2002) recently examined pseudomemary creation in people reporting the highly unlikely event of being abducted by space aliens. They divided this group into those who actually had recovered such experiences $(n=11)$ and people who merely believed they had been abducted but had no memories of such an episode $(n=9)$. Both groups were compared to people denying being abducted by allens $(n=13)$. The DRM paradigm (see chapter 2) was used to evoke false recall and false recognition. It turned out that, relative to the control group, individuals with recovered or repressed memories of alien abduction exhibited more false recall and recognition; yet, similar levels of correct recall and recognition performance. Because Clancy and co-workers found in earlier studies (cf. supra) that the recovered and repressed groups scored significantly higher on absorption and dissociation than control, it was predicted that these groups would do so too. However, whereas the abductees indeed had raised scores on the absorption subscale, they did not have elevated levels of dissociation. With regard to depression scores, though, individuals reporting recovered or repressed memories of aiten abductions reported more symptoms than controls. Note that these findings were only partly confirmed by a study of McNally, Lasko, and Clancy (2004). In this recent study, individuals reporting being abducted by aliens scored higher on both absorption and dissociation, but lower on depression than controls. The findings reported in chapter 7 are comparable to those found by Clancy et al. (2002). In the exploratory study on previous-life memories that was described in that chapter, no elevated levels of dissociation were found. However, 
reporting previous-life memories was accompanied by raised levels of fantasy proneness: Meanwhile, the study in chapter 7 described initial resuits and only recently a more systematic study on previous-life memories was finished. Below, the results of that study will be summarized.

\section{A PREVIOUS-LIFE INTERMEZZO}

In order to recruit participants with previous-life memories, six reincarnation therapists in the district of Maastricht were contacted. Eventually, 13 clients (2 men) claiming previous-life memories volunteered to participate in our study. Their age ranged from 33 to 62 years $(M=44.7 ; S D=9.7)$ and their mean years of education was $14(S D=1.6)$. The control group also consisted of 11 women and 2 men ranging from 32 to 62 years of age $(M=44.9 ; S D=9.2)$. On average, controls had $14.2(\mathrm{SD}=1.4)$ years of education. Both groups did not differ in age or education [t $(24)$ 's $<1.0$ ].

Participants completed the Dissociative Experiences Scale (DES), Creative Experiences Questionnaire (CEQ), Cognitive Failures Questionnaire (CFQ), and the Symptom Check List-90 (SCL-90; Derogatis, Richels \& Rock, 1976). This latter test is a measure of general psychopathology and exists of several subscales, like depression and somatisation. Mean scores on these questionnaires are given in table 1. The reincarnation group scored significantly (two-tailed) higher than the control group on the DES, $t(24)=2.7, p=.01$, on the CFQ, $t(24)=2.4, p=.02$, on the $\mathrm{SCL}-90, \mathrm{t}(24)=3.5, \mathrm{p}=.002$, and on the $\mathrm{SCL}-90$ depression subscale, $\mathrm{t}$ $(24)=3.5, p=.002$. As for the CEQ, the reincarnation participants had marginally higher scores than the controls: $t(24)=1.7, p=.09$. So, like Clancy et al. (2002), we found that memories of highly unlikely events go hand in hand with elevated levels of depression and psychopathological symptoms in general. Moreover, such reports were also accompanied by elevated levels of dissociation and cognitive fallures. However, in the sample of reincarnation people described in chapter 7 , we did not find heightened levels of dissociation, although they 
exhibited raised fantasy proneness levels. Furthermore, in the current sample, that was smaller than that in chapter 7. fantasy proneness only marginally differed between normals and individuals reporting previous-life memories.

Table 8.1. Psychometric data of the reincarmation and wontol group.

\begin{tabular}{|c|c|c|c|c|}
\hline \multirow[b]{2}{*}{ Measure } & \multicolumn{2}{|c|}{ Reincarnation group } & \multicolumn{2}{|c|}{ Control group. } \\
\hline & $M$ & so & $M$ & SD \\
\hline \multicolumn{5}{|c|}{ Dissociative Experience } \\
\hline Scale & 18.9 & 11.7 & 9.7 & 4.9 \\
\hline \multicolumn{5}{|c|}{ Creative Experience } \\
\hline Scale & 9.2 & 4.2 & 6.3 & 4.4 \\
\hline \multicolumn{5}{|l|}{ Cognitive Failures } \\
\hline Questionnaire & 41.6 & 12.6 & 30.5 & 10.6 \\
\hline$S C L-90$ & 141.9 & 37.8 & 101.9 & 19.6 \\
\hline \multicolumn{5}{|l|}{ SCL -90} \\
\hline Depression scale & 28.3 & 7.4 & 20 & 4.7 \\
\hline
\end{tabular}

Our fresh sample of reincarnation and control participants underwent a false fame task (see chapter 3). In Figure 8.1, proportions of old and new nonfamous names judged as famous are given. Proportions were calculated in the same way as in chapter 3. A 2 (group: reincarnation vs. control) $\times 2$ (false fame: old vs. new nonfamous names) Analysis of Variance (ANOVA) with repeated measures on the last factor yielded a highly significant false fame effect [F $(1,24)=9.7, p=.005]$, a highly significant main effect of group $[F(1,24)=56.3, p=.001]$, and a significant interaction effect $[F(1,24)=5, p=.03]$. Thus, the new data shows that the reincarnation group displayed a stronger false fame effect and therefore made more source monitoring errors than a comparable control group. 


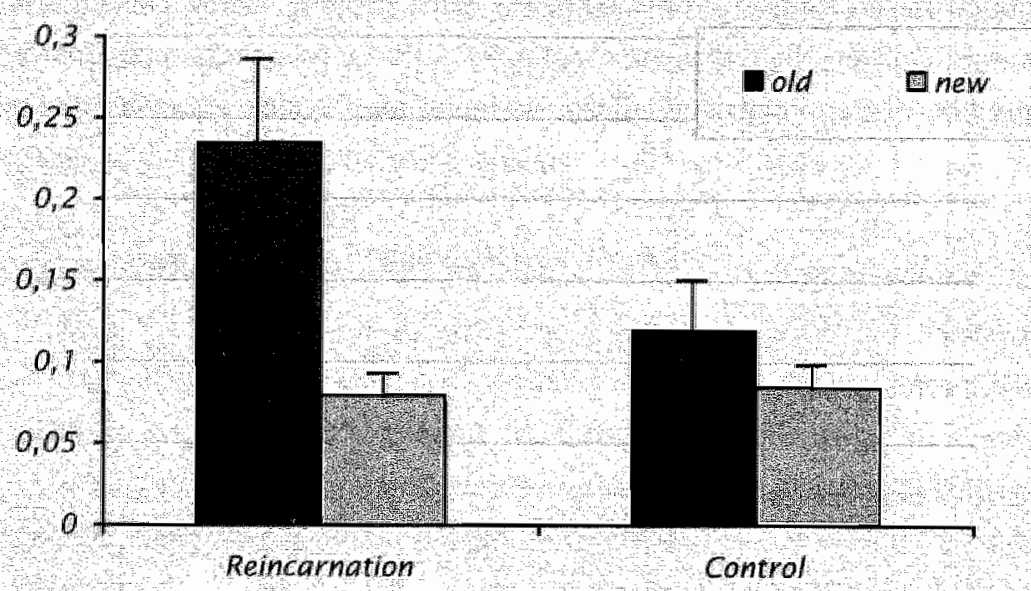

Figure 8.1: Propartion of old and hew nomfomas names falsely identifed as famous by the reincarnation and control group (MSEs are given in thats).

As was done in the false fame studies in chapter 3 , a false fame index was calculated by subtracting the proportion of new nonfamous names judged as famous from the proportion old nonfamous names judged as famous (range: .58 to .10; see Rybasch, Rubenstein \& Deluca, 1997). Again, the difference between the reincarnation and control group was significant $[t(24)=-2.3, p=$ $.034 \mathrm{~d}$ and the effect size was large (Cohen's $d=.82$ ).

All in all, data reported by Clancy, MeNally and co-workers (cf. supra) and our most recent data on previous-life memories support the idea that if one wants to explore how personality characteristics relate to pseudomemories, this can best be done by selecting people with highly unlikely, yet personally relevant autobiographical memories. 


\section{TYPE OF PARTICIPANTS}

The inconsistent findings as to whether personality characteristics are associated with pseudomemories might also have to do with the type of participants that figured in the present studies. Although pseudomemories were ellicited, this was primarily done in student samples. When we decided to test another sample, the expected links between personallity characteristics and pseadomemories emerged (see chapter 7). The case study below demonstrates why it might be fruitful to look at people with extreme scores on the personality characteristics of interest (e.g., suggestibillity).

In December 2003, a counsel asked us whether a client of him could be tested in our laboratory. His client, Mr. X, obtained a large shed from his father a few years ago. Because he wanted to earn some money with it, he decided to let the shed to a close friend of him, Mr. Y. This Mr. Y wanted to implement some changes in the interior of the shed and, therefore, $\mathrm{Mr}$. $X$ bought renovation materials. He also changed the locks, which was another request of Mr. $Y$. One day "Mr $\mathrm{X}$ drove by the shed, with Mr. $Y$ on the passenger seat, and saw a crowd gathered in front of the building. Mr. $Y$ immediately asked to drive him home, and after that, to return to the shed. By the time Mr. X had returned to the shed and got out of the car, he was arrested by the police because he was the owner of the building. It appeared that there was a fire in the shed, detected by a concerned neighbour. When the fire brigade entered the building, they found an XTC laboratory capable of producing a considerable amount of XTC tablets.

Mr. X was accused of the production of XTC in his shed. After all, he had made the building suitable for XTC production and the renovation materials were bought by him, as a bill for these materials was found in his car. He was interrogated for several davs. During these interrogations, several tactics like good cop/ bad cop and maximization and minimization were used, eventually ending up in self-incriminating statements. These statements, however, were immediately retracted by him. Nevertheless, based on his confessions and other 
evidence, the court sentenced $\mathrm{Mr}$. $\mathrm{X}$ to several years in prison. He served his time im prison before coming to our lab. During an interview with us, $\mathrm{Mr}$. $X$ was asked why he had made a suspect statement. He stated that he wanted to end the horrible interrogations and was convinced that when the police searched further, they would find out themselves that he was innocent. Interestingly, this is a common as sumption of peaple who made such a statement (Gudjonsson, 2003). It is not impossible that Mr. X made a coerced-compliant false confession (see chapter 6.1 and 6.2). Based on the extensive work of Gudjonsson, Mr. X's suggestibility (CSS) and compliance (GCS) were measured. Furthermore, his fantasy proneness was measured (CEQ). Figure 8.2 shows his positions on these scales. As can be seen, Mr. X not only had elevated levels of suggestibility (15), but also had a very high score on the compliance scale (17).

The pattern manifested by Mr. $X$ is, indeed, highly comparable to that described by Gudjonsson (2003; see for example figure 14.1 on p. 406)" "Gudjonsson's (2003) data suggest that there is a linear relationship between scores on the CSS and GCS and whether one resists to false confessions. False confessors have extremely high scores on these tests. On their own, these scores don't mean much, though. First of all, "it is only by implication that one can suggest [...] that the resister's' low suggestibility and compliance scores and the alleged false confessors" high scores-influenced their behaviour at the time of the police interrogation" (Gudjonsson, 2003; p. 407). Secondly, fallse confessions are unlikely to be caused by single factors such as suggestibility or compliance which make one susceptible. These personality characteristics interact with other factors like the "seriousness and nature of the alleged offence, the circumstances and nature of the interrogation and confinement, and the subjective experiences and interpretations of the suspect" (Gudjonsson, 2001; p. 591). 


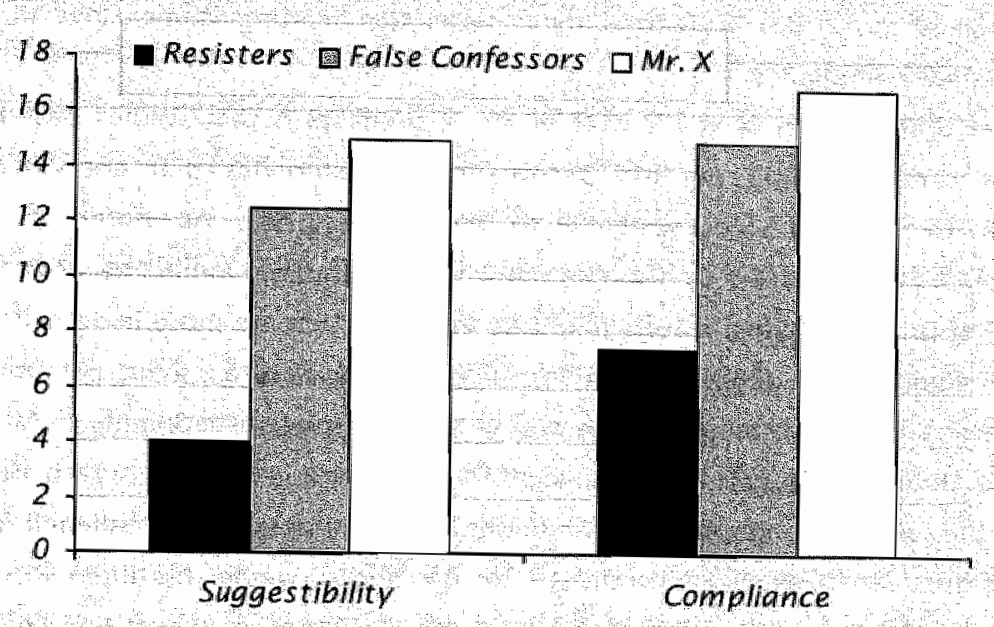

Figure 8.2: Suggestibily and compliance scores of resisters. folse confessors and MrX.

Interestingly, besides his impressive suggestibility and compliance scores, Mr. $X$ had an elevated level of fantasy proneness. In the study described in chapter 6.2, we found some indications that this factor is related to falsely confessing. Furthermore, the psychometric profile of the false confessor described in study 3 of chapter 6.2 shows remarkable resemblance with that of Mr. X. That fantasy proneness is involved in coerced-compliant false confessions is a new finding. The mechanisms that underlie this involvement, are not clear. Yet, recent work of Sảnchez-Bernardos and Avia (2004) indicates that especially the more benign components of fantasy proneness, i.e., vividness-intensity of fantasy and makebelieve/suggestibility, are associated with agreeableness, one of the factors of the Big Five (Costa \& McRea, 1992). Agreeableness, in turn, is closely related to reducing negative affect and self-control in interpersonal situations Jensen- 
Campbiell et all 2002). Note that these latter two features come close to the definition of compllance.

However that may be, what the case of $\mathrm{Mr} . X$ suggests is that studies based on student samples might not tap personality characteristics that are extreme enough to modulate susceptibility to pseudomemories. As noted in the discussion of chapter 6.1 , if the computer crash paradigm would be used in a sample of prison inmates, results might be expected that are more in accordance with Gudjonsson"s (2003) position, notably, the idea that personality characteristics such as suggestibility and compliance fuel susceptibility to falsely confess. Unifortunately, $M r, X$ did not want to take part in a computer crash study. Yet, in the future, running such a task might be revealing in cases of alleged false confessions. One excellent candidate to be tested would be Kees $B_{*}$ the defendant who was wrongfully convicted for the murcler of an eleven vear old girl named Nienke Kleiss because, amongst other things, he confessed for further detalls, see Van Koppen, 2003).

\section{FUTURE RESEARCH}

Although it is clear that pseudomemories can be elicited relatively easy, it remains obscure which factor(s) influence(s) such memories most. Taken together, research on internal factors (i.e., personality characteristics) largely reported mixed findings, whereas research based on external factors (i.e., experimental approach) revealed consistent findings. The merits of the internal and external approaches of pseudomemories have been extensively discussed by Schooler and Loftus (1986; 1993) and Gudjonsson (Cudjonsson \& Clark, 1986; Gudjonsson, 2003). Based on the bulk of research on pseudomemories, one cannot conclude otherwise than that the score so far in this discussion is in advance of the approach stressing extemal factors (i.e., manipulations such as hypnosis, imagination etc.). Are there other factors that may sensitize people to develop pseudomemories? Recently, researchers have drawn attention to a 
number of under researched factors that possibly influence memory performance. These are sleep distortion, psychopathology, lack of short term memory, and the social context of recall. Why these factors are of interest is explained in the following paragraphs.

\section{SLEEP DISTORTION}

There are substantial individual differences in sleep experiences, like sleep quality and quantity, sleep schedule, and dream recall. These differences are stable over time and consistent across contexts. Furthermore, good dream recall is associated with higher scores on measures of fantasy proneness, creativity, absorption, dissociation; schizotypy, and openness to experience (Watson, 2001). Heightened levels of dissociation, in turn, have been linked to reports of sleep phenomena like vivid and unusual dreams, narcolepsy, and nocturmal experiences (Ciesbrecht \& Merckelbach, 2004; Watson, 2003).

Watson (2001; see also Thalbourne \& Houran, 2000) argues that the overlap between sleep-related experiences, on the one hand, and measures such as dissociation, fantasy proneness, and schizotypy, on the other hand, define a common domain of intense and unusual cognitive-perceptual phenomena. That is, individuals high on these traits change from a relatively normal or realitybased state to a more sleep-based state of awareness (e.g., daydreaming) more easily than those low on these traits. These labile sleep-wake cycles are context dependent, yet, resullt in dissociative episodes (McCreery, 1997).

Distorted sleep might be the origin of dissociative experiences, fantasy proneness, and cognitive failures (Giesbrecht \& Merckelbach, 2004). So far, the relationship between sleep distortion and pseudomemories has not received much attention. There is some indirect evidence, though, that sleep deprivation leads a decrease in alertness and performance (e.g., Jewett, Dijk, Kronawer \& Dinges, 1999) and an increase in suggestibility (Blagrove, 1996). Researchers 
would be well-adwised to look at the association between sleep experiences and pseudomemories in their future studies.

\section{PSYCHOPATHOLOGY AND MEMORY}

We have argued that fallure to find clear personality correlates of pseudomemories has to do with the fact that most studies in this thesis relied on student samples. Pseudomemories have been extensively studied in people suffering from dissociative disorders or Post Traumatic Stress Disorder "If one takes a closer look at other forms of psychopathology, there are at least two disorders that warraint future study. These are depression and obsessivecompulsive disorder. Both disorders have been related to memory problems, albeit not to pseudomemories in particular (Roediger \& McDermott, 1992; Merckelbach \& Wessel, 2000). That these disorders might be related to pseudomemories will be explained below.

It is often thought that depression produces a decline in cognitive resources (Estes, 1998) thereby producing memory deficits. Indeed, Hertel and Rude (1991) observed that depressed participants were impaired relative to controls on a task that required recall of specific words embedded in sentences they had read during a study session. More specifically, recall, but not recognition, was. impaired in depressed participants (Hertel \& Milan, 1994). Another typical memory deficit consistently found in depression is overgeneralized autobiographical memories (e.g., Van Vreeswijk \& De Wilde, 2004). That is, relative to non-clinical samples, clinically depressed individuals are less specific when they are asked to respond with autobiographical memories to cue words (e.g., happy, clumsy, etc). Thus, when it comes to recall, depressed individuals are particularly prone to making mistakes. There are severall pathways along which depression might promote the development of pseudomemories. For example, disrupted sleep (e.g.. insomnia, cf. supra) is a very common symptom in major depression (Watson, 2001; cf. supra). Furthermore, dissociative 
symptoms overlap with the tendency to endorse fictitious autobiographical items; but it is also true that a large proportion of individuals with a dissociative identity disorder have co-occurring psychopathology such as depression (Gianaway, 1995). However, it might not be source monitoring errors per se causing pseudomemories in depression. Or, as Estes states (1998; p. 619): "Much more [...] research will be needed to support [...] the view that depression [...] produces effects on standard measures of memory by reducing tendencles to produce voluntary actions, including rehearsal and direction of selective attention, that are important to test performance."

As for individuals with an obsessive-compulsive disorder (OCD), pathological doubt about one"s memory is often found to accompany this disorder (Tolin, Abramovitz, Brigidi, Amir, Street \& Foa, 2001). For example, patients with OCD frequently report uncertainty about whether they have performed actions correctly, have committed infractions, or have contacted contaminants. In an attempt to reduce their doubts "OCD patients are likely to engage in compulsive behaviours such as checking, washing, assurance seeking, and repeating activities (Rachman \& Hodgson, 1980), which in turn, paradoxically, lead to more doubts (Van den Hout \& Kindt, 2003a,b).

These doubts are related to a lack of confidence that OCD patient have in their memories. Among the first to test this idea were McNally and Kohlbeck (1993; see also Constans, Foa, Franklin \& Mathews, 1995; Foa, Amir, Gershuny, Molnar \& Kozak, 1997; Hermans, Martens, De Cort, Pieters \& Eelen, 2003; MacDonald, Antony, Macleod \& Richter, 1997; Merckelbach \& Wessel, 2000; Radomsky \& Rachman, 1999; Radomsky, Rachman \& Hammond, 2001; Tolin et al., 2001). They, indeed, found that obsessiwe-compulsive checkers tended to express less confidence in their memories than did control patients. However, checkers' memory and reality monitoring performances did not show any deficiencies compared to control patients.

Van den Hout and Kindt $(2003 a, b)$ argued that checking increases familiarity which in turn reduces vividness and detailedness of memories and therefore 
produces a lack of memory confidence. These authors found supporting evidence for their hypothesis. That is, repeated checking was not accompanied by decline of memory accuracy, but checking did result in less detailed and less vivid recollections, while memory confidence eroded. Mearwhile, it is known that familiarity undermines reality monitoring capacity, and therefore one expects to find a decrease of memory accuracy in OCD patients (Johnson et al., 1993).

A possible explanation for this apparent discrepancy could be that memory accuracy was incorrectly operationalized in the Van den Hout and Kindt $(2003 a, b)$ studies. Memory accuracy comprises several components (Smeets, Candel \& Merckelbach, 2004). Giving a correct response on a recall or recognition task is one ingredient of memory accuracy. Yet, distortions (changes of details of an existing element) and commission errors or confabulations (introductions of entirely novel elements; Gudjonsson \& Clare, 1995) are also relevant to accuracy. These elements are likely to be affected by reality monitoring errors. Until now little to no attention has been paid to these elements when measuring memory accuracy in OCD, or anxiety patients in general. It might well be the case that if these elements are taken into account, memory accuracy of people engaging in typical $O C D$ behaviour will be found to be deficient. Note in passing, that Giesbrecht, Merckelbach, and Smeets (submitted) recently reported a connection between thought suppression, a key feature of OCD, and dissociation.

\section{WORKING MEMORY}

Working memory plays a general role in assisting memory (Ruffman. Rustin, Garnham \& Parkin, 2001) and binds together parts of stimuli so that they are encoded into episodic memory and remembered together later on (Reinitz \& Hannigan, 2004). A limited working memory capacity might hamper encoding, resulting in memory gaps, which, in turn, are filled in by people. In this way, a reduced working memory capacity might result in confabulations (Brewin \& Saunders, 2001). 
Results of laboratory studies converge on the notion that dissociation may be related to a basic skill that does not have the avoidance of traumatic memories as its primary goal, but rather dividing attention (e.g., De Ruiter, Phaf, Elzinga \& Van Dyck, in press). Besides attentional abilities, dissociation may be linked to working memory. There are some indications for working memory deficits in individuals reporting elevated dissociative experiences (e.g., DePrince \& Freyd, 1999; Freyd, Martorello, Alvarado, Hayes \& Christman, 1998). Perhaps, cognitive mechanisms that seek to keep working memory free of irrelevant stimuli are weakened in dissociative individuals (Dorahy, 2001). In addition, the study of Waller, Quinton, and Watson (1995) offers further support for working memory deficits among high dissociators, especially when they are faced with emotional stimuli. Similarly, in a sample of forensic inpatients, Cima, Merckelbach, Klein, Schellbach-Matties, and Kremer (2001) found that heightened levels of dissociative symptoms were related to reduced working memory functioning. Yet, Giesbrecht, Geraets and Merckelbach (in press) did only find that certain aspects of working memory were inversely related to dissociation in a non-clinical sample.

On the other hand, recent work of de Ruiter and colleagues (De Ruiter et al., in press; De Ruiter, Phaf, Veltman, Kok \& Van Dyck, 2003) noted that superior working memory capacity (i.e., the ability to divide attention) goes hand in hand with heightened dissociative experiences. This finding is supported by Veltman et al. (in press). These authors recently conducted a fMRI study in which dissociative participants showed greater activity of brain regions related to working memory (i.e., the left middle dorsolateral prefrontal cortex) than controls. Interestingly, in order to explain their positive relation between dissociation and working memory, de Ruiter and colleagues (in press) argue that this link may be carried by fantasy proneness. They suggest that in order to engage in fantasising, a high working memory capacity is a prerequisite. Clearly, the precise connections between working memory, personality characteristics, and pseudomemories require more study. 


\section{MEMORY AS A SOCIAL CONSTRUCT}

Another point raised in the general discussion, concerned the sensitivity of paradigms used in this thesis. Germane to this issue is a novel and sensitive method to elicit memory illusion that was recently introduced and that strongly relies on the misinformation paradigm (Ayers \& Reder, 1998) and techniques used by Asch (1956). When two eyewitnesses discuss an event, they may influence each other and, in subsequent recall, report what the other said. This phenomenon has been described as social contagion of memory (Meade \& Roediger, 2002; Roediger, Meade \& Bergman, 2001), collaborative story telling (Crombag, 1999), or memory conformity (Gabbert, Memon \& Allen, 2003; Gabbert, Memon, Allan \& Wright, 2004). Since socially encountered misinformation produces more memory errors than misinformation from a nonsocial source, these studlies suggest that "it is not just misinformation per se that affects memory, but also how it is encountered" (Cabbert et al., 2004; p. 223).

Memory-based accounts (e.g., Belli, Lindsay, Galles \& McCarthy, 1994; Johnson, Hashtroudi \& Lindsay, 1993; Loftus \& Hoffman, 1989; Loftus, Miller \& Burns, 1978; Roediger et al., 2001; Zaragoza \& Lane, 1994) cannot fully explain why participants" reports often incorporate information learnt from others. In the study of Gabbert et al. (2003), the actual memory performance of people who had been exposed to social contagion and controls was similar. Also "the age of participants did not make them more susceptible to social contagion. Furthermore, as the studies of Meade and Roediger (2002) show, social contagion of memory persists when participants are explicitly warned about the possibility that other participants" responses might induce pseudomemories or even given the choice to attribute suggested items to other persions.

Even under stringent conditions, the social contagion or memory conformity effect is powerful enough to persist. Is this, then, a fruitful paradigm to further explore the relation between pseudomemories and personality characteristics? The recent work of Gabbert and colleagues (Gabbert, Memon \& Wright, 
submitted) does suggest so. In two studies, they found that susceptibility to memory conformity depends on response order. That is, the memory of the first to report an item that either adds, omits or contradicts a detail seen by a partner, even when the memory is disputed by the partner, is highly resistant to influence. In addition, the persons who are not the first to mention a critical item, thus hearing details that differ from their own memory, are highly susceptible to the report of the partner. Gabbert and co-workers suggest that traits like, for example, memory distrust, compliance, and a combination of extraversion of the partner and introversion of the participant might fuel this phenomenon. Note that such a relationship was already reported by Porter, Birt, Yuille, and Lehman (2000). Their results indicated that participants exhibiting more memory distortions score lower on extraversion in combination with a thigher extraversion score of the interviewer.

\section{FINAL REMARKS}

In this thesis, personality characteristics were implicitly conceptualized as antecedents of (pseudo)memories. But can this relation be reversed? Do the memories that people have affect their personality characteristics? In other words, is "the self a memory illusion" (Oakes \& Hyman, 2000; p. 64)? In the search for the self, memories and narratives play a vital role. After all, as these authors suggest, "the remembered self becomes the basic fabric of self that is communicated to others and used to plan for future" COakes \& Hyman, 2000; $p$. 45).

In this light, the recent work of Marsh and Tversky (2004) is relevant. They showed that when students retell events to their peers. $61 \%$ of their retellings were distorted (e.g., exaggerated, parts omitted or added, minimized). The kind of distortion strongly depended on the social context. Sharing facts reduces exaggerations, but increases minimization. In contrast, entertaining others with ones retellings vields the opposite pattern, namely an increase in exaggeration 
and few minimizations and omissions. When people try to elicit sympathy in others, more exaggerations occur in their narratives. These biased retellings, in turn, elicit biased memories (e.g., Hashtroudi, Johnson, Vnek \& Ferguson, 1994; Twersky \& Marsh, 2000).

All these memory changes have the purpose of preserving a confident self (Greenwald, 1980). If, however, these changes are too radical (i,e, becoming to believe that one was abused as a child), they may be damaging and have negative affect on the self. Therefore, psychologists, on the one hand, need to discern false from historically accurate memories, but, on the other hand, need to focus on the practical implications of individuals dealing with what they believe is their past. Obviously, these practical implications differ across various settings. As for the therapeutical situation, pseudomemories might be useful in order to treat a person. In the legal context, of course, only the historical truth counts. 


\section{SUMMARY}

In this doctoral thesis, we examined whether certain personality characteristics are related to pseudomemories. By now, it is common sense that everyone"s memory is fallible since it is reconstructive (Schacter, 1999). For various practical reasons it is important to know which individuals are more susceptible than others to develop pseudomemories. For example, the legal setting heavily depends on eyewitness memory (Haber \& Haber, 2000). Therefore, eyewitmess statements should be as complete and accurate as they possibly can be (Candel, Merckelbach \& Wessell, 2002).

Chapter 1 focuses on several techniques (standard interview, guided memory, cognitive interview, hypnoses, and narco-analysis) the police can use in order to get an eyewitness to tell more than he or she initially did. It is important that a good interview technique produces more correct information, but also no increase in false alarms or commission errors. The chapter starts with an outline of memory mechanisms, in particular the memory of eyewitnesses, and then various interview techniques are discussed. The core of most techniques is context-reinstatement, meaning that memories are conjured by the context of the event and that by taking the witness back to that same situation (in wivo or by way of imagination, hypnosis or narco-analysis), memories are better accessible. However, as this review clearly shows, each of these techniques produces commission errors and it is concluded that the standard interview is the best way to interview an eyewitness.

In chapter 2, two theoretical explanations for pseudomemories, namely the Fuzzy Trace Theory (FIT; Brainerd, Reyna \& Poole, 2000) and the model of Hyman and Kleinkmecht (1999), are discussed. According to FTT, when new information is. 
processed, two kinds of memory traces are generated: verbatim for episodic; e, $g$., in his left hand the robber had a bag and in his right hand a gun) and gist (or semantic; e.g., armed robbery story) traces. These traces leave behind different types of impressions. On the basis of these impressions one decides whether an event actually occurred. Yet, when time passes by, problems may arise. Verbatim traces easily decay, while gist traces are rather persistent (e.g., Koriat, Coldsmith \& Pansky, 2000). Thus, as time passes, people will increasingly rely on global gist traces to reconstruct their memories. False memories occur because items seem familiar (gist retrieval), or because both gist and verbatim traces of post event misinformation are strong and the traces of original experiences are suppressed. Hyman and Kleinknecht (1999) suggest that, in order to accept an event as real, three distinct ingredients need to be present. To begin with, one needs to accept that the suggested event is plausible. Only when this criterion is fulfilled, the next stage can be entered, in which a "memory" of the suggested event needs to be constructed. This memory should be constructed in such way that it consists of a narrative and a clear image of the event. Finally, a person needs to make a crucial error: he or she needs to confuse the sources of his or her memories. Source refers to the conditions under which a memory is acquired Johnson, Hashtroudi \& Lindsay, 1993), while source monitoring involves attributions about the origins of memories (e.g , did I see the event with my awn eyes or was I told about it by others). Source monitoring is basically accurate when the memory is detailed, is accompanied by unique characteristics, and if correct decision processes and criteria are used during remembering. However, over time people tend to forget the source of their memories (Zaragoza \& Lane, 1994) and often do recognize the content of what happened or what was said, but not the source. In that case, they are vulnerable to source monitoring errors and mistakenly take fantasies or dreams for real memories.

Both models agree that familiarity judgements lead to pseudomemories. Various paradigms aim at increasing subjective feelings of familiarity for fictitious events so as to elicit pseudomemories. Yet, in studies relying on such paradigms, only in 
about one out of five research participants is susceptible to the development of pseudomemories (Loftus, 1997). It is not clear what characterises these participants, though. Several traits have been nominated and have been studied over the past decade (e.g. Eisen \& Lynn, 2001). These characteristics are: dissociation, absorption, fantasy proneness, imagery vividness, absent mindedness, suggestibility "depression, compliance, and social desirability, It can be argued that these characteristics compromise source monitoring. However, the influence of compliance and social desirability, are not thought to be related to source monitoring errors. Possibly, these traits interact with the demand characteristics of the experimental context.

In chapter 3, we describe two studies in which source monitoring errors were provoked by having participants read out loud names of nonfamous persons. The next day, participants had to rate a list of names, amongst which the nonfamous names read the day before, but also new nonfamous names, and names of famous persons. Participants were instructed to rate the names on remownedness. Due to a misinterpretation of their increased familiarity (cf. supra) "people tend to mistakenly judge old nonfamous names as famous ones. This memory illusion is dubbed the false fame effect (lacoby, Kelley, Brown \& Jaschenko, 1989). The studies explored whether high levels of absorption or fantasy proneness were assaciated with the fallse fame effect. An overall false fame effect was found in both studies, although neither absorption nor fantasy proneness increased the false fame effect. In study 1, however, a modest correlation between depressive symptoms and the false fame effect was obtained but this finding was not replicated in study 2 .

Pseudomemories can be elicited using psychotherapeutic interventions such as imagination or journaling (Destun \& Kuiper, 1996; Poole, Lindsay, Memon \& Bull, 1995). A vast amount of research on one of these techniques (i.e., imagination) has repeatedly documented the so-called imagination inflation effect (e.g., Garry, Manning, Loftus, \& Sherman, 1996; Garry \& Polaschek, 2000). This effect refers to the phenomenon that imagining a low probability childhood event promates 
subjective confidence that the event actually occurred. In chapter 4, two studies are described exploring this phenomenon in relation to certain personality characteristics. In study 1, a higher percentage of increased confidence ratings was found for target items (l.e., items describing events that people had imagined about) than for control items. The magnitude of this imagination inflation effect, however, was modest. The onlly personality characteristic that was related to this effect was imagery vividness. That is, individuals with higher Imagery vividness displayed a larger imagination inflation effect. In study 2 , a slightly different procedure was used to explore the imagination inflation effect. This time, mimicking a journaling intervention, participants had to write down their imaginations instead of just mental imagining. Writing about fictitious events resulted in a very robust imagination inflation effect, but, unexpectedly this was not related to any of the personality characteristics.

Many authors have argued that psychotherapeutic interventions like imagination, journaling, and dream interpretation affect the development of pseudomemories (e.g., Destun \& Kuiper, 1996). There is solid experimental evidence that they indeed do so (e.g., Garry \& Polaschek, 2000; Mazzoni \& Loftus, 1996, 1998; Spanos, Burgess, Burgess, Samuels \& Blois, 1999), but even in the absence of these interventions, spontaneous pseudomemories do occur (Barclay \& Wellman, 1986). The study described in chapter 5 aimed at a large scale replication of the study of Barclay and Wellman (1986) on spontaneous pseudomemories. Participants were asked to record each day, for a 2-weeks period, three autoblographical events in a diary. Six months later, participants were invited for a surprise recognition task that consisted of original items and foil items (e.g.. modifications of original items or items from other participants). Although participants performed relatively well on this recognition task, they had some difficulties discriminating original items from foil-items. Curiously enough, of all characteristics (fantasy proneness, dissociation, absorption, suggestibility, and depression), fantasy proneness was related to superior, rather than worse recognition performance. 
There is a close resemblance between pseudomemories and internalized fallse confessions (Cudjonsson; 2003; Loftus, 1993). An internalized false confession is a confession where suspects actually belleve that they are guilty of a noncommitted crime. There are two other types of false confessions, namely voluntary false confessions, involving spontaneous self-incriminating statements, and compliant false confessions. In the latter type, suspects still belief that they are innocent, but nevertheless confess in order to secure a benefit or to avoid threatened harm or an aversive state (Cudjonssion, 2003). In the chapters 6.1 and 6.2, we describe four studies that explored laboratory-induced false confessions in relation to personality characteristics. In the first three studies, undergraduate students were accused of causing a computer to crash analogue to the paradigm introduced by Kassin and Klechel (1996). It was studied how plausibility of the event and consequencies of confessing would affect rates of false confessions. In the first study (6.1), the majority of participants $(82 \%)$ were willing to falsely confess and about half of them internalized their confessions. Chapter 6.2 (study 1) replicated this finding. In the high plausibility condition, $77 \%$ of the participants falselly confessed, whereas in the low plausibility condition this was $58 \%$. This difference was not significant. False internalized confessions, however, were significantly affected by plausibility. In the case of a highly plausible event, $26 \%$ of the participants internalized, whereas none of them internalized the event when a low plausibility event was involved. In the separate conditions, there were no robust connections between false confessions and personality characteristics. However, when data were collapsed over conditions false confessors scored higher an fantasy proneness than non-confessors. In study 2 of chapter 6.2 . participants not only were accused of having caused a computer crash, but they were also requested to pay for the damage. Compared to previous studies, this led to a dramatic drop in false confession rates. Only one oult of nine participants (1) did confess, although this participant had not internalized her confession. Study 3 in chapter 6.2 , introduced a new paradigm to study false confessions. Here, participants were accused of exam fraud. Even under ecologically valid 
conditions, one participant was willing to confess (8\%). Again, this participant had not internalized his confession. Due to the low sample sizes in studies 2 and 3 , the contribution of personality characteristics were only studies in a preliminary fashion.

There are indications that fantasy pronemess plays an important role in UFOabductions (Clancy, McNally, Schacter, Lenzenweger \& Pitman, 2002; Spanos, Cross, Dickson \& DuBreuil, 1993). Furthermore, there are reasons to bellieve that fantasy proneness and reports of previous-life memories go hand in hand (Spanos, Menary, Gabora, DuBreuil \& Dewhirst, 1991" Spanos, Burgess \& Burgess, 1994). This latter finding was based on laboratory studies in which students were hypnotized and then questioned about their previous lives. However, previouslife memories have never been studied outside the laboratory. For this reason, the exploratory study in chapter 7 was conducted. It was found that people reporting previous-life memories had elevated levels of fantasy proneness, but not of dissociative experiences. Furthermore, eccentricity of previous-life memories was associated with fantasy proneness.

In chapter 8 , the main results of this thesis are summarised and discussed. It is concluded that all paradigms which were used in this thesis elicited pseudomemories. With regard to the contribution of personality characteristics, no clear picture emerged. Moreover "only when personally relevant memories, strong manipulations and/or clinical samples were used links between personality characteristics and pseudomemories began to arise. Thus, fantasy prone inclividuals were more easily led into a compliant-coerced false confession or had more eccentric previous-life memories than individuals low on fantasy proneness. On the other hand, fantasy proneness was counter-intuitively related to memory distortions in that individual high on the CEQ performed better than controls on a surprise recognition task involving authentic and false diary records. In sum, then, although there are strong a priori arguments for suspecting that certain personality characteristics undermine source monitoring and in this way promote pseudomemories, the results of the studies in this thesis 
show that this link is not so straightforward and is presumably more complex as previously thought. 


\section{SAMENVATTING}

Sven en Eric fietsen samen van hun werk naar huis. Onderweg zijn ze getuige van een ernstig ongeval. Ze melden zich keurig als getuigen en de volgende ochtend worden ze verhoord door de politie. Ze leggen echter verschillende verklaringen af over wat er gebeurd is. Zo beweert Eric dat de automobilist die het ongeval veroorzaakte als een bezetene het kruispunt genaderd zou zijn. Terwijl Sven, die zelf in een Porsche rijdt, juist zegt dat er hooguit sprake was van sportief rijgedrag. Verder meldt Eric, na aanvankelijk erover getwijfeld te hebben en nadat de verhoorder hier vaker naar vroeg, dat de verlichting van de flets van het slachtoffer in orde was en dat de Porsche niet stil had gestaan zoals het stopbord gebood. Sven zegt zich daar helemaal niks over te kunnen herinneren, ook niet na herhaaldelijk aandringen van dezelfde agent die eerst Eric verhoord had.

Hoe komt het nu dat Eric over dezelfde gebeurtenis andere herinneringen heeft dan Sven? Kan het zo zijn dat Eric andere zaken onthouden heeft, of heeft de agent tijdens het getuigenverhoor dusdanig aan Erics herimneringen zitten duwen en trekken zodat Eric belangrijke details is gaan verzinnen? Maar waarom heeft Sven, die door dezelfde agent werd verhoord, zulke vervormingen van zijn geheugen dan niet? is Eric vatbaarder voor suggestie of meegaander? Of heeft Eric een dergelijk grote fantasie dat hij die niet meer goed kan onderscheiden van de werkelijkheid? Anders gezegd: kunnen geheugenvervormingen (pseudaherinneringen) bij mensen worden uitgelokt, en bovendien, is er een bepaalid slag mensen dat vatbaarder ils voor het ontwikkelen van dit soort herinneringen? Deze twee vragen vormen het uitgangspunt van dit proefschrift.

Hoewel het hier een fictief geval betreft, is de kans dat een dergelijke situatie in werkelijkheid ontstaat, niet uitgesloten. In hoofdstuk 1 worden verschillende 
verhoormethoden (standaard interview, geleide herinnering, cognitief interview, hypnose en marcoanalyse/waarheidsserum) van ooggetuigen besproken. Deze technileken worden door de politie ingezet met als doel de getuige zich meer te laten herinneren en dientengevolge ook te laten vertellen. Van groot belang is dat zo'n verhoortechniek er voor zorgt dat er meer ware herinneringen naar boven komen en dat er zo weinig of zelfs geen pseudo-herinneringen opduiken. En dat is lastig, zo blijkt uit het overzicht dat in dit hoofdstuk wordt gegeven. Het hoofdstuk begint met het opsommen van de verschillende geheugenprocessen, die een rol spellen bif een getuige en vervollgens worden de verschillende technieken op hun merites beoordeeld. De crux van alle verhoortechnieken is "context reinstatement". Dit betekent dat de persoon wordt "teruggebracht" naar de situatie waar hij of zij getuige van was. Dit "terugbrengen" hoeft niet per se in het echt plaats te wimden. Vaker worden mensen mentaal teruggevoerd. Dat wil

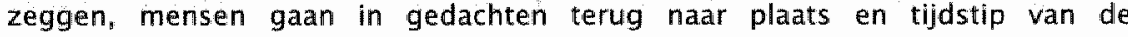
gebeurtenis en maken zich daar dan een voorstelling van. Wat duidelijk wordt uit hoofdstuk 1 , is dat de meeste technieken niet zozeer meer correcte informatie opleveren, maar juist hand in hand gaan met een toename van pseudotherinneringen. De conclusie luidt dan ook dat het voor een verhoorder al moeilijk genoeg is om een getuige te laten uitpraten. En dat open vragen blijven stellen de meeste garantie geeft op een toename in accurate geheugendetails zonder een toename in pseudo-herinneringen.

Nadat in het eerste hoofdstuk het praktische probleem van de verhoortechnieken is geschetst, wordt in hoofdstuk 2 nader ingegaan op de kern van dit proefschrift. Hier bespreken we, naast de verschillende experimentele methoden die kummen worden gebruikt om pseudo-herinneringen uit te lokken, twee verklarende modellen. In het kort komen deze verklaringen op het volgende neer. Volgens de Fuzzy Trace Theory (FTT; Brainerd, Reyna \& Poole, 2000) worden herinneringen in twee geheugensporen opgeslagen. Enerzijds bewaar je gedetailleerde (oftewel episodische) herinneringen, en anderzijds vorm je een herinnering die gaat over de plot of de algehele strekking van een gebeurtenis. 
Dit kan het beste met een voorbeeld worden uitgelegd. Neem Sven uit onze casus van hierboven. Bij het ongeval was volgens Sven een mooie witte Porsche 924 ; in sportuitvoering - dat zag hij aan de extra striping en spoilers - met kenteken LK86-JS betrokken. Dit is een heel gedetailleerde omschrijving van wat hij heeft gezien. Tegelijkertijd heeft zich een algemeen spoor van deze gebeurtenis gevormd: een ongeval tussen een auto en een fietser. Beldie geheugensporen laten verschillende indrukken achter en op basis van deze indrukken nemen mensen beslissingen of ze een antwoord op een vraag kunnen geven. Het probleem is echter de tijd die verstrijkt. Naarmate er meer tijd zit tussen de gebeurtenis en het ophalen van de herinnering hieraan, verslechteren de detail sporen, terwijl juist de plotsporen redelijk bestendig zijn (zie bijvoorbeeld: Kortat, Coldsmith \& Pansky, 2000). Dit heeft als gevolg dat mensen, als ze antwoord geven op vragen, zich steeds meer laten sturen door wat zij denken dat de plot van de gebeurtenis was. Geheugenfouten doen volgens de FTT hun intrede als een vraag onjuiste informatie bevat die de betreffende persoon enigszins bekend voorkomt, omdat deze informatie overeenkomt met de plot ("de bestuurder van de Porsche thad toch een snor en naar actiteren gekamd haar $\left.7^{13}\right)$, of als het denken aan die informatie zelf een gedetailleerd en een plotspoor achterlaat.

Hyman en Kleinknecht (1999) geven een andere verklaring voor het optreden van geheugenfouten. Volgens deze auteurs moeten mensen de informatie die in een vraag wordt gesuggereerd, eerst aannemelijk achten. Zo is de suggestie van een te hard rijdende Porsche voor Eric erg aannemelijk terwill dit voor Sven minder waarschijnlijk is omdat hij zelf met zijn porsche nooit te hard rijdt. Vervolgens dient bij dat wat glesuggereerd werd een verhaal en bijbehorende beelden gemaakt te worden. Dit zal Eric eerder lukken aangezien hif deze gebeurtenis als waarschijnlijk heeft beoordeeld en hij iemand kent die altijd te hard in een Porsche rijdt. Voor Sven is een te hard rijdende Porsche überhaupt al onwaarschijnlijk, met als gevollg dat hij het stadium van een verhaal construeren niet eens haalt. Als dan een gesuggereerde gebeurtenis als waarschijnlijk ingeschat wordt en er bovendien een verhaal en beeld bij bedacht is, moet die 
persoon de fout maken dit bedachte verhaal voor een echte herinnering te houden. Dit kan gebeuren als mensen een zogenaamde bronfout maken Uohnson, Hashtroudi \& Lindsay, 1993). Een mens neemt vila allerlei bronnen informatie tot zich. Deze bronmen kunnen bestaan uit andere personen, boeken, media $_{*}$ maar ook de persoon zelf kan als bron fungeren (fantasie "dromein). Over het algemeen zijn mensen goed in staat die bron aan te geven als een herinnering gedetailleerd is en gepaard gat met allerleil unieke kenmerken zoals tijdstip, locatie en context. Daarraast is het zo dat mensen heel goed de gegeven informatie onthouden, maar dat ze de bron vergeten (Zaragoza \& Lane, 1994). Het vergeten van de bron van de informatie zorgt er juist voor dat jemand, bijvoorbeeld, andermans ideeen voor eigen inzichten gaat aanzien (unconscious plagiarism), of dat men suggesties, fantasieën of dromen met de werkelijkheid verwart en eventuele pseudo-herinneringen hierover ontwikkelt.

Beide verklaringen delen de opvatting dat een zekere vertrouwdheid met een suggestie of idee leidt tot pseudo-herinneringen. Het is echter niet zo dat het geheugen altijd en bij iedereen sllecht is: Integendeel, het blijkt dat bij benadering 1 op de 5 mensen zulke herinneringen zai ontwikkelen (Loftus, 1997). Gedurende de afgelopen jaren zijn er meerdere persoonskenmerken aangedragen en onderzocht die het type persoon dat vatbaar is voor pseudo herinneringen karakteriseren (Eisen \& Lynn, 2001). Deze kemmerken zullen nu koirt worden besproken.

Het eerste persoonskenmerk is dissociatie. Vaak wordt de definitie van Bernstein en Putnam $(1986 ;$ p. 727) aanglehaald om dit kenmerk uit te leggen. Zij beweren dat dissociatie een gebrek aan de normale integratie van gedachten, gevoelens en ervaringen in het bewustzijn en het geheugen is. Dissociatie bestaat in allerlei soorten en maten. Een betrekkelijk alledaags voorbeeld is dat men van A naar B reist en plotseling is men op $B$ aangekomen terwijl men zich niks of weinig meer kan herinneren van de weg ernaar toe. In de kern zorgt dissociatie voor geheugenproblemen en verhoogde suggestibiliteit. Een begrip dat sterk aan dissociatie gerelateerd is, is absorptie. Personen die hierdoor gekenmerkt 
worden, kunnen bijvoorbeeld helemaal opgaan in muziek, natutir, een film et cetera. Verder speeit fantasierijkheid een mogelijke rol bij het ontstaan van pseudo-herinneringen. Dit kenmerk kan het beste met behulp van voorbeeld items uit de vragenlijst die fantasierijkheid meet worden geillustreerd. Als iemand aangeeft dat zijin/haar fantasieèn zo levendig zijn als een film, of dat hij/zij de meeste tijd van de dag doorbrengt met dagdromen, is zo iemand hoogstwaiarschijnlijk fantasierijk. Woorts zou het hebten van een levendig inbeeidingsvermogen (imagery vividness), of juist het verstrooid zijn (absent mindedness) mensen kwetsbaar maken. Een ander, veel onderzocht, kenmerk is suggestibiliteit. Hier bestaan grofweg twee vormen van, hypnotische suggestibiliteit en suggestibiliteit die opspeelt tijdens een politieverhoor. Deze laatste variant wordt gebruikt in dit proefschrift en behelst een complexe samenhang van communicatie tussen interviewer en geinterviewde in de vorm van een verhoor, een suggestieve vraag tijdens dat verhoor, de acceptatie van die suggestie en vervolgens het vertonen van gedrag gebaseerd op die suggestie. Van een geheel andere orde is het volgende kenmerk. Het rapporteren van depressieve klachten kan mensen kwetsbaarder maken voor pseudoherinneringen, aangezien zij niet alleen aan hun geheugen twijfelem "maar ook een gebrekkig werkgeheugen hebben waardoor ze niet goed in staat zijn herinneringen op te halen. De laatste twee kenmerken die mogelijk samenhangen met pseudo-herinneringen zijn compliance en sociale wenselijkheid. Deze kenmerken hebben meer te maken met het feit dat personen die hierdoor gekenmerkt worden respectievelijk liever geen ruzie willen maken met anderen of omdat ze zich graag beter willen voordoen.

Hoofdstuk 2 wordt afgesloten met de vaststelling dat deze kenmerken interfereren met het 'source monitoring' proces, het proces dat bijhoudt wie of wat de bron is van geheugeninformatie. Herinneringen die met cen overdaad aan zowel perceptuele en contextuele informatie, als allerlei details en emoties gepaard gaan, worden makkelijk voor waar gehouden. Kenmerken zoals fantasierijkheid, een levendig voorstellingsvermogem, of suggestibiliteit kunnen 
echter ook voor zo'n overdaad zorgen en kunnen daarmee een gedachte, droom, of fantasie de contouren van een ware herinnering laten aannemen. Gedetailleerde geheugeninformatie kan ook überhaupt ontbreken doordat lemand veel dissocieert, opgaat in zigh/haar omgeving, afwezig en/of depressief Is. In dat geval kan een suggestie die een goedwillende therapeut, rechercheur of proefleider aanreikt, eerder worden geaccepteerd, met een pseudo-herinnering als mogelijk gevolg. Deze processen verkllaren compliance en socialle wenselijkheid niet volledig. Deze laatste kenmerken hebben mogelijk meer van doen met de sociale druk die uit de experimentele opzet voortkomt.

Zoals eerder vermeld, speelt het maken van bronfouten een grate rol bij het ontwikkelen van pseudo-herinneringen Johnson et al., 1993). Met dat in thet achterhoofd werden de twee studies in hoofdstuk 3 uitgevoerd. In het kort komt het er op neer dat in deze studies proefpersonen werden aangezet bronfouten te maken. Bit gebeurde door hun op dag 1 een lijst van namen te laten voorlezen. Deze lijst bestond uit namen van onbekende personen (Ingrid Candel, Maaike Cima, etc.). Vierentwintig uur later moesten de proefpersonen weer een lijst met namen doornemen. Dit keer werd hen gevraagd aan te geven of iemand beroemd was of niet. De te beoordelen namen bestonden inderdaad uit beroemheden (Wim Kok, Ron Brandsteder, etc.), maar ook uit de namen die ze de dag erwoor hadden gelezen. Bovendien bevatte de lijst nog meer onbekende namen die ze niet eerder hadden gelezen of gehoord. Uit eerder onderzoek is gebleken dat proefpersonen tijdens deze taak, de onbekende namen van de dag ervoor als beroemd bestempelen. Als proefpersonen later gevraagd wordt waarom die (onbekende) naam beroemd is, kan het gebeuren dat Ingrid Candel plotseling een kinderboekenschrijfster is en Maaike Cima een bekende actrice uit Goede Tijden, Slechte Tijden. Dit als beroemd beoordelen van onbekende namen die de dag eerder hardop zijin gelezen, wordt het false fame effect genoemd (Jacoby, Kelley, Brown \& Jaschenko, 1989). Het berust op het verkeerd beoordelen van die vertrouwdheid met de naam. Onze studies onderzochten of hoog verstrooidle personen (studie 1) of personen die een goed ontwikkelde fantasie hebben 
(studie 2) een sterker false fame effect vertoonden dan mensen die laag op deze kenmerken scoorden. Hoewel geen van beide persoonskenmerken het false fame effect beïnloedde, werd er wel een false fame effect gevonden. Verder wonden we in studie 1 dat mensen met depressieve klachten een sterker false fame effect vertoonden, maar dit effect was afwezig in studie 2.

Pseuda-herinneringen kumnen worden uitgelokt door psychotherapeutische interventies zoals imaginatie of journaling (Destun \& Kuiper, 1996: Poole, Lindsay, Memon \& Bull, 1995). Een grote hoeveelheid onderzoek heeft aangetoond dat imaginatie leidt tot het imaginatie inflatie effect (bijvoorbeeld Garry, Manning, Loftus \& Sherman, 1996; Garry \& Polaschek, 2000). Stel, iemand wordt gevraagd om op een lijst aan te geven hoe waarschijnlijk het is diat hem/haar een bepaalde gebeurtenis is overkomen voor het tiende levensjaar (bijwoorbeeld met de hand door de ruit gevallen). Stel vervolgens dat deze persoon twee weken later wordt gevraagd om van een gebeurtenis die hij of zij onwaarschijnlijk achtte een voorstelling te maken (oftewel te imagineren). En vrijwel direct erna geeft hij/zij wederom een waarschijnlijkheidsoordeel over de gebeurtenis. De kans is dan groot dat de gebeurtenis in waarschijnlijkheid is toegenomen. Deze toename wordt het imaginatie inflatie effect genoemd en wordt beschreven in hoofdstuk 4 . In studie 1 van dat hoofdstuk werd inderdaad zo'n effect gevonden, hoewel de omvang ervan bescheiden was. Wel bleek dat mensen die een beter voorstellingsvermogen hadden, een groter imaginatie inflatie effect vertoonden. In studie 2 werd een lets andere procedure gebruikt om het imaginatie inflatie effect uit te lokken. Dit keer werden proefpersonen verzocht, in plaats van een mentale voorstelling te maken van de gebeurteriis, deze gebeurtenis gedetailleerd op te schrijven. Hierdoor lijkt de procedure op een andere, weelgebruikte therapeutische techniek, te weten journaling. Het schrijven over de fictieve gebeurtenis leidde tot een groter imaginatie inflatie effect, maar er werden geen persoonskenmerken gevonden die hieraan waren gerelateerd. 
Er is in de literatuur waak benadrukt dat psychotherapeutische interventies zoals imaginatie, journaling en droominterpretatie, het ontwikkelen van pseudoherinneringen bevordleren (bijwoorbeeld Destun \& Kuiper, 1996). Er bestaat ook veel experimenteel bewijs dat deze stelling ondersteunt (zle bijvoorbeeld: Garry \& Polaschek, 2000; Mazzoni \& Loftus, 1996, 1998; Spanos, Burgess, Burgess, Samuels \& Blois, 1999). Maar zelfs als deze technieken afwezig zijn, kunnen pseudo-herinneringen spontaan optreden (Barclay \& Wellman, 1986). De studie die beschreven wordt in hoofdstuk 5 is een grootschalige replicatie van de studie die Barclay en Welliman uitvoerden naar spontane pseudo-herinneringen. Er werd aan proefpersonen gevraagd om gedurende twee weken een dagboek bij te houden van drie opvallende gebeurtenissen per dag. Na zes maanden kregen de deelnemers onverwachts de opdracht om hum dagboekaantekeningen te identificerren. De aantekeningen die zij imoesten beoordelen, bestonden echter niet alleen uit hun eigen aantekeningen, de overgrote meerderheid was veranderd of waren van een andere persoon. Over het algemeen waren proefpersonen goed in staat om hun originele aantekeningen te herkennen (ongeveer $80 \%$ goed), maar ze hadden grote moeite om de veranderde aantekeningen te ontdekken. Gemiddeld genomen sloegen ze de plank mis bij $45 \%$ van hun eigen, maar veranderde dagboekaantekeningen, en werd $9 \%$ van andermans aantekeningein geaccepteerd als een eigen dagboeknotities. Slechts één eigenschap hing samen met de prestatie die geleverd werd op deze taak. Mensen met een rijke fantasie leverden de beste prestatie op deze herkenningstaak, dit in tegenstelling tot de verwachting.

In hoofdstuk 6 worden vier studies besproken die betrekking hebben op valse bekentenissen. Valse bekentenissen, en dan in het bijzonder die waarin de persoon ook daadwerkelijk is gaan geloven "hebben een sterke overeenkomst met pseudo-herinneringen (Loftus, 1993; Gudjonsson, 2003). Naast zogeheten geïnternaliseerde valse bekentenissen, bestaan er nog twee soorten valse bekentenissen. Zo bestaan er vrijwillige valse bekentenissen (bijwoorbeeld orn een geliefde te beschermen) en afgedwongen valse bekentenissen. Bij de laatste soort 
wordt een valse belkentenis afgelegd, ondat daar op de korte termijn winst mee behaald kan worden (het vervellende verthoor stopt dan tenminstel, terwijl men weet dat het niet klopt (Gudjonsson, 2003).

De eerste drie studies die in hoofdstuk 6 worden gerapporteerd, maakten gebrukk van een computercrash om valse bekentenissen uit te lokken. Deze methode werd geïntroduceerd door Kassin en Kiechel (1996) en werkt als volgt: proefpersonen krijgen de opdracht om letters die op thet scherm verschijnen zo snel mogelijk na te typen. Ze werden ook gewaarschuwd om tijdens dat taakje miet op een bepaalde toets te drukken omdat anders de computer crasht. Dit gebeurde uiteraard na verloop van tijd. Proefpersonen worden er vervolgens van beschuldigd dat zij de verboden toets hebben aangeraakt. Uit de studie die beschreven wordt in hoofidstuk 6.1 blijkt dat het overgrote deel (82\%) van de proefpersonen een valse bekentenis aflegt, dat wil zeggen dat ze hun handtekening onder een schuldverklaring zetten. Ongeveer de helft van de deelnemers vertelde een verhaal over waarom zij peir ongelluk aan de Shift-toets hadden gezeten. Zij vertoonden dus internalisatie van de bekentenis. In studie 1 van hoofdstuk 6.2 werden soortgelijke percentages gevonden. In deze studile werd de plausibiliteit van de toets gemanipuleerd, omdat het drukken op een Shift-toets meer voor de hand ligt dam thet drukken op de F12-toets. Hoewel er inderdaad een lager percentage van proefpersonen bekende aan de F12-toets te hebben gezeten (58\%), was dit niet significant minder dan het percentage proefpersonen dat bekende de Shift-toets te hebben aangeraakt (779). Wel bleek de plausibiliteit van de toets effect te hebben op het internaliseren van een bekentenis. In de Shift-toets conditie lag het percentage nog op $26 \%$, terwijl niemand in de F12-toets conditie internaliseerde. Toen de resultaten van beide groepen werden samengevoegd, dook er een effect van fantasierijkheid op. Mensen die fantasierijk waren, hadden meer de neiging om een valse bekentenis af te leggen dan mensen die weinig fantasie bezaten. In studie 2 van hoofdstuk 6.2 werd een soortgelijke procedure gebruikt. De proefpersonen mochten weer niet aan de Shift-toets komen en dit keer werd hen, zodra de computer eenmaal 
was gecrasht, ook verzocht te betalen voor de schade die zij veroorzaakt hadden. Hoewel er maar negen bruikbare proefpersonen aan deze studie meededen; legde er toch één een valse bekentenis af. Deze persoon internaliseerde deze bekentenis overigens niet. In studie 3 van hoofdstuk 6.2 werd een nieuwe methode om een valse bekentenis uit te lokken geintroduceerd. In deze methode werden studenten in het laboratorium beschuldigd van examenfraude. Zij zouden in een door de proefleider per ongeluk achtergelaten toets, die ze binnenkort zouden moeten maken, hebben gekeken. Zelfs nu de laboratoriumsituatie natuurgetrouw was, bekende één proefpersoon (8\%). Ook deze keer internaliseerde deze persoan niet. Doordat er maar weinig deelnemers in studie 2 en 3 zaten, konden er geen persoonskenmerken worden bestudeerd.

De laatste studie dlie voor dit proefschrift werd uitgevoerd, wordt besproken in hoofdstuk 7. Er zijn aanwijzingen dat fantasierijkheid een grote rol speelt bij het rapporteren van UFO-ontvoeringen (Clancy, MCNally, Schacter, Lenzenweger \& Pitman, 2002; Spanos, Cross, Dickson \& DuBreuil, 1993). Verder zijn er aanwijzingen dat fantasierijkheid hand in hand gaat met het rapporteren van herinneringen aan voorgaande levens (Spanos, Menary, Gabora, DuBreuil \& Dewhirst, 1991: Spanos, Burgess \& Burgess, 1994). Deze laatste bevinding is gebaseerd op laboratoriumstudies waarin studenten onder hypnose werden gebracht met als doel zulke herinneringen naar boven te halen. Wat echter nog nooit gedaan is, is kijken naar dit soort herinneringen buiten het laboratorium. De studie die in hoofdstuk 7 wordt besproken, is een explorerende studie naar persoonskenmerken van mensen die bij een reincarnatietherapeut in behandeling zijn geweest en daar herinneringen aan voorgaande levens hebben ontdekt. Het bleek dat deze mensen fantasierijk waren, maar geen verhoogde dissociatie scores hadden. Toen er naar de inhoud van deze voorgaande levens werd gekeken, bleek dat naarmate de persoon fantasierijker was, er excentriekere levens werden gerapporteerd.

Tot slot vat hoofdstuk 8 alle bevindingen samen. Hoewel er in alle studies pseudo-herinneringen werden uitgelokt, werd er geen duidelijk verband 
gevonden met persoonskenmerken. Slechts als er sprake was van persoonlijk relevante herinneringen die werden aangesproken, er een sterke manipulatie werd uitgevoerd, en/of een klinische steekproef werd gebruikt, dook er eenzelfde persoonskenmerk op: fantasierijkheid. Soms speelde dat kenmerk een tegenintuitieve rol. Immers, fantasierijke personen waren beter in het herkennen van hun eigen dagboekaantekeningen en in het identificeren van nepaantekeningen. Indien er een sterke manipulatie of een klinische steekproef werd gebruikt, werd het verwachte effect gievonden. Aldus bleken fantasierijke mensen eerder geneigd een valse bekentenis af te leggen of excentrieke herinneringen aan voorgaande levens te ontdekken. Hoewel er sterke a-priori argumenten bestaan om te veronderstellen dat bepaalde persoonskenmerken het maken van bronfouten en dus pseudo-herinneringen aanmoedigen, blijkt uit onze bevindingen dat deze relaties complexer zijn dan aanvankelijk gedacht. 


\section{REFERENCES}

Aleman, A., Boecker ${ }_{1}$ K.B., \& De Haan, E.H.F. (1999), Disposicion towards hallucination and subjectiwe verstus objective vividness of imagery hn normal subjects. Personafity and individial Differences. 27 . $707-774$

Aleman, A., De Haan, E.H.F. (2004). Fantasy proneness, mental imagery and reatity momitorimg. Papsonality and Individual Differences, 36, 1747-1754.

Allen, J.G., \& Coyne, L. (1 995). Dissociation and vulnerability to pswehotic experiences. Jouranf of Nervous an Mental Disease, $183,615-622$.

Arntz; A. (1993). Endorphins stimulate approach behaviour, but do not reduce subjective fear: A pilot siltudy. Behaviour Research and Therapy, 3\%,403-405.

Asch, S.E. (1956). Studies of independence and conformity: A. A minority of one agatinst a unaninous majority. Psychological Atonographs, $70_{1} 70$.

Avers, M.S. \& Reder, L.M: (1998). A theoretical review of the misinformation effect: Predictions from an activation-based memory model, Psychonomic Bulletion and Review, $5,1-21$.

Banaji. M:R., \& Greenwald. A.C. (1995). Implicit gender stereotyping in judgentents of fame. fouma." of Personatity and Soctal Psychology, 68, 181-198.

Barclaw, C.R. (1986\%. Schematization of autoblographical memon. lin D.C. Rubin (Ed.), Autobiographical memory. Cambridge: Cambridge University Press, p. 82-99.

Barclay, C.R., Welliman, H.M. 01986). Accuracies and inaccuracies in atutoltographical memories, Journa/ of Mentory and Lumguage, $25,93-103$.

Banier, A.J. McConkey, K.M. (1992). Repots of reat and false memorims: The relewance of hyphosis. hypnotisabiliry, and context of memory lest jounzal of Abnormal Psychology, 101, $521-527$.

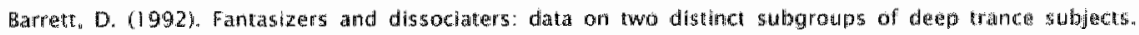
Psychoiogical Reports $71,1011+1014$

Bartholomew. R.E. Basterfielid "K. Howard, G.S. (1991). UFO abdactes and contactees: psychopathologr or fantasy pronemess? Professional Psychology: Research and Practice; 22, $215-222$.

Bartlett, F.C. (1932). Remembering. Oxfard, England: Uniwersity Press.

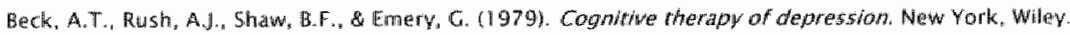

Bedau, H.A.n \& Putram, C. (1996). False confessions and other folles, In D.5. Connery (Ed), Convicting whe innocemr. Cambridge, MA: Brookline Books, p. 69-83.

Bedar, H.A. Radelet. M.L. (1987). Miscarriages of justica in potemtially capital cases. Stanford Law Rewetw, $40,21-179$. 


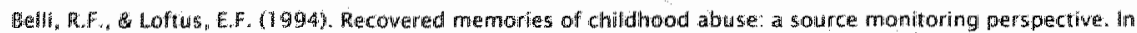
5.1. Lynn \& 1.W. Rhue (Eds.). Dissoctation: Cirnical and theoretical perspectivas. New York: Guitord, $415-433$.

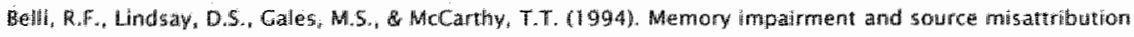
in postevent milsinformation experiments whth short retention intervals. Menory and Cognition, 22: $40 \mathrm{j}-54$.

Bem, D.J. (1966). Inducing belief in false confessions, journat of Personality and Social Psychology, 3,707 710.

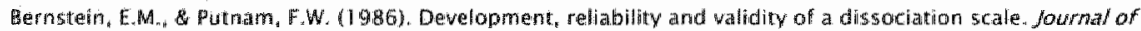
Nerkous and Atertal Diseasie, 174, 727-735.

Beringer, 1. (1996). Experimental Run Time 5ystem; Version 3.18. Frinkfurt am Main IGiermami: Berisoft Corporation.

Bernstein, E.lla, \& Putram, F.W. (1986). Development, reliability, and valídity of a dissociation scale. Journat of Nervous and Mental Disease; $174,727-735$.

Bagrove, $M$. (1996). Effects of sleep deprivation on interrogative suggestibility. Journal of Experimential Psychology: Applied, 2, 48-59.

Wiair, I.V., Lentor, A.P. Hastie, R. (2002). The reliability of the DRM paradligm as a measure of individual difference in fallse memories. Psychonomic Bulletin and Review, $990-596$.

Bianamno C.A. (1990). Remembering and psychotherapy. Pspchorherapy, 27, 175-186.

Brandimonte, M.A., Schooler, J.W., Gabbino, P. (1997). Atrentuating verbal overshadowing through coior retmeval cues. Journal of Experimental Psychology: Learning, Afemory, and Cognition, 23 , $915-$ 9311.

Brandon, S. \& Boakes, J. (1999). Memory recovery among adults in therapy. British fournal of Psyctwatry $157,588$.

Bramerd, C. I. Reyna, V. F., Poole, D. A. (2000). Fiuzzy-trace theory and false memory: Memory theory in the courtroom. In. D. F. Bjorkilund (Ed.), False memory creation in chilliren and aduhs: Theory, restearch, and implications. Mahwah, Na: Erlbaum, p. 93-127.

Brewh, C.R., Saunders J. (2001). "he offect of dissociation at encoding on intrustwe nemorias for a stressful fition. Bithish Jow hal of Medical Psychology, $74,467-472$.

Broadbent, D.E. Coopen, P.F. Fitzgerald, P., Parkes, L.R. (1982), The Cogmitive Failure Questionnaîre (CFO) and its correlates. British Jourhal of Chinhal psychohogy, 21, 1-16.

Brown, A.5. \& Nlx, L.A. (1996). Turning lies into truths: Referential validation of falsehoods. foumd of Experimentat Psjchology: Learning, Wemory, and Cognition, 22, 1088-1100.

Buchandm, G. Beligman, M.E.P. (1995). Explanatory sty/e. Hillsdale N.j: Entbatum.

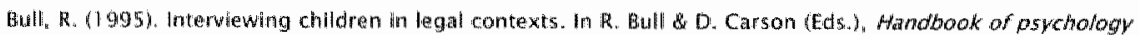
in legal contewts. Chichester: Witey, p. 235-246.

Burnham, WH. (1889). Memory, historically and experimentally considered. III. American journal of Psichology, 2, 43:1-464.

Candel, $I_{\text {, \& }}$ Merckelbach, $H_{4}$ (2004h, Peritraumatic dissociation as a predictor of PTSD: A critical rewiew. Compretensive Psychiatry. 45,44, 50 
Candel, l., Mercketbach, H. \& Kuipers; M. (2003). Dissociative experiences are related to commissions in emotional memory. Behawiour Research and Therapy, $41,719-725$.

Candel, 1., Merckelbach: H. Loyen, $S_{k}$ \& Reyshens, H. (2005). " hit the Shift-key and then the comguter crashed": Children and false confessions. Personality and motiwidual Differences, $30,1381-1387$.

Canctel. A. Merckelbach; $H_{\text {. }}$ \& Wessel, I. (2002). Traumatische herinneringen. In P.J. van Koppen, D.J. Hessing.

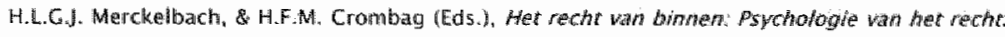
Deventer: Klluwer, p. 417-431:

Cassell, P.G. (1996). All benefits, no costs: The grand flusion of Miranda"s defenders. Northwestem Uniwersity Laily Review, 90, 1084-1124.

Cassell, P.C. (1998). Protecting the innocent from false confessions and lost confesstons and from Mirandin. Journal of Criminal Law and Criminology $s 8,497+556$.

Churchill, R. (1997). Become the dreany: The transforming power of hypnotic dreamwork. Salata Rosa, CA: Transforming Press.

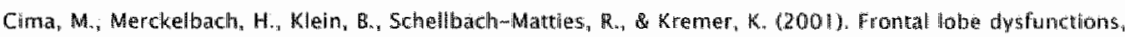
dissociation, and trauma self-reports in Foretsic psychiatric patients. Joumal of Nerwous amd Mental Disearse, $189,188-190$.

Clancy. S.A., MCNally, R.J., \& Scharter, D.L. (1999). Effects of guided imagery on memory distiontion in women reporting recovered memories of childhood sexwal abuse. fownat of Traumatic Stress, 12, 559 569.

Clancy, S.A., MCNally, R.J., Schacter, D.L., Lenzenweger, Mt.F., \& Pitman, R. K. (2002). Memory distortion in people reporting abduction bw aliens. fournal of Abnormal Psychology, 11/, 455-461.

Cohen. A.R. (1962). An experiment on small rewards for discrepant compliance and attatude change. In l.W.

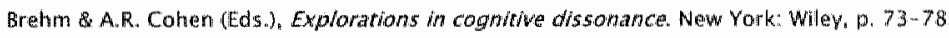

Constans, J.l., Foa, E.B., Franklin, M.E., \&athews, A. 1995). Memory for actual and imagined events in OC checkers. Behawiour Research and Therapk, 33,665-637\%.

Conte, J.R. (1999). Memony, research and the law: Future directions. In L.M. Willians \& W.L. Banyard (Eds.). Trauma and memory. Thousands Oaks, CA: Sage Publications, p. 77 92.

Corstens, G.M.M. (1999\%. Het Nederlards straforocessechi Deventer: Gouda Ouint

Comin. 1. (1994). On measuring discrimmation and response bias: Unequal numbers of hargers and distracters and two dasses of distracters. Neuropspchalogy $B_{0}, 110-11 \%$

Costa, P.T. McCrae, R. (1992). The fve-factor modell of personality and its relevance to personality disonders. Jourral of Personality Disorders. $6.343-359$

Crombag. H.F.M. 11999). Collaborative stom-telling: A hpothesis in new of experthental testing. Psychologw, Crime Law, 5, 279-289.

Crombag. H.F.M. (1999\%. 'A la recherche du temps perdu'. Un R. Welters (red), Grenzehoze selectie. Nijnegem: Nijmegen University Press, p. $171-182$.

Crombag. H.F.M., Merckelbach, H., \& Elffers. H. (2000). Other people's mernory: Psychology, Crime \& Law, 6 , $251-265$.

Crowne, D., \& Marlow, D. (1964). The approval motive. New York: Wiley.

De Pauw, W. (1999). Forensische bypnose. Criminologische studies 4. Brusswel: vulspress. 


\section{REEERENCES}

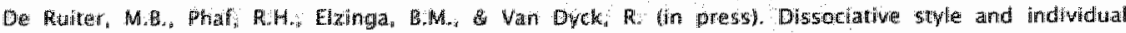
differences fra werbal working memory span. Consciousness and Cogwition.

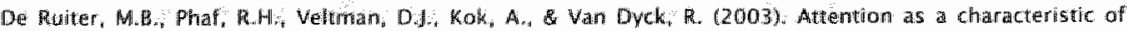
nondinfai dissociation An everterelated potential study. Neuroimage, 19,376-390.

Defse, J. (1959). On the prediction of occurrence of particular verbal intrusions in immedatie recall. Jowmat of Experimential Psychology, $58,17-22$.

DePrince, A.P. \& Frevd; 1999). Dissociative tendencies, attention, and memory. Psychological Scrence. $10449-452$

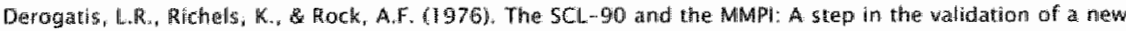
scale: Brotish journal of Psychiatry. 4280-4389.

Destum. L.M. Kuiper. N.A. (1996). Autobiographical inemony and recovered memory therapy: Integrating cogntive, clinical, and individual difference perspectives. C/mica/ Psychology Review $16,4211-$ 450 .

Destun, LM, Kuiper; N.A; (1999). Phenomenological charafteristics associated with real and imagined ewents: the effects of event valence and abisorption. Applied Cognitive Psychology, 13, $1175-186$.

Dobyon, M. Marktham, R. (1993). Imagery ability and source monitoring: Implication for eyewwiness memory. British jowrsiat of Psychology. 32, $111-118$ :

Dorahy, M.J. (2001). Dissociative identity disorder and memory dysfunctian: The current state of experimental reseatch and its future directions. Chisical Psychology Rewew, $27,771-795$.

Drivdahl, 5.B. Zaragoza, M.S. (2001). The role of perceptual elaboration and individual differences in the creation of false memaries for suggested events. Applied Cognitive Pspichology $15,265-281$.

Eich, E. (1 989). Theoretical is sues in state dependent memory. In H.L. Roediger \& F.I.M. Craik (Eds.), Warieties of memony and consciousness: Essays in honor of Endel Twlwing. Hillsdale, NJ: Erlbaum, p. 33 l 354.

Eisen, M.L., \& Carlson, E.B. (1998). Individual differences in suggestibility: Examining the influence of dissoxiztiom, absorption, and a history of childhood abuse. Applied Cognitive Psychology, 12, $\$ 47-\$ 61$.

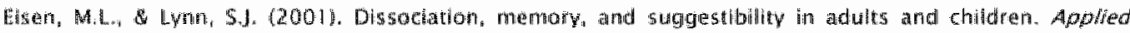
Cognitive Pisychology, 15. $549-573$.

Estes, W.K. (1998). Models of human mennory and their implikeations for research on aging and psychopathology. Dewelopment and Psthopatholog, 10,607-624.

Falshore, M. \& Schooler, JW. (1925), Verbal vulnerability of perceptual expertisie, Joumar of Experimemtal Pskchology: Leirning, Memony and Cognition, 21, $1608-1623$

Finger $r_{\mathrm{i}}$ K. \& Perdek, K. (1999). The effect of cognitive untervew on face identification accuracy, Release from verbal overshadowing. jloumal of Apolied Psychologk, 84, 340-34.48.

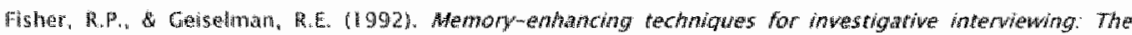
cognidive interview, Springfield IL: Thomas.

Fisher, R.P., Geiselmath, R.E. \& Raymond, D.S. (I9BD). Critical analysis of police interwiew techuiques. fournal of Pofice Science and Administration, 15, 177-185. 


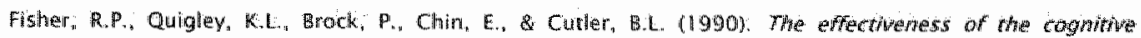
interview description and iftentification tasks. Paper presented at the Amertican Psychology Law Society, Williamsburg, WA.

Foa, EB., Amir, N., Cershum, B., Molnar, C. \& Kozah. M. . (1997). Implicit and explicit memory if obsessivecompulsive disorider. Journal of Anxiery Disorders $1 /, 119429$.

Forrest, K.D., \& Wilson. SL. (2003). Thinking about what you have done in the paste Does ruminarion alicit false confessions? Paper presented at the Intermational and Interdisciplinany Psychology \& Law conference, Edinburgh, $7-12$ Jully.

Forrest, K.D., Wadkins, T.A., \& MHller, R.L. (2002). The role of pre-existing stress on false confessions: An empirical studw. Journal of Credibility Assessment and Witness Psychology, 3, 23-45.

Frankel, F.H. (1996). Dissociation: The clinical realities. Americam fotimal of Psifthatry fFestschift Supptement), $753,64-70$.

French, C.C. (2003). Fantastic memories. Journal of Consciowsmess Studies, 10, 153-174.

Freyd, J., \& Gleaves, D.H. (1996), "Remembering" words not presented in Hsts: Relewance to the current recovered false memory controvarsy. Joumal of Experimental Pspchology: Learming Memon a Cognition, 22,811-813.

Freyd, 1.)., Martorello, 5.R., Alvarado, I.S., Hayes, A.E., \& Cinistman, J.C. (1998\%. Cognitime enwironments and dissociative tendencies: Performance on the standard stroop task for high versus low dissociators. Applied Cognitive Psychology, 12, $\$ 91-5103$.

Gabbert, F., Memon, A., Allan, K. (2003). Memory conformity: Can evewitnesses influence each other's memaries for an event? Applied Cognitive P5ychology" $77,533-543$.

Gabbert, F. Memon, A., Allan, K., Wright, D. (2004). Say it to my face: Examining the effects of socially encountered misinformation. Legal and Criminological psprhology, $215-227$.

Gabbent, F.: Memon, A. \& Wright, D. (submitred). Memery conformity: Disentangling the steps towards infuence during a discussion.

Ganaway, Gi.K. (1995). Hypnosis, childhood trauma, and dissociative identity disorder: Toward an integrative theory. International Journal of Clinical and Experimental Hyphosis, 43, 127-144.

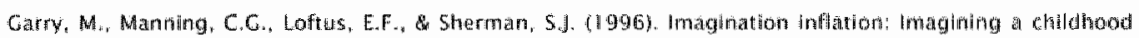

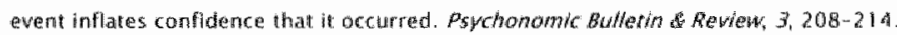

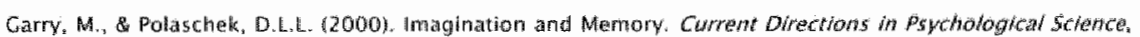
9. $6+10$

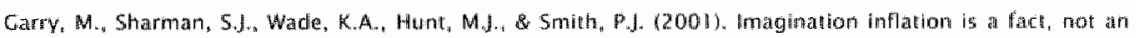
artefact: A reply to Pezdek and Eddy. Menrom and Cognition, 29,719-729.

Geraets, E, Smeers, E., Jelicic, M., Van Heerden, J. Methelbach. H. (sulbmitted), Retrieval inhbition of

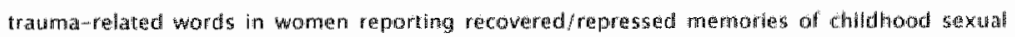
abuse.

Giesbrecht, T., Merckelbach, H. (2004). Subjectwe slep experiences are related to dis sioclation. Personality and molwowal Differences, $37,1341-1345$.

Giesbrecht, T., \&herckelbach. H. (ift press). Uber die kausale Beziehung zwischen Dissozituonen wnd Trauma: Ein kritischer Uberblick. Der Nenemartz. 


\section{REFERENCES}

Ciesbrectit. T. Merkedbach, H, smeets, (in press. First you find them; then wou don't? Thought suppresson, dissociation, and context effects. Journal of Nerwous and Mental Disease.

Goff, LM. \& Roed iger, Fi. 1 (1998). Imagination inflation for action events: Repeated imainings lead to Hlus ony recollections, Memony \& Cognition, 26, 20-33.

Grenberg, A. Wortmin, C.B. Stone; A. (1996). Emotional expression and physieal health: Reviwing

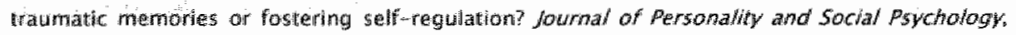
71,588602

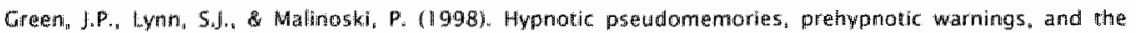
malleability of suggested memories. Applied Cognitive Psychology. $12,431,444$.

Curenwald, A.G. (1980). The rotalitarian ego: Fabrication and revision if personal history. American Psyctionogist, 35, 603-618.

Grisham, J.C. (1987). "Hypnatically refreshed" testimony Review gramed by U.S. Supireme Court. APA Montor, 18, 41 :

Cudjolnsson, GH. (1984). A new scale of interrogarive suggestibility. Persorialing and individual Differences, 5. $303-314$ *

Cudjonssion, G. H. (1989). Compliance in an interrogation situation: A new scale. Personatity and individual Differences, $10,535-540$.

Gudjonsson, G.H: (1991), Suggestiblility and compliance among alleged false confessors and resisters in criminal trials. Medicine, Sicience, arif the Law $31,147-151$.

Cuilfonisson, G.H. (1992). The psychology of interrogations, confessions, and yestimony. Chichester: John Wiler.

Cudjonsson, G.H. (1997). The Gudjonsson suggestibility scales. Hove: Psychologv Press.

Cudjonsson, G.H. (1999a). The making of a false confessor: The confessions of Herry Lee Lucas. Journal of Forensic Psychiatry, $10,416 m-426$.

Gudjonsson, C.H. (1999b). The IRA funeral murders: The confessilion of PK and the expert psychological testimony. Legal and Criminal Psyctsology, 4, 45-50.

Gudjonsson, G.H. (2001). False confessions. The Psychologist, 14, 588-591.

Gildongsw. C.H. (2003). The psychorogy of interogations and confessions: A handbook. Chichester: John Wiley.

Gudjonsson, G.H, Clare, 1,C.H. (1995). The relationshap between confabulation and intellectual ability. memorw, nterrogative suggestibutity, and acquhiescence. Personality and Indiwdwat onferences, 19.3334338 .

Cudjonsson, G.H., Clark, N.K. (1986). Suggestability in police interrogation: A social pisychological model. Sochat behatwour, $1,83-10 \mathrm{~A}$.

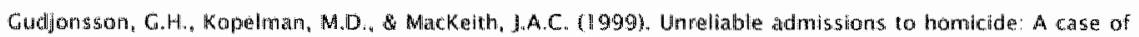

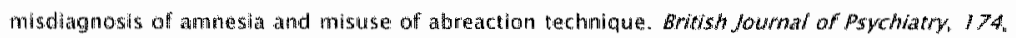
$455-4596$

Guitonsson. G.H., Mackelth, J.A.C. (1982). False confessions: pswchological effects of interrogation. A discussion paper. In A. Trankell (Ed), Recanstructing the past the role of psychologists in criminat trials. Deventer: Klluwer, p. 253-269. 


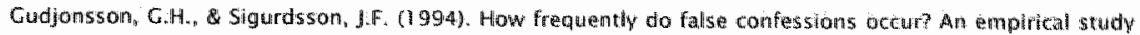
among prison inmates. Psychology, Crime and Law $1,21-26$.

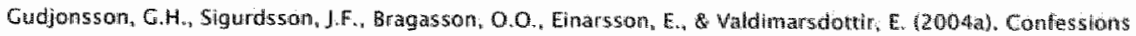

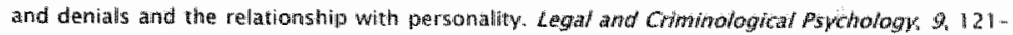
133.

Gudjonssion, G.H., Siguredsson, J.F. \& Einarsson; E. (2004b). The role of per sonality in rellation to confesstorts and denals. Psychologw Comme and Law 10,125-135.

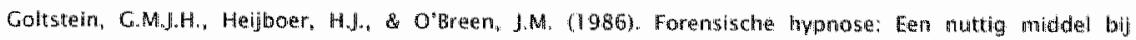
opsporing. Algemeen Politieblad, $135,3-8$.

Gwyer, P. \& Clifford, B.R. (1997). The effects of the cognitive interview on recall, idelltification and the confidence/accuracy relationship; Applied Cogmithe Pspchology, $11,121-145$.

Haber, R.N, \& Haber, L. (2000\%. Experiencingi, rememberihg and reporting events. Psychology, Pwblic Policy Law, 6il 1057-1097.

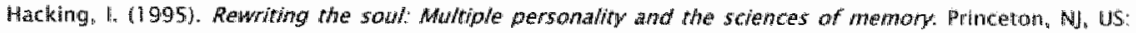
Princeton University Press.

Haraldsson. E. (1995). Personality and abilities of chiluren claining previouswife mertories. Jowmal of Nerwows and Mental Disease, $183,445-451$.

Haraldsson, E. (2003). Children who speak of past -life experiences: Is there a psychological explanation? Psychology and Psychotherapy: Theory, Research and Practice, $76,55-67$.

Harallsson, E., Fowler, P.C. \& Periyannanpillat, V. $2000 \%$. Isychological characteristics of children who speak of a previous life: A further field study in Sri Lanka. Transculturat Psychiath, 37, 525i-544.

Hashtroudi, S., Johnson, M.K., Vnek, N. \& Fergusion, S.A. (1994). Aging and te effect of affective and factual focus on source montoring and recall. Psychology and Aging, 9, 160-170.

Health Coumcis of the Netherlands (2004). Disputed memories. The Hague: Health Council af the Netherlands:

Heaps, C., Nash, M.R. (11999). Individuall differences in imagination Inflation. Psychonomic Bu/tern w Review, 6, 313-318.

Heijboer. H.J. (1985). Forensische hwposa, verdiept verhoor: Spoorzoeken in de gehenhe grottern wan het geheugen. Tidschriff wor de Politie, 47, $325 \cdots 32$. 2 .

Hermans, D. Martens, K. De Con. K. Pieters, G. \& Eelen, P. (2003). Realliy monitoring and metacograitive bellefs related to cognitive confiderce in obsessive-compulswe disorder behawow Rescarch and Therapy, $41,383-40 \%$.

Hertel. P.T. \& Milan. S. (1994). Depressiwe deficis in recogntion: Dissociation of recollertion and familianty. fournal of Abnormaf psychology, 103, 736-742.

Herel, P.T., \& Rude, 5.5. 11991 \%. Depressive deficits in memory: Focusing attention improves subsequent recall. Jourmal of Experimental Psychology: Gerteral, 120, 301-305.

Hoenkamp, E. (1990\%. Sexual abus and the abuse of hponosis in the therapeutic relationship. hrernatronal Journal of clinical and Experimental Hypnosis, $37,283-297$.

Horselenberg, R, \& Merckelbach. H. (submited). Fantasy proneness and prewious-life memaries.

Horselenberg, R., Meirckelbach, H. \& Josephs, S. $(2003)$ Individual differences and false confessions: A

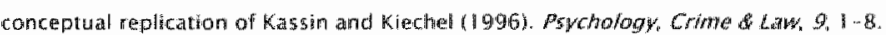




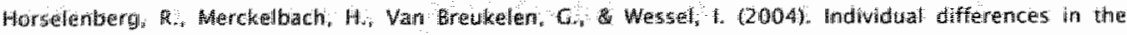

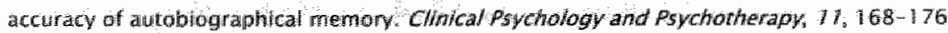

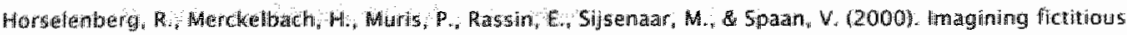
childhood events: The role of individual diffepences in imagination unflation. Cinical Psychology and Pathotherapy, 7. 128 in 137 .

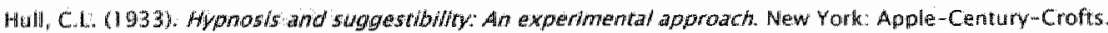

Hyrnan, LE, \& Billings, F.) (1998\%. Indiwidual differences and the creation of childhood memories. Memary, $6: 1-20$.

Hyman, I.E., Husband, T.H. Billings, F.J. 1995). False memories of childhood experiences. Applied Cognitive psychology, $9181-197$.

Hyman, I. E. Keinkmecht, E. E. (1999). False chitchood memoniers. Research, theory, and applications. In L. M. Williamis \& V. L., Banyard (Eds). Trauma and Memory. Thousand Oaks, CA, U.5: 5alge Publications, Inc, p. 175-189.

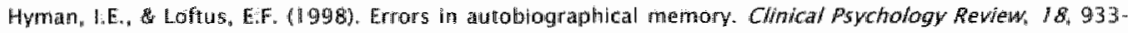
947.

Hyman, I.E.; Pentand, 1: (1996). The role of imagery in the creation of false childhood memories. Journal of Memory ard Language, 35,101-117.

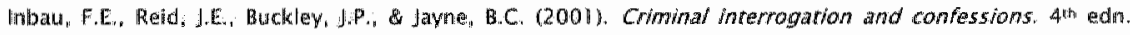
Gaithersiberg, MD: Aspen.

Jacoby, Lij, Kelley, C., Browm. J., \& Jasechko, J. (1989). Beconing famous overnight: Lirnits on the ability to avoid unconsciousness influences of the past. Journal of Personality and Social Psychology 56 326-33is,

Jensen-Campbell, L.A., Adams, R., Perry, D.C.; Workman, K.A., Furdella, J.Q., \& Egan, S.K. (2002). Agreeabenes5, extrawersion, and peer relations, in early adolescence: Whining friends and deflecting aggression. fournal of Research in Personality. 36, 224-251.

Jewetit, M.E., Dijll, D-J., Kronauer, RE., Dinges, D.F. (1999). Dose-response relationship between sleep duration and human psychomotor wigitance alnd subjective alertness. 5leep yournal of sleep

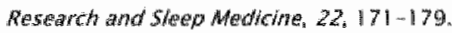

Jôhuson. M.K. (1988). Reality monitoring An experinnental phemomenolongical approach. Journat of Experknemtal Psychology: General, in $7,390-394$.

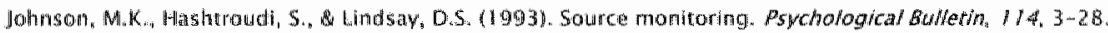

Johnson, M.K. B Rays, C.L. (1998). Falsememories and confabulation. Trends in Cogntive Sciences, $2,137-$ 14.5 .

Kassin, S.M. (1897). The psychology of confession evidence. American Pswchologist $52_{n}, 221-233$.

Kassin, S.M. Wiechel, K.L. (1996). The social psychology of false confessions: Compliance, internalizanion. and confabulation. Psychological Science, $7.125-128$.

Kassin, 5.M., \& Mchall, K. (1991). Potice interrogations and confessions. Law and Human Behavior, 15, 233251.

Kassin, S.M. Neumann, K. (1997). On the power of confession evidence: an experimental test of the fundamental difference hypothesis. Law and kitunan behavior, 21, 469-484. 
Kassin, 5.M. \& Sukel, H. 1997). Coerced confessions and the jury: An experimental thest of the "hathless error ${ }^{\nabla}$ rule: Law and Himan Betiation, 21, 27-46.

KKassin, S.M., Wrightsman; L.5, (1985). Confession evidence. Ir: S. Kassin \& L. Wrightsman (Edts., The psychology of evidence and tria/ procecture. Beverly wills: Sage Books 5 . $67-9.4$.

Kebbell, M.R., Milne, R., \& Wagtaff, C.F. (1999). The cognitive interview: A survey of its forensic effectiveness. Ps phology, Crime \& Law, $5,101-115$.

Kelley, C.M. Lindsay, 5.0. (1993). Rememberng mistaken for knowing: Ease of retrieval als a basis for confidence in answers to general knowledge, Journat of Memony and Languge, $32,1-24$.

Kihlstrom, J.F. (1998). Exhumed memory. in S.J. Lynn \& K.M. MCCorkev (Eds.). Thwh in memon. Nhew York. Guilford, p. 3-31.

Kihistrom, J.F., Gliskw. M.L., \& Angtulo, M.). (1994). Dissociative tendencies, and dissoctative disorders. Jownal of Abnormal Psychology, 103, 117-124.

Kirsch, I. Lynn, 5.J. (1995j. Altered state of hypnosis: Changies to the theoretical landscapd. American Psychologisit, 50, 84.6-858.

Klaver, In, Gordon Rose, V., \& Lee, Z. (2003). Differential effects of minthatzation and maximization interrogation techniques and the role of platubibility in an experimental false confession paradigm. Paper presented at the International and Interdisciplimary Psychology Law conference, Edinburgh $7-12$ July.

Knibbeler, J.M.H. (1985). Hypnose-werhoren in Nederland: Criminologische en politiele analyse van getuigenwerhoor onder hypnose. Algemeen Politieblad, $13.4,435-44.2$.

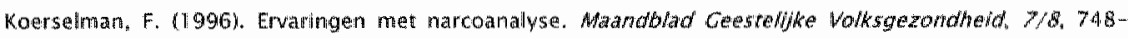
760.

Köhnken, G. (1995). Interviewing adults. In R. Bull \& D. Carsan (Eds.y, Handbook of psvehalogh in legat contexts. Chichester: Wiley, 0. 235-246.

Kohnkem, G., Milne, R., Memon ${ }_{1}$ A., \& Bull, R. (1999). The cognitiwe interview: A meta-amalysis, Psychology, crime daik, 5, 3-27.

Könken, Gn, Schimossek, E., Aschermann, E. \& Hofer, E. (1995). Statement validity analysis and the cogrative interview. Journal of Applied Pisychology, $30,6,72-684$.

Koehler, D.J. (1991). Explamation, imagimation, and confidence in Judgement. Pswothological Bulfetion, 180. $499-53 \%$

Koriat, A., Coldsmith. M. Pansky, A. (2000). Toward a psychology of memory accuracy. Anmuall Review of psychology, $51,481-537$.

Laurence, J.R., Perry, C. (1988). Hypnosis, whi, and memary. New York Gullford.

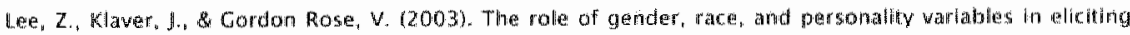
false confessions. Poster presiented at the international and Interdisciplinary Psycthology \& Law conference, Edinburgh, $7-12 \mathrm{July}$.

Leo, R.A.. Ofshe, R.J. (1998). The consequences of false confessions: Deprivations of litberly and

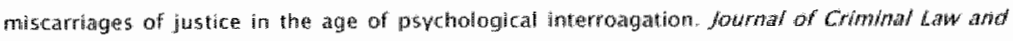
Criminology, $88.429-497$.

Lepore, 5.j. \& 5myth, J.W. K2002). The writing cure: how expressive writing promotes health amd ermotionat wedl-being Washington, DC. Americian Psychological As saciation. 
Lighthart, LEE, (2004), Hypmose tien behoeve wart het opsporingsonderzoek. Hn B.A.J. Cohen, H. Holtshag"

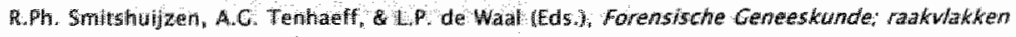
wissen geneeskunst gezondheidszorg en rectt Assen: Kon nktwke Wan Corcum, p. 512-531.

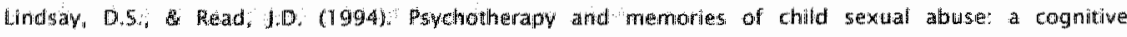
per splective: Applied Cognitive Psychology, $8,281-338$.

Lindsay, D.S., Wagen, L., Read, J.D.; Wade; K. A, Garry, A. (2004). True photographs and fallse memories. Pspchological Science, $15,149-154$.

Limen, M. (1975). Menory for real-morid events. In D.A. Norman D.E. Rumethart (Eds). Exploration ign cogntion: San Fainsisco: Freeman. p. 376 . 404 .

Lipinisk, J.F, \& Pape, H.C. (1994). Do "flashbacks" represent obsessional imagery? Comprehensive Psychistriw: 35, 245-247.

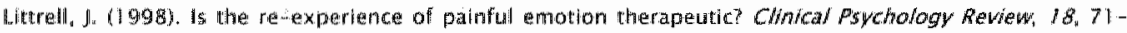
102 :

Loftus, F. F, (1979). Eyewitness restmony: Cambridge, MA: Harvard University Press.

Loftus, E.F. (1993). The reality of repressed memonies. Amevican Psychologisu, 48, 518-537.

Loftus, EF. (1997). Researchers are showing how surgestion and imagination cain treate "memortes" of events that did not actually occur. Scientific American, $262,71-75$.

Lof tu5, E.F. (2003a). Make-believe memories: American Psychologist, 58, 867-873,

Loftus, E.F. (2003b). Memary in Candidian counts of llaw. Canadian Psychology, 44, 207-212.

Loffus, E.F. (2004). Memories of things unseen. Current Directions in Psycholagical Science, $13,145-147$.

Loftus, E.F., Hoffman, H.G. (1989). Misinformation and menory: The creation of new memories. Journal of Experimental Psychology: General, 118, 100-104

Loftus, E.F., Miller, D.Ci, \& Burns, H.J. (1978). Semantic integration of verbal information into as wisual menton. Journal af Experimental Psychology: Human Learring and Memony, $19-31$.

Loftus, E.F., \& Palmer, J.C. (197.4), Reconstruction of automobile destruction: An example of the interaction between language and memory. Journal of Kerbal Learning and Werbal Behawor, 13, 585-589.

Lofilus, E.F., \& Pickrett, J.E. (1995). The formation of false memories. Psychiatric Annals, 25, 720-725.

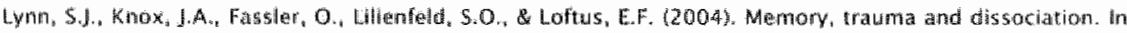

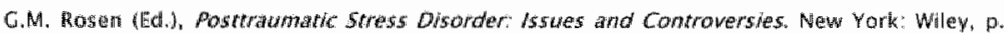
$163-186$.

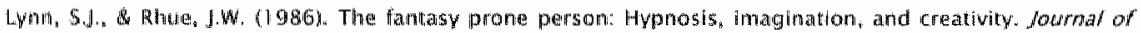
Personality and Social psychology, $5 J_{1} 404-408$.

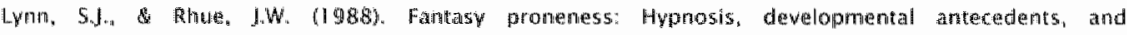
prychopathology. Amprorican Psychologist, 43,35-44.

MacDonald, P.A., Antony, M., MacLeod, C.M., Richter, M.M. (1997). Merrory and confidence in memory Judgements among indiwiduats with obsessive-compulsive disorder and non-cinical controls. Behawiour Rasearch and Therapy $35.497-505$.

Malpass, R.5. (1996. Enhancing evewithess memory. Im S.L. Sporer, R.S. Malpass \& G. Kotmken (Eds." Psychological issues in ejewitness ridientification. Mahwah, NJ: Erlbaum, p. 177-204.

Matpass, R.S., Deving. P.C. (19811. Guided mernory Im evewitness identification. Jownal of Applied Psythology, 66, 343-350. 
Marmar, C.R., Weiss, D.S., Metzler, T.j. \& Deluchi, C.A. (1996), Cluatucteristics of emengency personal related to peritraumatic dissociation during critical incident exposure. Amertcan foumbal of Psyebrami: $153,94-102$.

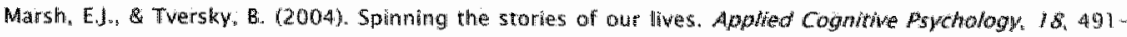
503.

Mazzoni, G.A., Loftus, E.F. (1996). When dreams become teallty, Consciousness and cogniton, 5,442 462 .

Mazzoni, G.A., \& Loftus, E.F. (1998). Dream interpretation can change beliefs abour the pust. Psychotheraph $35.177-187$

Mazzoni, C.A.L. Loftus, E.F., Seqz $z_{1}$ A., \& Lynn, S.J. (1999) Changing beliefs and memorites through drean interpretation. Applied Cogritive Psychologk: $13: 125-144$.

MoCann, J.T. (1998). A conceptual framework for identifying various types of confessidns. Behavional Scrences and the Law. $16,441-453$.

McCreery. C. (199\%). Hallucinations and arousatbility: Pointers to a theory of psychosis. In Clarddge, G. (Ed.), Schizatypy: Implications for Whess and healeh. Londom: Oxford Universiry Press, p. $251-273$.

McConkey, K.M., Labelle, L., Bibto. B.C., \& Bryant, R.A. (1 990). Hypnosis and suggested pseudomemony: The relevance of test context. Austratian floumat of Psyctiology 42, 197-205.

McMahon, M. (2000). The affect of the enhanced cognitive interwiew on recall and confidence in eiderly adults. Psychiahy, Pspchology, and Laty, $7,9-32$.

MCNally, R.J. Clancy, S.A., \& Schacter, D.L. (2001). Difrected forgetting of trauma cues in actults reporting repressed or recovered memories of childhood sexual abuse. fournal of Abnomat Psychologw. $110,157-15,6$.

Mc.Nally, R.J., Clancy, S.A., Schacter, D.L. \& Pitman, R.K. 2000). Personatity profles, dissociation, and absorption in women reporting represses, recovered, or continuous memories of childhood sexual abuse Journal of Consulting and Chinical Psychologys, $08,1033-1037$.

McNally, R.M.. \& Kohilbeck, P.A. (1993). Reality monitoring in obsessive-compulsive disorder. Bebatwour Research and Therapy: $3 l_{1} 249-253$.

MCNally, R., Lasko. N.B., \& Clancy, 5.A. (2004). Psychophysiological responding duing scripi driven imagery in people teponting abduction by space allens. Psychological science $15,493-497$.

Meade, ML., \& Roediger, H.L. (2002D. Explowations in the social contagion of memory. Mtomory and Cognition, 30; $995-1009$.

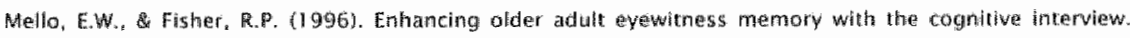
Applied Cognitive Psychalogy, $10,403-418$.

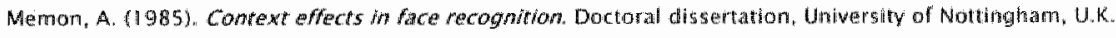

Menton, A. \& Higham, P.A. (1999). A rewiew of the cognitive interwiew, Psychology, Crime \& Law, 5. 177196.

Memon, A. \& Köhnken, C. (1992). Helping witness to remenber more: The cognitive interview. Expert Evidence, $1,39-76$.

Memon, A., Wark, H., Hollew, A., Bull, R., \& Kohnken, G. (1997). Eyewiness performance in cognhive and structured interview. Memory, 5, 639-6,56. 


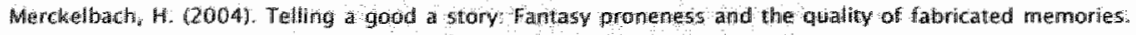

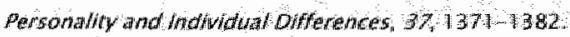

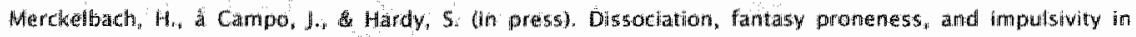
patients with sthumphrenta, borderline personatity distarder, and major depresswe disorder. Comprehensive Psychiatry.

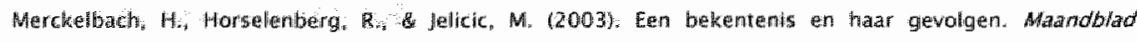
Geestellke wolksgezondheid, $58,997-1017$.

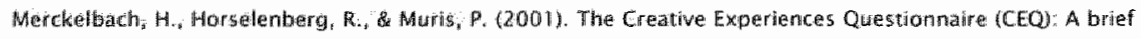
self-report mealsure of fantasy pronemess. Personatity and undividual Differences, 3l, 987-995.

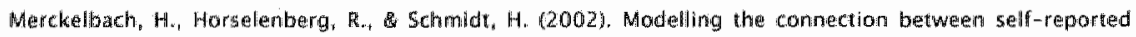
trauma and dissociation in a student sample: Personakity and Individual Differences, 32,695705.

Merckelbach, H. Jellicic. M. Candel, I., Horstenberg, T. (2002). Slewtelen aan geheugen werlies. latrogene Elaboratie van ewn retrograde amnesia. Aaldb/ad Ceestelijke wolksgezondheid, 57, 923-935.

Merckelbach, $H_{4}$, Muris, P, (2001). The causal link between self-reparted tratua and dissociation: a critical review. Behawiour Reseanch and Therapy, 39, 245-254,

Merckelbach, $H_{4}$, Muris; $P_{n}$, Horselenberg, $R_{n}$, Stougle, S. (2000). Dissociative experiences, nesponse bias, and fantasy-proneness in college students. Personality and holvidual Differences, 28, 49-58.

Merckelbach, H. Muris, $P_{*}$ Ressin, E. 1999). Fartasy proneness and cognitive failures as correlates of dissociative experiences. Personality and holividual Differences, 26, 961-967.

Merckelbach, H., Muris, P. Wijman, $w_{4}$, De Jong, P. (1996) 5elf-reported cognitive failutes and neurotic swmptomatology. Personality and thdividual Differences. $20,715-724$.

Merckelbach, H., Muris, P.. Rassin, E, Horselenherg. R. (2000). Dissociative experiences and interrogative suggestibility in college students. Personafity and Individual Differences, 29, $1133-1140$.

Merckelbach, H., Muris, P., Wessed, 1., \& Van Kopprem, P. (1998). The Gudjonsson Suggestibility Scale (GSS): Some further data on its reliability, validity, and metacognilion correlates. Sociaf Behavios a Personality" An whermational journal, 26, 203-210.

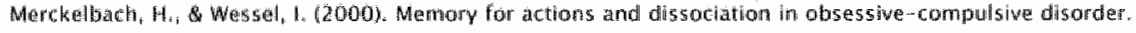
Joumal of Nerwous and Mentwit Disease, 158; B46-848.

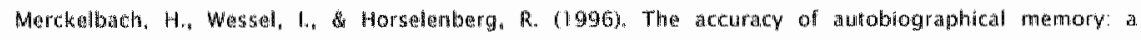

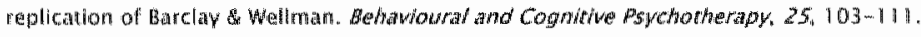

Merckelbach, H., Zeles, G., Van Bergen, $S_{n}$, Giesbreche, $T$. (submitted). Trait dissociation and commission errors in mentory reports.

Multhaup. K. S., De Leonardis, D.M. \& Johnson, M.K. 1999). Source memony and evewitness suggestibility in

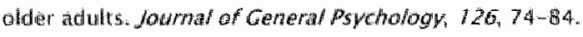

Mingterberg. H. (1908). On the witness stand New York: Mc Clure.

Nanninga, R. (200) J. Werkrach met towerkracht: Hagise rechtbank geloofi in zwarte magie. Skepter. 14/3. $8+11$.

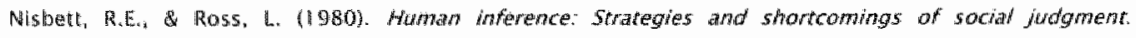
Englewood Clifts, No: Prentice - Hall. 


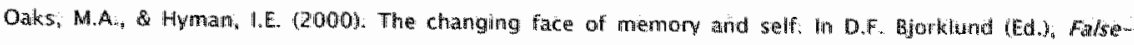

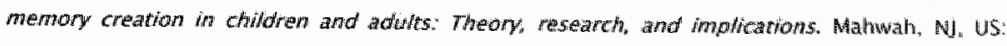
Lawrence Fribaum Pulolishers; p. $45-67$.

Orshe, Ru. L Leo, R.A. [1 997). The social psychology of police interrogations. The meory and classification of true and fallse confessors. Studies in Law Polvics and 5ociety. $16,189-251$.

Ost. J., Costatl, A., \& Bull, R. (2001). False confersions and false memonies: A madell for understanding retractors" experiences. journat of Forensie fsychatry, 12, 549-579.

Ost, J., Fellows, Bis, Bull, R. (1997). Individuall differences and the suggestibility of humian memony. Contenporary Hypnosis, $14,132-137$,

Ost, 1., Wrij。. A., Costall, A., Bull, R. (2002). Crashing mementes and reality monitoring: Distinguishing

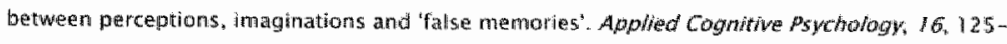
134.

Paddock, J.R., Joseph, A.L., Chan, F.M., Terranowa, S., Manning, C., \& Loffus, E. F. (1998). When guided wistualization procedures may backfire: limagination inflarion and predicting individual differences in suggestibility. Applied Cognitive Psychology. 12,563-575.

Paddock. J.R., Noel, M., Teramowa. S. Eber, H.W., Manning, C. \& Loftus, E.F. (1999). Imatinaton inflation and the perils of guided visualization. Joumat of Psychology $133.581-595$.

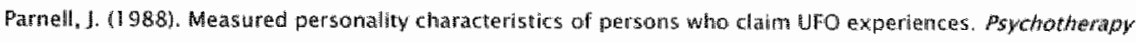
and Private Practice, $6.159-165$.

Peetters, F., Wessel, I. Merckelbach, $H_{+}$\& Boon-Vermeeren, M. (2002). Autobiographical memory specificity and the course of majar depression disorder. Camprehensive Psychatry, 43, 344-350.

Pennebaker, JW. (1993). Putting stress intto words: Health, linguistic, and therapeatic impications. Bethaviout Research and Therapy, 31, 539-5.48.

Pennebaker, J.W. \& Memon, A. (1996). Recovered memories in context: thoughts and elaborations on Bowers and Farvolden (1996). Pspcholagicat Bulketion, 119, 381-385.

Pezdek K. (1994). The lllusion of illusory memory. Applied Cogminke Psyctralogy, $8,339-350$.

Pezdek. K., Finger, K. Hodge, D. (1997). Planting false childhood memories: The role of event plausibility. Psychological Science, $\$_{\mathrm{i}} 437 \sim 441$.

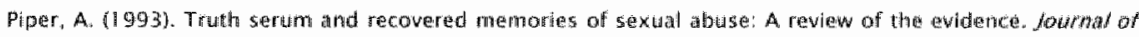
PSychiatry and Law $Z 7,447-471$.

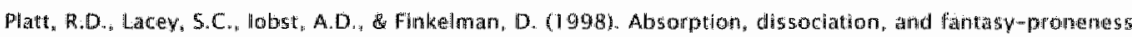
as predictors of menory distortion in aturoblogianhical and laboratory generated memorias. Applied Cognitive Psychology, $12,577-589$.

Poole, D.A., Lindisay, D. S., Memon. A., \& Bult, R. (1995). Psychoherapy and the recovery w memorle5 of chiluhood sexual abuse: U.S. and british practitioners' beliefs. practices, and experiences. Jouryal of Consulting and Clinical Psychology, 6.3.426-437.

Porter. S., Yullle, J.C.a Lefman, D.R. 11999 \%. The nature of reat, Implanted, and fabricated menories for emotional childhood events Implications for the recovered memory debata. Law and Human Biehawior, $23,517-537$.

Porter, S., Birt, A.R. Yuille, J.C. \& Letman, D.R. (2000). Negotiating false memories. Hateriewer and rememberer characteristics relate to inemony distortion. Psychological Science, $11,507-510$. 


\section{REFEREACES}

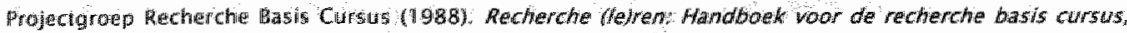

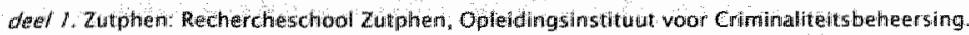

Projecturoep Recherche Basis Cursus 1989). Hecherche (lejren: Handboek voor de recherche basis cursus,

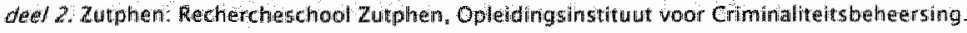

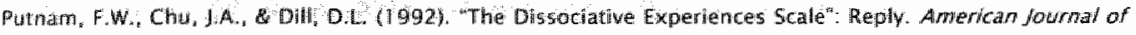
Psyctiatry, 149:143-144:

Putram, F.W. Carlson, E.B. Koss, C.A. Andersion, G. Clark, P., Torem, M., Bowman, E.S, Coons, P.H. Chu, 1.4h, Dill, D.L, Loewentein, R., \& Baun, BC. (1996). Patterns of dissociation in clinical and nonclimical samples. Journal of Nerwous and Mantal Disease" $184,673-679$.

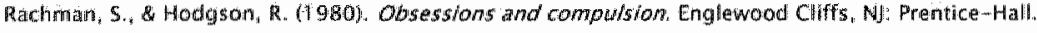

Radomsky, A.5.: \& Rachman. S. (1999). Memory bias in obsessive-compulsive disorder (OCD). Bethaviour Research and Therapy $37,605-678$.

Radornsky, A.5, Rachman, 5, \& Hammond, D. (2001). Wemory bias, confidence and responsubility in compulsive checking. Behavour Research and Therapy, 39, 813-822.

Rassin, E, Merckelback, H., Spatan, V. (2001). When dreams become a royal road to confusion: Realistic dreams, dissociation, and fantasy proneness. Mourmal of Nerwous and Mema/ Disease, $189,478-$ 481.

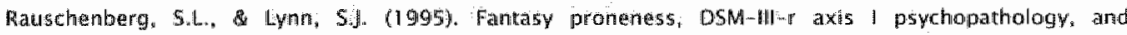
dissociation. Journal of Abmormal Psychology. 104, 373-380.

Redich, A.D., \& Goodnan, G.S. (2003). Taking responsibility for an act not committed: The influence of age and suggestibility. Law and Auman Behavior, $27,141-156$.

Reinitz, M.T. \& Hamban, S.L. (2004). False memories for compound words: Rolle of working memory. Mexrory and Cognition, 3,2, 463-473.

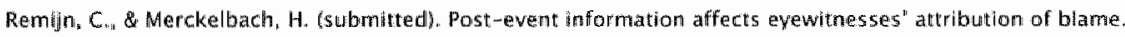

Robinson, M.P., \& Jolinson, J.T. (1996). Recall memory, recognition memory, and the eyewitmess confictenceaccuracy correlation. foursal of Applied Psychology, 81, 587-594.

Roediger, H.L., \& McDermott, K.B. (1992). Depression and implicit memory: a commentary Journat of Abrothal Pychology 101, 587-591.

Roediger, H.L. MCDermott, K.B. (1995\%. Creating false memories: Remembering words not presented in

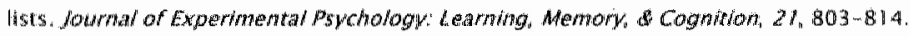

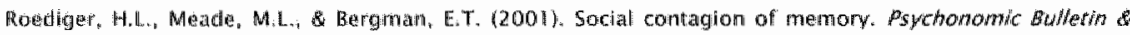
Reweth, $8,365-371$.

Ross, C.A. \& Joshi, 5. (1992). Paranomal experiences in the general population. fournar of Werwous arnd Mertal Disease, $l s 0,357-36 \pi$.

Rulfman, T, Rustin, C., Garnham; W., Parkin, A.J. 2001). Soutce monitoring and false memories in childrell: Relation to certanty and executive functioning. Joumal of Experimental Child Psychologr, $80,95 \div 111$.

Rybash. J.M., Rubenstein, L. \& Deluca, K.L. (1997). How to become famous but not necessarily recognasable: encoding processes and study-test delays dissociate source monitoring from recagnition. American journial of pyychology: $110,93-114$. 
Sánchez-Bernardos, MHL, Avia, M.D. (2004). Personalty correlates of fantasy promeness among adolescents: Personaltity and Individual Differences, $37,1669-1079$.

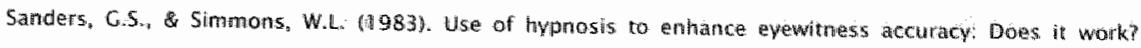
Journal of Apolied Pychology, 68,70-77.

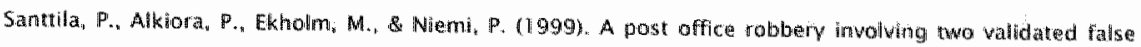
confessions: The role of interrogative suggestibility anxiety, memory distubance, and whithawal symptoms. Joumal of Forensic Psychatry 10, 399-415.

Schacter, D.L. (1999). The sewen sins of memory: insights trom pswchology and cognitive netwroscitence. American Psychologist, 54, 182-203.

Sehacter, D.L., Koutstaal, W., Korman, K.A. (1997). False memories and aging. Trends in Cognitive Science, 1. $29-236$.

Scheck. B., Neufelld, F". \& Omyer, J. (2000k. Acruat inmocence: When justice goes wrong and how to make ih right. New York: Signer.

Scoboria, A., Mazzoni, G., Kirsch, I., Relyea, M. (2004). Plausibility and belief in autobiographical memory. Applied Cognitive Psychorog, $18,791-807$.

Schooler, J. W., \& Loftus, EF. (1986). Indiwichual differences and experimentation: Complententary approaches 10. interrogative suggestibility. Social Bahatiow, $1,105-112$.

Schooler, 1. W. \& Loftus, E.F. (1993). Multiple mechanisms mediate individual differences in evewitness accuracy and suggestibility in J.M. Puckett \& H.W. Reese (Eds.). Atechamisms of exerydar cognition, Hillsdale, Wi. England: Lawrence Eribaum Associates. p. 177-203.

Schoutrop, M., Lange, A., Hanewald, G. Dutaland, C., B Bermond, G. (1997). The effects of structuned wrting assignments on overcoming major stressfui events: an uncontrolled stuidy. Clinical Psycholagy and Psychotherap $4,170,185$.

Strapiro, P.N. \& Penrod, S.D. (1986). A meta-analysis of facial identification situdies. Psychological Eulletin. $100,139-156$.

Sheehan, P.W. (1967). A shortened form of Betr's questionnaire upon mental imagery. Jounnal of Clinical Psychology, 23, 386-389.

Sherman, S.A. Cialdinl, R.B., Schwartzman, D.F. \& Rewnolds, K. D. (1985). Imagining can hatighen or tower whe pefceived the thood of contrarting a disease: The mediating effect of case nf imageny.

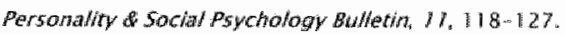

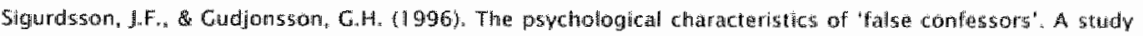
among Icelandic prison inmates and juwente offenders. Personally and individual Differences. $20,321-329$.

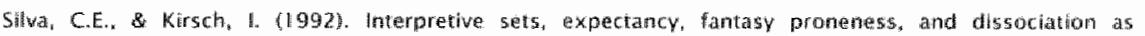
predictors of hypnotic response. Journal of Personality and Social Psychology, 63, 847-856.

Smeets, T. Jelicic, M., Horselenberg, Ro, \& Merckebach, H. Uir press. Trying to recollect past ewents. Confidence, beliefs, and memories. Chinical Psychologly Rewiew.

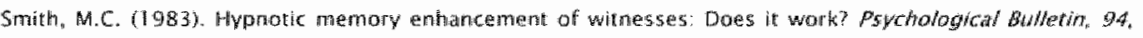
$387-407$.

Snelders, \$. (2000). 450-therapie in Nederland. Die experimented-psychiatrische benadering wan I.

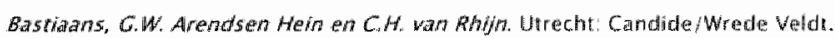




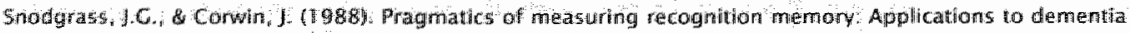

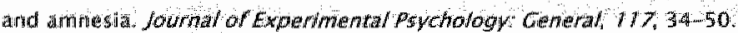

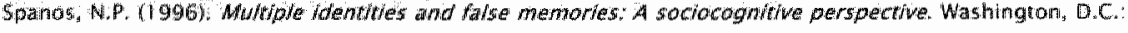
American Psychological Association.

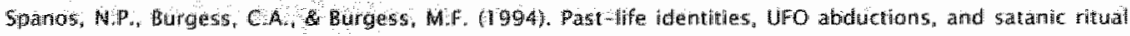
abuset the sochal construction of memories. International joumal of Clonical and Experimental Hiponosis: $42,433-46$.

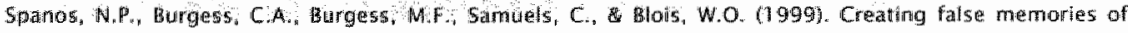
infancy with hypnotic and mon-hypmotic procedures. Applied Cognitive Psychology, 13, 20121:

Spanos, N.P., Cross, P.A. Dickson, K. D DuBreunl, S.C. (1993). Close encounters: An examination of UFO experiences, Journal of Abnomal Psychology, $102 ; 624-632$.

Spanos, N.P., Menary, E, Gabora, Nid., Dubretwil, S.C., \& Dewhirst, B. (1991). Secondary identity enactments during hyphotic past life regression: A sociocognitive perspective. journal of personality and Socral Psychology, 6l, 308-320.

Szücs, A. Janskv, J., Holló, A., Migléczi, E. \& P. Halász (2003). Misleading hallucinations ir unrecognised narcolepsy. Acta Psychiatrica 5candinavica, 108; 31.4-317

Technical Working Growp for Eyewitness Evidence (1999). Eyewithess ewidence: A guide for law enforcentent (Booklel). Washington, DC: United States Department of Justice, Office of Justice Programs.

Tellegern, A. A Atkinson, C. (1974). Operness to absorbing and self-attering experiences. ("absorption"), a trait refated to hypnotic susceptibility. Joumal of Abnormal Psychologk, 83, 268-277.

Thalboturne, M.Au, \& Houran, J. (2000). Trantsliminatity, the Mental Experience Inventory and tolerance of ambiguity. Personality and individual Differences, 28,853-863.

Thiecke, M.C., Sijbling, R., \& Jackson, d. (1996). De oplsrengst: vani het getuigenverhoor: De ralate tussen werhoor en verklaring. De Psycholoog, 31, 472-477.

Trierweiller, 5. J. Donovan , C.M. (1994): Exploring the ecological foundations of memory in pswchotherapy: interpersional affordance, perception, and recollection in teal time. Cinnical Psychology Review, $\sqrt{4}+301-30$.

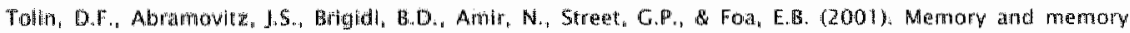

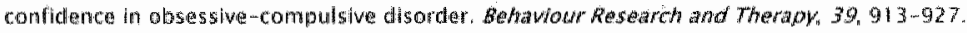

rversky, B., Marsh, E.J. 2000). Based retellings of events viald biased memones. Cognitive Psychology, 40, $1:-38$

Van den Adel, H.M. (1097). handleiding verdachrenverhoor Handhaving controle en opsporing in de

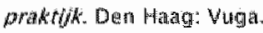

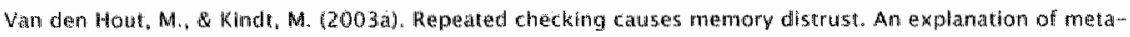
memon problems in compulsilwe checking. Behaviour Research and Therapy, $41,301-316$.

Van den Hout, M. Kind, M. (2003bi. Phenomenological walictity of an OCDmemory model and the ramember/know distinction. Betsatiow Research and Therapy, 4l, 369-378.

Van der Ploeg, H.M., Defares. P.B., S Spleberger, C.D. (1980) Handleiding bij de Zelf-Beoordelings Vragentijst: Een Nedelindstallige bewerking wan de 5pieberger State-Trait Anxiely Inventory. 


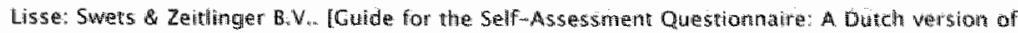
the Spielberger State-Trait Anxiety lnventoryl.

Wan Koppen, P.J. (2003). De Schiedammer parkmoond. Ean rechtspsychologinche reconstructie. Whightegen: Ars Aequi Libri.

Van Koppen, P.t.n Merckelbach, 4t. (1999). Characteristics of recovered memosies: A Dutch replication of Cudijons50n"s (1997) Butitish survey. Applied Cogmirive Psychologk, $13,485-489$.

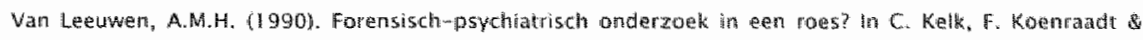

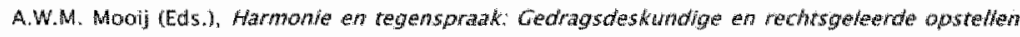
over psychiatrie en strafrechttoepassing aangeboden aan F.H.L. Beyeart. Arrahent: Gowda Quint. р. $159 \cdots 168$.

Vary Jzendoorr, M.H. \& 5chuengel, $C$, 1996). The measurement of dissociation in normal and clinical populations: meta-analytic walidation of the Dissociariwe Experiences Scale (DES). Cinuca Psychology Review, 16, 365-382

Van Vreeswijk. M.F., \& De Wildie, E.J. (2004). Autobiographical memory specificity, psvchopathologkn, depressed mood and the use of the Autobiographical Memory Test: A. mean-analysis. Behaviow Research and Therapy, 42,731-743.

Veltratan, D.J. De Ruiter, M.B., Rombouts, S.A.R.B., Lazeron, R.H.C., Barktwof, F, Phaf, R.H., Wan Dyck, R., \& Dolan, R. (in pres5). Neurophysiological comelates of increased verbal wionking memory th highdissociative subjects: A functional MRI study. Psychological Medicine.

Vermaas, P, (2000), De Zwolse verhoomethode. Algerneen Politieblad, 22, 1.4-15.

Viclor, J.S. (1993). Satanic panic. The creation of a comtemporary legend. Chicago: Open Court.

Wade, $K_{n} A_{\text {. }}$ Garry. M., Read, J.D., \& Lindsay, D.5. (2002). A picture is worth a thousand lies: using fallse photographs to create false childrood memontes. Psychonomic Bunketin \& Review 9, 597-603.

Wagenaar, W. A. (1986). My memory: A case study of autobiographical memories over six years. Cognithe Psychology, $18,225-252$

Walkefield, $H_{n}$, A Underwager, $R$, (1998). Coerced or nonwoluntary confes sions. Bethawioura/ Sciences and the Law, $16,423-4,40$.

waller, C.., Quinton, 5 , Watson, D. (1995). Dissociation and the processing of threat-relioted information. Dissachation: Progress in the Dissociathe Disorders. $8,84-90$.

Watson, D. (2001). Dissoriations of the night. Individual differences in steep-related experiences and the:

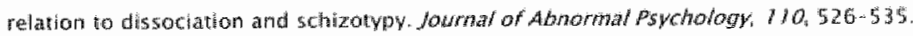

Watson, D. (2003). To dream, perchance to remenber: Individual differences in dream recall. Persomity and Individual Differences, 34, 1271-1286.

Wiltams, J.M.G. (1992). Autoblographical memory and emotionall disonders. in S. A. Christianson (Ed.).

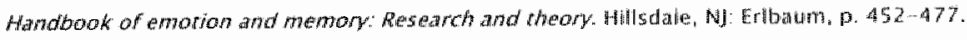

Willams. J.M.C. (1996. Depression and the specificity of atoblographical memory. In D.C. Rubin UEd.), Remenbering our past: sewdies in autobiographical memory. New York: Cambridge Universily Press, p. $244-267$.

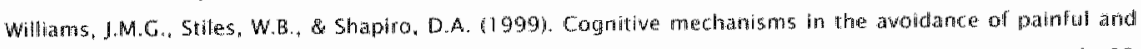

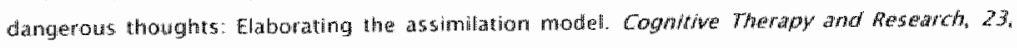
$285-306$. 


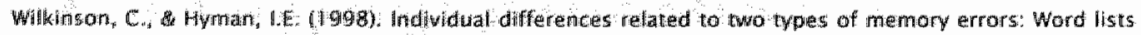

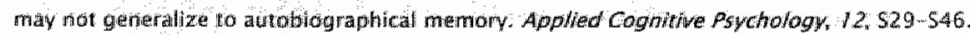

Wilson, SC, \& Barber, TX (1983). Fantasy-prone persomallty implications for understanding imagery, hypnosis, and parapswctiglogical phenomena. in A.A. Sheikth. Jmagery. current theory, research, and application. New Vork Wiley, p. $340-387$.

Wistson, $5 . C$. garber, T, $x$, (1982). Fantasy-prone piersonality: implications for winderstanding imagery, hypnosis, and parapswchological phenomena. PS/-Research $l_{2} 94-116$.

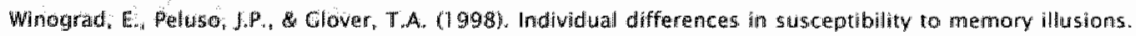
Appolied Cogntive Psycthology; $12,55-527$.

Wolfard, U. Mever, T. (1998). Interrogative suggestibility, amxiety, and dissociation among anxious pattents and normal controlls. Personality and Irdiwiduat Differences, 25, 425-432.

Wright, L. (1994). Remembering Satan. Wew York: Alfred A. Knopf.

Wright, D.B. Loftus, EF, 1999). Measuring dissociation: Comparison of altermatiwe forms of the dissodatiwe experiences scale. American Jourmal of Psyctiology, $112,497-519$.

Zaragoza, M.5." \& Lamie, S.M. (1994). Source misattribution and the suggestibility of eyewitness memory.

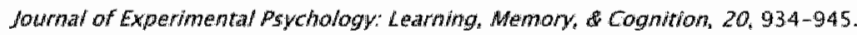

Zaragoza, M.S., \& Milchell, K.J. 1996). Repeated exposure to suggestion and the creation of false memories. Psychological science; $7,294-300$ 


\section{DANKWOORD}

Hoewell er wordt beweerd dat promoveren een eenzame bezigheid is, moge het ook duidelijk zijn dat er meerdere mensen hebben bijgedragen aan de totstandkorming van dit proefschrift. Op deze plaats zou ik graag enkele mensen willen bedanken.

Allereerst wil ik Harald Merckelbach bedanken. Al naar gelang dit proefschrift vorderde ben ik me gaan realiseren hoe zeer ik het heb getroffen met jow als begeleider: ondanks je drukke agenda was je altijd berelkbaar em wist je op snelle en heldere wijze experimenten of manuscripten van commentaar te voorzlen. Je optimisme, stimulerende en deskundige kritiek trof altijd doel en zorgde voor een zeer prettige werkrelatie.

Peter de Jong: het is door jouw enthousiasme voor onderzoek doen, dat ik wetenschap beoefenen als een grote uitdaging ben gaan zien (en een eventuele therapeutische carrière gedag zei). Veel dank hiervoor, een betere basis kon ik niet krijgen.

Beste leden van het IRP, ik dank jullie voor de keer op keer inspirerende en vruchtbare bijeenkomsten. Ik verheug me op de volgende survival in spa!

De collega's van de capgroep EP: Bedankt! 
Uiteraard wil ik Remy Cima bedanken woor het verzorgen van de lay-out van dit proefschrift.

Maake en Ingrid, fijn dat jullie naast me staan/zitten op deze dag en ik verheug me op onze toekomstige samenwerking.

Tot slot, vergeten is immers menselijk, bedank ik iedereen die ik vergeten ben. 


\section{CURRICULUM VITAE}

Robert Horselenberg werd geboren op 24 februari 1973 in Hengelo, Twente. In 1991 behaalde hij het Atheneum-B diploma aan het Twickel College in Hengelo. In dat zelfde jaar begon hij zijn studie Gezondheidswetenschappen, afstudeerrichting Geestelijke Gezondheidkunde, aan de Universiteit Maastricht. Deze studie werd afgerond met het behalen van het doctoraal diploma in 1996. Van 1997 tot 1999 was hij werkzaam als docent aan de Faculteit der Psychologie van de Universiteit Maastricht om vervolgens als Assistent in Opleiding/Docent (AiODo) te worden aangesteld bij de capaciteitsgroep Experimentele Psychologie van diezelfde faculteit. Na een korte uitstap als universitair docent klinische psychologie aan de Faculteit der Psychologie van de Open Universiteit Nederland, is hij sinds april 2005 wederom verbonden aan de Faculteit der Psychologie van de Universiteit Maastricht als universitair docent rechtspsycholagie. 



\section{LIST OF PUBLICATIONS}

Horselenberg, R. (2000). Wie confabuleert? Persoonskenmerken en pseudow herinneringen. De Psycholoog, 35, 218-223.

Horselenberg, R. (2003). Excentrieke levens: Fantasierijke clienten in reincarnatietherapie. Skepter, 16, 16-19.

Horselenberg, R., \& Merckelbach, $H_{*}$ (accepted pending revision). Fantasy proneness and previous-life memories. International Journal of Clinical and Experimental Hypnosis.

Horselenberg, R., Merckelbach, H., Van Breukelen, G. \& Wessel, I. (2004). Individual differences in the accuracy of autobiographical memory. Clinical Psychology and Psychotherapy, 11, 168-176.

Horselenberg, R., Merckelbach, H., Crombag, H., \& Van Koppen, P. (2002). Getuigen helpen herinneren (p. 445-464). In: P.J. Koppen, H.L.C.J. Merckelbuach, D.J. Hessing, \& H.F.M. Crombag (Red.), Het recht van binnen. Deventer: Kluwer.

Horselenberg, Rn, Merckelbach. $H_{2}$ \& Josephs, S. (2003). Individual differences and false confessions: A conceptuall replication of Kassin and Kiechel (1996). Psychology, Crime and Law, $9_{n} \mid-8$.

Horselenberg, R., Merckelbach, H., Muris, P., Rassin, E., Sijsenaar, M., \& Spaan, V. (2000). Imagining fictitious childhood events: The role of individual differences in imagination inflation. Clinical Psychology and Psychotherapy, 7, 128-137.

Horselenberg, R., Merckelbach, H., Smeets, T., Franssens, D., Peters, G.J.Y., \& Zelles, G. (in press). False confessions in the laboratory: Do plausibility and consequences matter? Psychology, Crime and Law. 
Horselenberg, H., Merckelbach, H. \& Spaan, V. (1999). Schijiven over fictieve gebeurtenissen leidt tot imaginatie-inflatie. Directieve Therapie, 19 , $120-133$.

Horselenberg, R., Merckelbach, H., Wessel, I., Werhoeven, C., \& Zeles, C. (2005). Absorption, fantasy proneness, and the false fame effect. Manuscript submitted for publication.

Crombag, H., Rassin, E., \& Horselenberg, R. (2003). On vengeance. Psychology, Crime and Law, 9, 333-344.

Jang, de P. J., Weertman, A., Horselenberg, R., \& Hout, M. A van den (1997), Deductive reasoning and pathological anxiety: Evidence for a relatively strong belief bias. Cognitive Therapy and Research, 21,647-662.

Merckelbach, H., Crombag, $H_{\text {., }}$ \& Horselenberg, R. (2002). Hervonden herinneringlen ( $p$, 485-505). In: P.J. Koppen, H.L.G.J. Merckelbach, D.J. Hessing \& H.F.M. Crombag (Red.), Het recht van binnen. Deventer: Kluwer.

Merckelbach, H., Horselenberg, R., \& Jelicic, M. (2003). Een bekentenis en haar gevolgen. Maandblad Geestelijke volksgezondheid, 58, 997-1017.

Merckelbach, H., Horselenberg, R., \& Muris, P. (2001). The Creative Experience Questionnaire (CEQ): a brief self-report measure of fantasy proneness. Personality and Individual Differences, 31, 987-995.

Merckelbach, H., Horselenberg, R., \& Schmidt, H. (2002). Modelling the connection between self-reported trauma and dissociation in a student sample. Personallity and Individual Differences, 32,695-705.

Merckelbach, H., Horselenberg, R., Wessel, I., Rassin, E., \& Verhoeven, C. (1999). Beroemd of toch niet? Persoonlijkheidsverschillen en het "false fame"effect. Nederlands Tijdschrift voor de Psychologie, 54, 235-240.

Merckelbach, H., Jelicic, M., Candel, 1., \& Horselenberg, R. (2002). Sleutelen aan geheugenverlies: latrogene elaboratie van een retrograde amnesie. Maandblad Geestelijke volksgezondheid, 57, 923-935. 
Merckelbach, H., Jelicic, M., Giesbrecht, T., \& Horselenberg R. (2003). De wraak van Hughlings Jackson. Over gesimuleerde "fugue". Maandblad Ceestelijke volksgezondheid, 58,654-665.

Merckelbach, H., Muris, P., \& Horselenberg, R. (1996). Correlates of avergeneral memories in normal subjects. Behavioural and Cognitive Psychotherapy, $24,109-115$.

Merckelbach, H., Muris, P., Horselemberg. R., \& Jong, de PJ. (1997). EEG Correlates of a paper-and-pencil test measuring hemisphericity. Journal of Clinical Psychology, 53, 739-744.

Merckelbach, H. Muris, P., Horselenberg, R., \& Rassin, E. (1998). Traumatic intrusions as worse case scenario's. Behaviour Research and Therapy, 36, 1075-1079.

Merckelbach H., Muris, P., Horselemberg, R., \& Stougie, S. (2000). Dissociative experiences, response bias, and fantasy proneness in college students. Personality and Irdividual Differences, 28, 49-58.

Merckelbach, H. Muris, P., Rassin。 E., \& Horselenberg, R. (2000). Dissaciative experiences and interrogative suggestibility in college students. Personality and Individual Differences, 29, $1133-1140$.

Merckelbach, H., Muris, P., Schmidt, H., Rassín, E." \& Horselenberg, R. (1998). De Creatieve Ervaringen Vragenlijst als. maat voor "fantasy proneness". De Psycholoog, 33, 204-208.

Merckelbach, H., Sijsenaar; M., Horselenberg, R., Leunissen, $A_{*}$ \& Weltevrede, $M$. (1998). Hoe sterk is imaginatie-inflatie? Directieve Therapie, $18,79-92$.

Merckelbach, H., Wessel, I., \& Horsellenberg, R. (1997). The accuracy of autobiographical memory: a replication of Barclay \& Wellman (1986). Behavioural and Cognitive Psychotherapy, 25,103-111.

Merckelbach, H., Wiers "R., Horselenberg, R., \& Wessel, \#. (2001). Effects of retrieving childhood events on metamemory judgments depend on the questions you ask. British Journal of Clinical Psychology, 40,215-220. 
Muris; $P$, Merckelbach, $H$, Horselenberg, $\mathbb{R}$. (1996). Individual differences in thought suppression. The white bear suppression inventory: factor structure, reliability, walidity and correlates. Behoviour Research and Therapy, $34,501-513$.

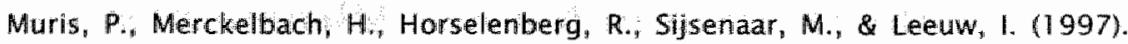
Thought suppression in spider phobia. Behaviour Research and Therapy, 35, 769-774.

Muris, P., Merckelbach, H, Nederkoorn, Sj, Rassin, E, Candel, I., \& Horselenberg, R. (2000). Disgust and psychopathological symptoms in a nonclinical sample. Persoriality and individual Differences, 29, 1163-1167.

Muris; P., Steerneman, P., Meesters, C., Merckelbach, $H_{.}$, Horselenberg, R., Hogen, van den T., Dongen, van L. (1999). The TOM-test: A new instrument for assessing theory of mind in normal children and children with pervasive developmental disorders. Journal of Autism and Developmental Disorders, 29, 67-80.

Muris, P., Winands, D., \& Horselenberg R. (2003). Defense styles, personality traits, and psychopathological symptoms in non-clinical adolescents. Journal of Nervous and Mental Disease, 191, 771-780.

Peters, M., Jelicic, M., Horselenberg, R., \& Merckelbach, H. (2004). De neuropsychologie van pseudo-herinneringen. Neuropraxis, 8, 97-103.

Simeets, T., Merckelbach, $H_{i}$, Horsellenberg, R., \& Jelicic, M. (2004). Vroeger met je hand door een ruit gevallen: schatting, geloof; of herinnering? De psycholoog, 39, 485-491.

Smeets, T., Merckelbach, H., Horselenberg, R., \& Jelicic, M. (in press). Clinical Psychology Review.

Wessel, I., Merckelbach, H., Kessens, C., \& Horselenberg, R. (2001). Dissociation and specific memories. Clinical Psychology and Psychotherapy, 8, 411415. 